Aus der Klinik für Mund-, Kiefer- und Gesichtschirurgie

(Prof. Dr. med. Dr. med. dent. H. Schliephake)

im Zentrum Zahn-, Mund- und Kieferheilkunde

der Medizinischen Fakultät der Georg-August-Universität Göttingen

\title{
Einfluss von TGF- $\beta$ auf die EMT-Marker-Expression in Ko-Kulturen oraler Karzinomzellen mit mesenchymalen Stromazellen
}

\author{
INAUGURAL-DISSERTATION \\ zur Erlangung des Doktorgrades \\ für Zahnmedizin \\ der Medizinischen Fakultät der \\ Georg-August-Universität zu Göttingen
}

vorgelegt von

Fabian Godek

aus

Bückeburg

Göttingen 2020 
Dekan:

Referent/in:

Ko-Referent/in:

Drittreferent/in:
Prof. Dr. W. Brück

Priv.-Doz. Dr. med. Dr. med. dent. F. Böhrnsen

Datum der mündlichen Prüfung: 
Hiermit erkläre ich, die Dissertation mit dem Titel „Einfluss von TGF- $\beta$ auf die EMTMarker-Expression in Ko-Kulturen oraler Karzinomzellen mit mesenchymalen Stromazellen“ eigenständig angefertigt und keine anderen als die von mir angegebenen Quellen und Hilfsmittel verwendet zu haben.

Göttingen, den 
Die Daten, auf denen die vorliegende Arbeit basiert, wurden teilweise publiziert:

Bohrnsen F, Godek F, Kiesel J, Kramer FJ, Brockmeyer P, Schliephake H (2017): Influence of TGF-beta1 on tumor transition in oral cancer cell and BMSC co-cultures $\mathrm{J}$ Craniomaxillofac Surg $\underline{45}, 731-740$ 


\section{Inhaltsverzeichnis}

Abldungsverzeichnis.........................................................................................................IV

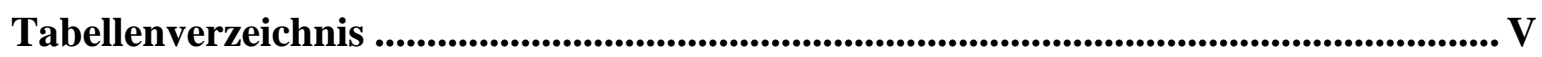

Abkürzungsverzeichnis .................................................................................................VI

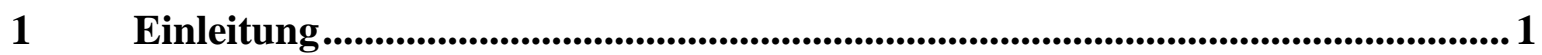

$1.1 \quad$ Das Plattenepithelkarzinom ............................................................................... 1

1.2 Tumor-Stroma-Mikroumgebung ………………………………………….... 2

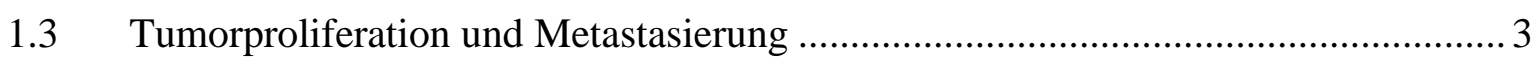

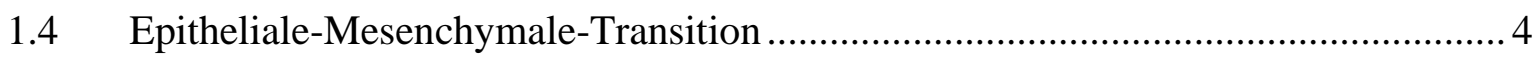

1.4.1 Die EMT-Marker Vimentin und E-Cadherin ....................................................... 5

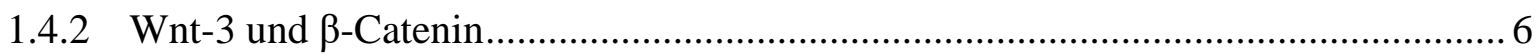

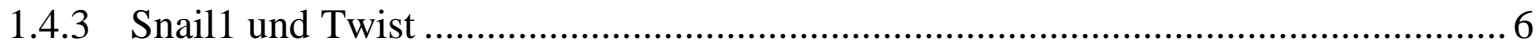

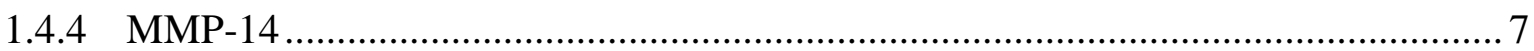

1.5 Regulierung von AKT-, Erk- und mTOR-Signalwegen im Rahmen der

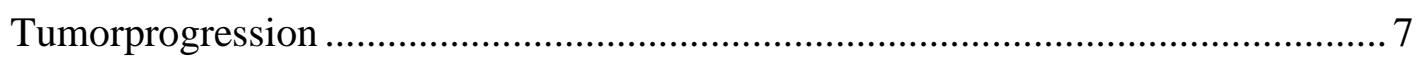

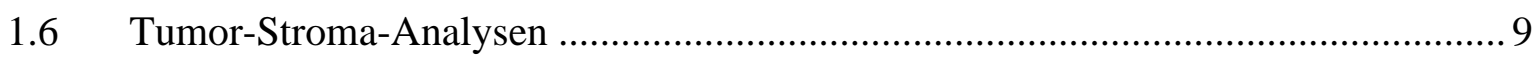

$1.7 \quad$ Zielsetzung der vorliegenden Arbeit....................................................................... 11

$2 \quad$ Material und Methoden ........................................................................................... 12

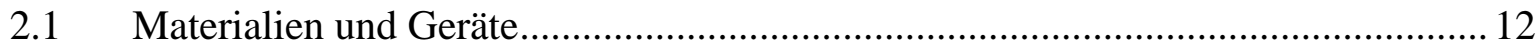

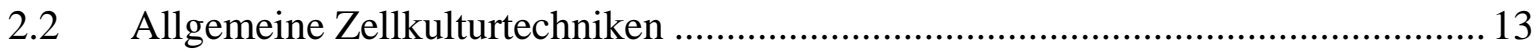

2.2.1 Ablösen, Zentrifugieren und Passagieren ………………………………………... 13

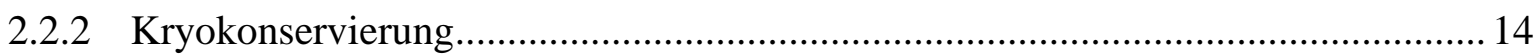

2.3 Isolation und Kultivierung von MSC aus humanen Knochenmarkaspiraten............ 14

2.4 Kultivierung der humanen PEK-Zelllinie PCI-13 ……………………………..... 16

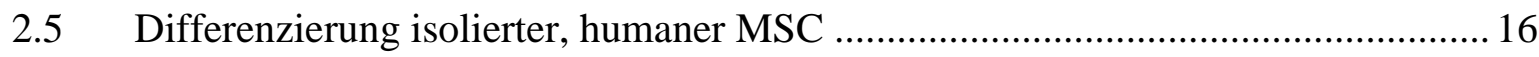

2.5.1 Osteogene und adipogene Differenzierung im Monolayer ………………………..... 16

2.5.2 Chondrogene Differenzierung im Micro-Mass-Body …………………………..... 17

2.6 Histochemische Analysen zur Charakterisierung der Differenzierung von

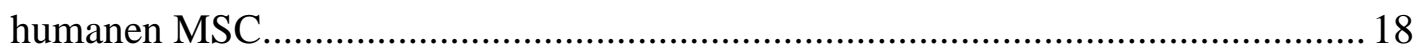

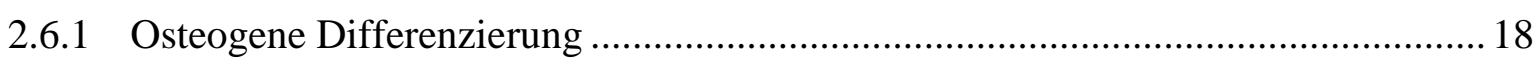

2.6.2 Sudan-III-Färbung zur Darstellung der adipogenen Differenzierung ....................... 19

2.6.3 Alcianblau-Färbung zur Darstellung der chondrogenen Differenzierung ................ 19 
2.7 Charakterisierung isolierter MSC mittels Durchflusszytometrie ............................ 20

2.8 TGF- $\beta_{1}$ induzierte Transwell-Ko-Kultur-Differenzierung...................................... 20

2.8.1 Transwell-Ko-Kultur von MSC und PCI-13 ...................................................... 20

2.9 Analyse der Proliferationscharakteristika von MSC und PCI-13 .......................... 22

2.10 Darstellung zelltypspezifischer Proteinexpression mittels direkter

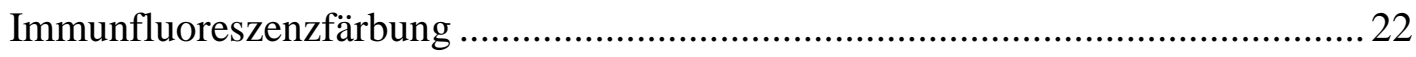

2.11 Darstellung zelltypspezifischer Genexpression mittels RT-qPCR ....................... 23

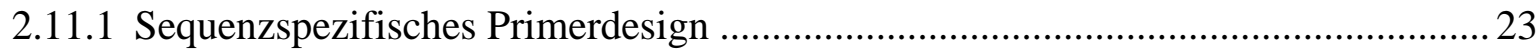

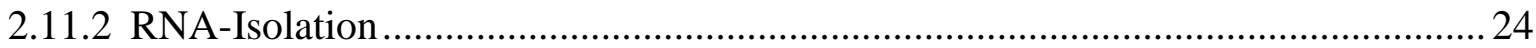

2.11.3 cDNA-Synthese mittels reverser-Transkriptase-Lösungen .................................. 25

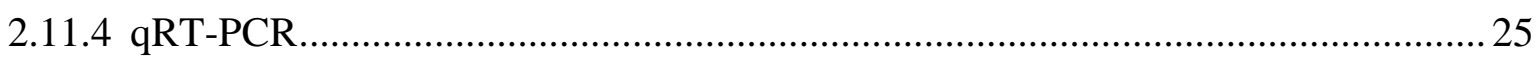

2.12 Darstellung zelltypspezifischer Proteinexpression mittels Antibody Array............. 26

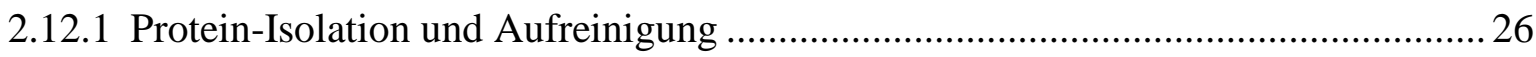

2.12.2 Quantifizierung des Proteingehalts mittels Bicinchoninic Acid Assay (BCA) ........ 26

2.12.3 Untersuchung des AKT-Signalwegs mittels PathScan ${ }^{\circledR}{ }^{\circledR}$......................................... 27

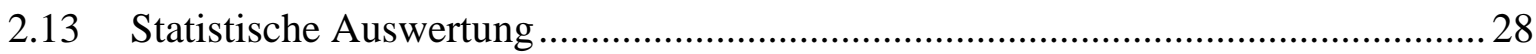

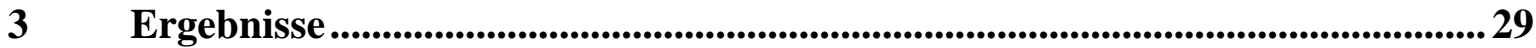

3.1 Charakterisierung humaner MSC mittels Durchflusszytometrie ............................ 29

3.2 Osteogene, adipogene und chondrogene Differenzierung humaner MSC ...............29

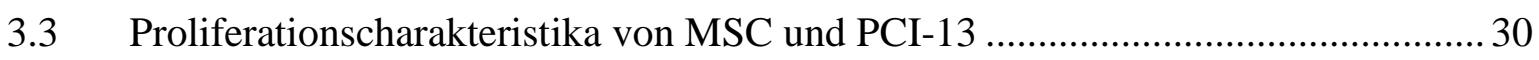

3.4 Monolayer-Differenzierung humaner MSC und PCI-13-Zellen unter dem

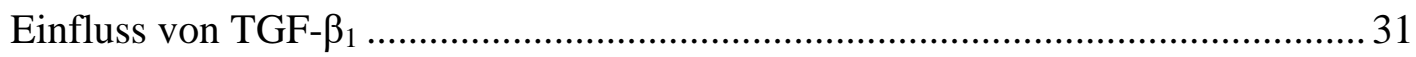

3.4.1 IF-Proteinexpression von Vimentin und E-Cadherin in im Monolayer

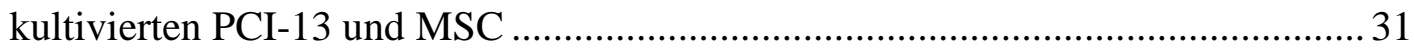

3.4.2 Genexpression von Mediatoren der Tumor-Stroma-Interaktion in im Monolayer kultivierten PCI-13 und MSC.

3.4.3 Proteinanalyse des AKT-Signalwegs, der Apoptose und des Erk-Signalwegs in im Monolayer kultivierten PCI-13 und MSC

3.5 Ko-Kultur-Differenzierung humaner MSC und PCI-13-Zellen unter Einfluss von TGF- $\beta_{1}$

3.5.1 IF-Proteinexpression von Vimentin und E-Cadherin in ko-kultivierten PCI-13 und MSC

3.5.2 Genexpression von Mediatoren der Tumor-Stroma-Interaktion in kokultivierten PCI-13 und MSC 
3.5.3 Proteinanalyse des AKT-Signalwegs, der Apoptose und des Erk-Signalwegs in ko-kultivierten PCI-13 und MSC.

4 Diskussion

4.1 Tumor-Stroma-Interaktionen beeinflussen die Proliferation der PCI-13

Ko-Kulturen 44

4.1.1 Die Ko-Kultur zwischen PCI-13 und MSC ohne TGF- $\beta$ verringert die Proliferation der PCI-13 45

4.2 TGF- $\beta$-Einfluss auf die Expression wichtiger EMT-Marker. 45

4.2.1 TGF- $\beta$-Induktion nimmt einen progressiven Einfluss auf die EMT. 46

4.2.2 TGF- $\beta$-Induktion führt zu Veränderung der MMP-14-Expression. 49

4.3 Veränderung von Wnt-, AKT-, Erk- und mTOR-Signalwegen in MSC- und PCI Ko-Kulturen

4.3.1 Wnt-Signalweg in PCI-13 und MSC

4.3.2 AKT-Signalweg wird durch TGF- $\beta_{1}$-Induktion und Ko-Kultivierung in PCI13 und MSC aktiviert.

4.3.3 Erk-Signalweg wird durch TGF- $\beta_{1}$-Induktion und Ko-Kultivierung in PCI-13 und MSC beeinflusst .51

4.3.4 mTOR-Signalweg in PCI-13 und MSC 51

$4.4 \quad$ Fazit 53

5

Zusammenfassung.. .54 


\section{Abbildungsverzeichnis}

Abbildung 1: Prozess der Epithelialen-Mesenchymalen-Transition nach Kalluri und

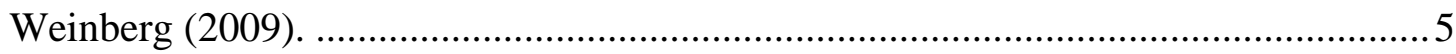

Abbildung 2: AKT-Signalweg und Erk-Kaskade ........................................................... 9

Abbildung 3: Darstellung der Dichtegradientenzentrifugation. ........................................ 15

Abbildung 4: Chondrogene Differenzierung von MSC im Micro-Mass-Body. ................... 18

Abbildung 5: Ausschnitt einer Multiwell-Platte mit Transwell-Ko-Kultur-Einsatz. ..........2 21

Abbildung 6: Eine repräsentative, durchflusszytometrische Analyse isolierter humaner MSC.

Abbildung 7: Osteogene, adipogene und chondrogene Differenzierung humaner

MSC. 30

Abbildung 8: Täglicher Verdopplungsfaktor der PCI-13 und MSC. 30

Abbildung 9: IF-Proteinexpression der PCI-13 Monolayer-Kulturen................................. 31

Abbildung 10: IF-Proteinexpression der im Monolayer kultivierten MSC......................... 32

Abbildung 11: qRT-PCR Analyse der im Monolayer kultivierten PCI-13 .......................... 33

Abbildung 12: qRT-PCR Analyse der im Monolayer kultivierten MSC ............................. 34

Abbildung 13: Die Proteinlevelanalysen mittels Pathscan der im Monolayer

kultivierten PCI-13

Abbildung 14: Die Proteinlevelanalysen mittels Pathscan der im Monolayer kultivierten MSC. 36

Abbildung 15: IF-Proteinexpression der ko-kultivierten PCI-13. 37

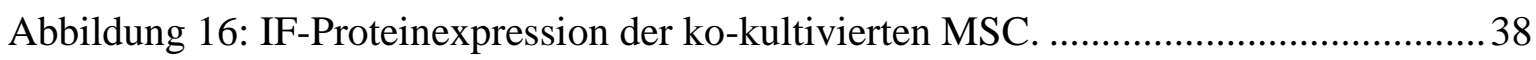

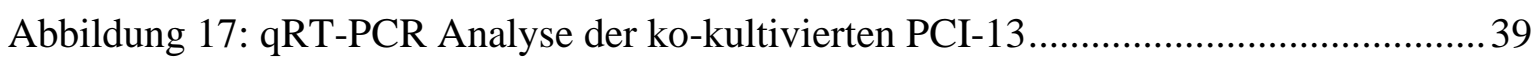

Abbildung 18: qRT-PCR Analyse der ko-kultivierten MSC ........................................... 40

Abbildung 19: Die Proteinlevelanalysen mittels Pathscan der ko-kultivierten PCI-13....... 41

Abbildung 20: Die Proteinlevelanalysen mittels Pathscan der ko-kultivierten MSC. 42 


\section{Tabellenverzeichnis}

Tabelle 1: Verwendete Materialien und Geräte …................................................................. 12

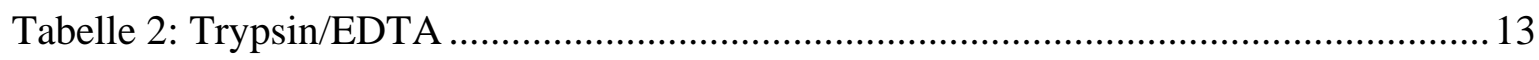

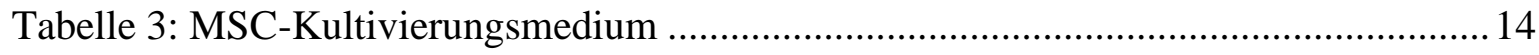

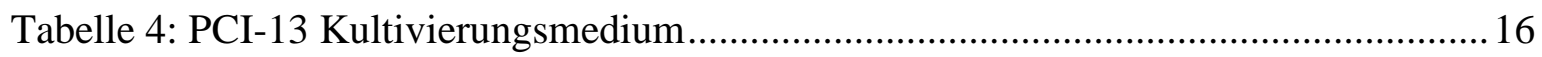

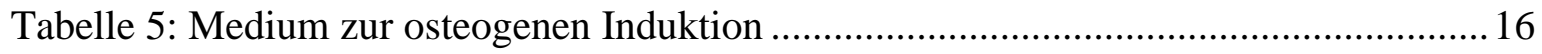

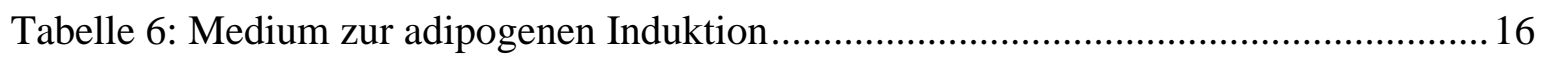

Tabelle 7: Medium zum Erhalt der adipogenen Differenzierung ...................................... 16

Tabelle 8: Medium zur chondrogenen Differenzierung ............................................... 17

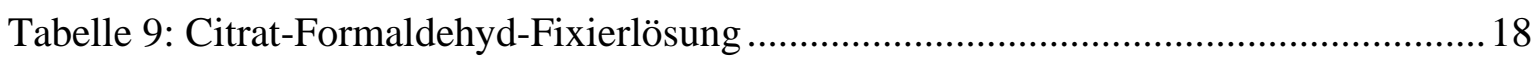

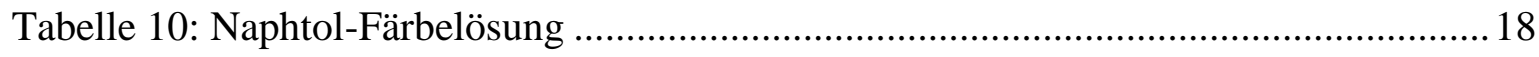

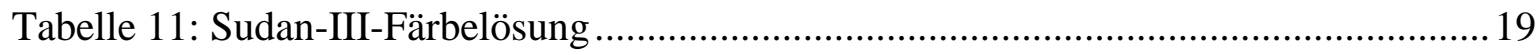

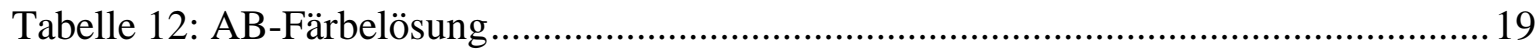

Tabelle 13: Verwendete Antikörper der durchflusszytometrischen MSC-

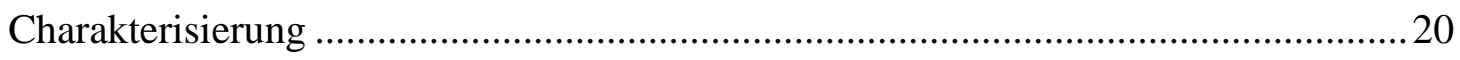

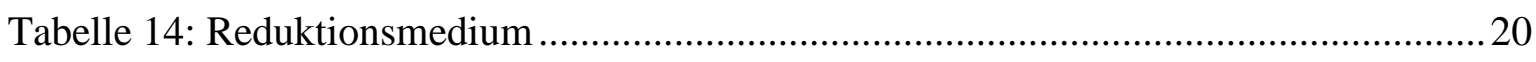

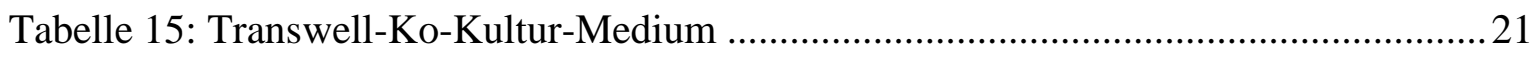

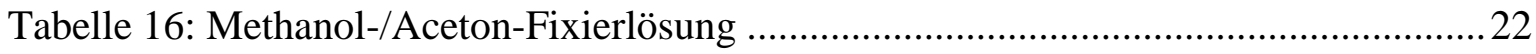

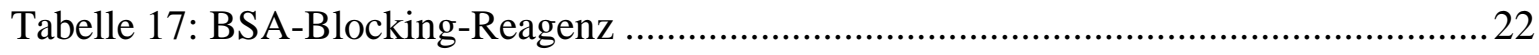

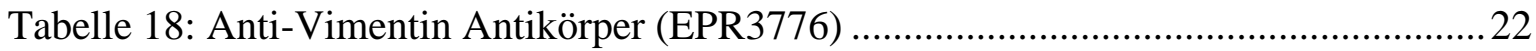

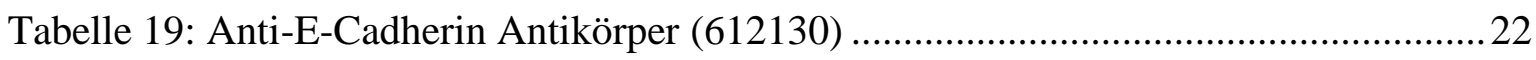

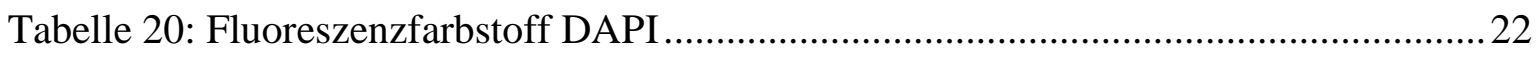

Tabelle 21: Verwendete Primer für die RT-qPCR........................................................ 24

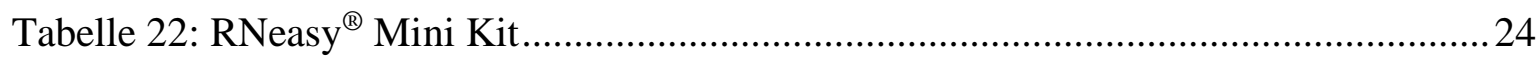

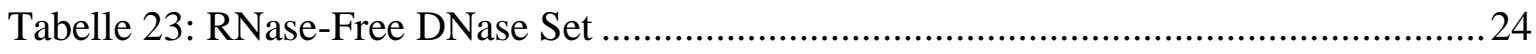

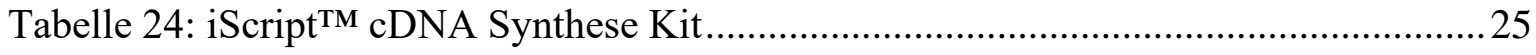

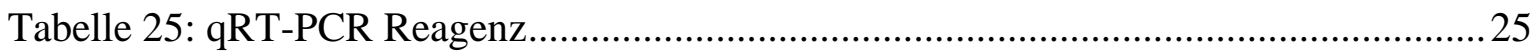

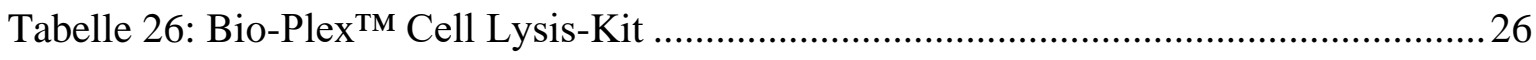

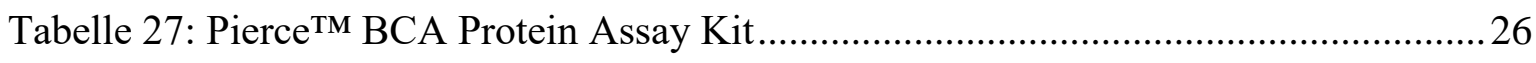

Tabelle 28: PathScan ${ }^{\circledR}$ AKT Signaling Antibody Array Kit ............................................ 27

Tabelle 29: Proteinlevel-Expressionsniveau der im Monolayer kultivierten Zellen im

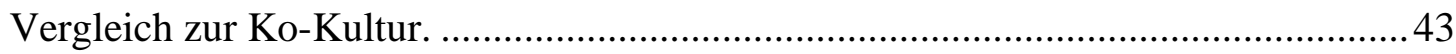




\section{Abkürzungsverzeichnis}

4E-BP1

$\mathrm{AB}$

ABB

ADB

AMPK $\alpha$

AP

AWB

$\mathrm{Bad}$

BCA

$\mathrm{Bp}$

BSA

CAF

$\mathrm{CD}$

cDNA

DAC

DAPI

DMEM

DMSO

DPBS

EDTA

EMT

FACS

FITC

FKS

GAPDH

GSK-3

IF

KK

MET

ML

MMB

MMP

mRNA

MSC

mTOR
4E-Bindungsprotein 1

Alcianblau

Array Blocking Buffer

Array Diluent Buffer

AMP-aktivierte Proteinkinase $\alpha$

Alkalische Phosphatase

Array Wash Buffer

Bcl-2-Associated Death Promoter

Bicinchoninic Acid Assay

Basepairs

Bovines Serum Albumin

Cancer Associated Fibroblasts

Cluster of Differentiation

komplementäre DNA

Detection Antibody Cocktail

4',6-Diamidin-2-phenylindol

Dulbecco's Modified Eagles Medium

Dimetylsulfoxid

Dulbecco's Phosphat-gepufferte Salzlösung

Ethylendiamintetraessigsäure

Epitheliale-Mesenchymale-Transition

Fluorescence Activated Cell Sorting

Fluorescein

Fetales Kälberserum

Glycerinaldehyd-3-Phosphat-Dehydrogenase

Glykogensynthase-Kinase 3

Immunfluoreszenzfärbung

Ko-Kultur

Mesenchymale-Epitheliale-Transition

Monolayer

Micro-Mass-Body

Matrix-Metalloproteinase

Messenger Ribonukleinsäuren

Mesenchymale Stromazelle(n)

Mammalian Target of Rapamycin 
Abkürzungsverzeichnis

mTORC

$\mathrm{NaCl}$

NCBI

PDK1

PE

PEK

Pen/Strep

PI3K

PMSF

PRAS40

PTEN

RSK1

qRT-PCR

SMAD

TGF- $\beta$

Wnt-3
mTOR Komplex

Natriumchlorid

National Center for Biotechnology Information

3-Phosphoinositid-abhängige Proteinkinase 1

Phycoerythrin

Plattenepithelkarzinom

Penicillin/Streptomycin

Phosphoinositid-3-Kinase

Phenylmethylsulfonylfluorid

Proline-Rich AKT Substrate $40 \mathrm{kDa}$

Phosphatase- und Tensin-Homolog

Ribosomale S6 Kinase 1

Qualitative reverse Transkriptase Polymerase-Ketten-Reaktion

Small Mothers Against Decapentaplegic

Transforming Growth Factor Beta

Wingless-Type MMTV Integration Site Family Member 3 


\section{$1 \quad$ Einleitung}

\subsection{Das Plattenepithelkarzinom}

Tumoren des Kopf-Hals-Bereichs gehören mit weltweit jährlich mehr als 500.000 Neuerkrankungen zu den zehn häufigsten Tumoren (Jemal et al. 2011). Bei mehr als $90 \%$ dieser Tumoren handelt es sich um Plattenepithelkarzinome (PEK) (Metelmann und Kaduk 2007). Lebensgewohnheiten wie Tabak- und Alkoholkonsum multiplizieren das Risiko, an einem solchen Tumor zu erkranken, wobei eine Prognose stark von der Tumorgröße sowie dem Vorhandensein von Lymphknoten- und Fernmetastasen abhängt (Hashibe et al. 2009; Jemal et al. 2011). Trotz kontinuierlicher Fortschritte in der Tumorbehandlung mittels Radiatio, Chemotherapie und weiterentwickelten chirurgischen Verfahren, liegt die 5-Jahres-Überlebensrate auch heute noch bei ca. 50 \% (Peitzsch et al. 2019). Damit hat sie sich in den letzten 40 Jahren kaum verändert (Kulasinghe et al. 2015). Die Erkrankung ist für die Patienten mit einer erheblichen Reduktion der subjektiv empfundenen Lebensqualität verbunden (Metelmann und Kaduk 2007). Aktuellere Behandlungsverfahren z. B. durch die Immuntherapie mit PD-1-Inhibitoren versprechen bei ca. 10-18 \% der Patienten ein besseres Therapie-Ansprechverhalten mit längeren Überlebensraten und ein Aufrechterhalten der individuellen Lebensqualität. Da Tumorzellen durch Mutation und Selektion genetische Varianten entwickeln können, ist diese Wirkung jedoch häufig nicht dauerhaft (Syn et al. 2017). Dabei hängen Merkmale der Tumor-Mikroumgebung eng mit dem Ansprechen auf solche Immuntherapien zusammen (Ferris et al. 2016). So wird u. a. das invasive Potential eines Tumors durch Interaktionen mit der Tumormikroumgebung beeinflusst (Curry et al. 2014; Poggi et al. 2014; Turley et al. 2015). Es treten oftmals progressive interzelluläre Aktionen am invasiven Rand eines Tumors auf (Böhrnsen et al. 2015; Routray et al. 2014). Dies nimmt Einfluss auf die Immunantwort und Reaktion der gesunden Tumorumgebung und kann so zur Bildung von Tumorsuppressorzellen und regulatorischen T-Zellen führen. So kann die Effizienz von Mechanismen der autologen Antitumorabwehr zur Eliminierung neoplastischer Zellen eingeschränkt werden (Poggi et al. 2014; Turley et al. 2015).

Zur Analyse der Tumor-Mikroumgebung werden für wissenschaftliche Untersuchungen Tumorzelllinien verwendet, wobei eine Vielzahl von primären und metastasierten PEK-Zelllinien bekannt ist. Diese unterscheiden sich nach Geschlecht des Entnahmeträgers, TNM-Klassifikation und anatomischen Entnahmestellen wie z. B. aus Mundhöhle, Oropharynx, Larynx oder Gesichtshaut (Lin et al. 2007). Eine etablierte 
Einleitung

Zelllinie stellt PCI-13 dar, die in dieser Dissertation verwendet wurde. Diese stammt ursprünglich aus dem PEK der oralen Mukosa eines 50 Jahre alten, männlichen Patienten. Dabei handelt es sich nach der Union internationale contre le cancer um einen $\mathrm{T}_{3} \mathrm{~N}_{1} \mathrm{M}_{0}$-Tumor (Heo et al. 1989). Hierbei bezeichnet das „ $\mathrm{T}^{“}$ die räumliche Ausdehnung des Primärtumors, „N“ beschreibt ein Fehlen oder Vorhandensein regionärer Lymphknotenmetastasen und das „, $\mathrm{M}^{“}$ beschreibt ein Fehlen oder Vorhandensein von Fernmetastasen. Der Ursprungstumor der in dieser Dissertation verwendeten Tumorzellen hatte eine Größe von $4 \mathrm{~cm}$ überschritten sowie eine unilaterale Lymphknotenmetastase gebildet, ohne dass Fernmetastasen vorgelegen haben.

\section{$1.2 \quad$ Tumor-Stroma-Mikroumgebung}

Neben den Tumorzellen finden sich in der Mikroumgebung einer Neoplasie auch Fibroblasten, mesenchymale Stromazellen (MSC), vaskulären Endothelzellen und Immunzellen, einschließlich T-Zellen, Makrophagen und Neutrophilen Granulozyten (Hanahan und Coussens 2012). Im Verbund werden diese Zellen oft als Tumor-Stroma bezeichnet und bilden zusammen mit der extrazellulären Matrix die TumorMikroumgebung. Interaktionen zwischen MSC und Tumorzellen finden sich oftmals in diesen Bereichen der Tumorproliferationszonen am invasiven Rand des Tumors (Routray et al. 2014). MSC werden in nahezu allen mesodermalen Geweben des fetalen und erwachsenen Körpers einschließlich Knochenmark, Fettgewebe und anderen stromareichen Organen gefunden (Collins und Thebaud 2014; Hass et al. 2011; Rallapalli et al. 2009; Rotter et al. 2008). Im Zuge operativer Eingriffe können diese Zellen aus dem Knochenmark des Beckenkamms gewonnen werden und wurden bereits detailliert charakterisiert (Pittenger et al. 1999). Die International Society for Cell Therapy definierte 2006 Minimalkriterien zur MSC-Charakterisierung (Dominici et al. 2006). Diese sind Kunststoffadhärenz, spezifische Oberflächencharakteristika (cluster of differentiation, $\mathrm{CD} ; \mathrm{CD}^{+} 3^{+}, \mathrm{CD} 90^{+}, \mathrm{CD} 105^{+}$, CD34-, CD45') und die Fähigkeit, sich in Adipozyten, Chondrozyten und Osteozyten zu differenzieren (Horwitz et al. 2005; Lv et al. 2014). Zu den Aufgaben der MSC gehören die Produktion und Sekretion verschiedener Komponenten der extrazellulären Matrix (Turley et al. 2015). Indem sie sich in Knochen-, Knorpel, Muskel-, Sehnen-, Fett- und Stromagewebe differenzieren (Pittenger et al. 1999), beteiligen sich MSC aber auch an der Geweberegeneration und -heilung nach Trauma, in Folge natürlicher Alterungsprozesse oder Krankheit (Turley et al. 2015). Darüber hinaus erfolgt bereits der klinische Einsatz von 
Einleitung

Mesenchymalen Stroma- und Stammzellen zur Therapie von onkologischen Erkrankungen wie Leukämie, Lymphomen und Myelomen (Steinberg et al. 2015) sowie im Rahmen der Graft-versus-Host Erkrankung. Aufgrund ihrer immunmodullierenden Aktivität sind MSC in der Lage, die Proliferation und Funktion von T-Zellen, B-Zellen, Dendritischen Zellen und natürlichen Killerzellen zu hemmen (Zhao et al. 2019). Um ihre Wirkung zu entfalten, produzieren MSC u. a. eine Vielzahl von Zytokinen, zu denen auch Transforming Growth Factor beta 1 (TGF- $\beta_{1}$ ) zählt (Eggenhofer et al. 2014). So können MSC zusätzlich Einfluss auf die Interaktion zwischen Tumor und Tumor-Stroma gewinnen. Es konnte gezeigt werden, dass der Einfluss von MSC und die Interaktionen zwischen Tumorgewebe und Tumor-Mikroumgebung das invasive Potential von PEK hemmen können (Böhrnsen et al. 2015). Hierfür müssen die MSC Umbau- und Transitionsprozesse durchlaufen, um an ihren Wirkungsort zu gelangen (Korbling und Estrov 2003). Diese Prozesse werden durch interund intrazelluläre Signalwege wie den Wingless-type MMTV integration site family(Wnt)$\beta$-Catenin-Signalweg modelliert und können hierdurch fördernd oder hemmend auf die Tumor- und Stromazellproliferation wirken (Böhrnsen et al. 2015; Curry et al. 2014).

\subsection{Tumorproliferation und Metastasierung}

Nach Hannahan und Weinberg bedarf die Entstehung und Proliferation von Tumoren sechs Kennzeichen (Hanahan und Weinberg 2000, 2011): (1) Unbegrenztes Potential zur Zellteilung, (2) Eigenversorgung mit Wachstumsfaktoren, (3) Resistenz gegenüber AntiWachstumssignalen, (4) die Fähigkeit, sich der Apoptose zu entziehen, (5) erhöhte Angiogenese und (6) invasives Wachstum bzw. Metastasierung.

Zentrale Prozesse wie invasives Wachstum und Metastasierung sind entscheidende Schritte während der Tumorprogression (Zhang et al. 2016) und können durch den Prozess einer Invasivitäts-Metastasierungs-Kaskade beschrieben werden (Fidler 2003; Talmadge und Fidler 2010): Durch invasives Wachstum gelangen überlebensfähige Tumorzellen in umliegende Gewebe wie z. B. Blut- und Lymphgefäße, werden durch diese Gefäße in den Organismus transportiert und siedeln sich anschließend in einem fernen Gewebe wieder an (Hanahan und Weinberg 2000). Eine besonders massive epitheliale Zellproliferation und Angiogenese gelten als Kennzeichen für eine Initiierung und ein frühes Wachstum epithelialer Karzinome (Hanahan und Weinberg 2000).

Dieser Metastasierungsprozess wird durch verschiedene Signalmoleküle und Zytokine beeinflusst (Lamouille et al. 2014), zu denen unter anderem auch Proteine der 
Einleitung

TGF- $\beta$-Superfamilie gehören (Yingling et al. 2004). TGF- $\beta_{1}$ ist ein Wachstumsfaktor, der je nach Zelltyp und Wirkdauer spezifische zelluläre Effekte wie Proliferation, Differenzierung, Migration und Apoptose reguliert (Oshimori und Fuchs 2012). Hierbei wirkt der TGF- $\beta$-Signalweg über das Onkogen STAT3, das in PEK des Kopf-Hals-Bereichs häufig verstärkt exprimiert ist (Chen et al. 2010). Je nach zellulärem Kontext kann TGF- $\beta_{1}$ das Tumorwachstum hemmen, also als Tumorsuppressor fungieren, oder aber auch das Tumorwachstum fördern, also als Tumorpromotor wirken (Massague 2012). In physiologischen Epithelzellen wirkt es hemmend auf Zellproliferation, Differenzierung und Motilität und fördert die Apoptose (Leef und Thomas 2013; Massague 2012). In Karzinomen wirkt die vermehrte Sezernierung von TGF- $\beta_{1}$ jedoch tumorproliferativ (Molinolo et al. 2009), indem Invasivität und Metastasierung gefördert werden (Nagaraj und Datta 2010). TGF- $\beta_{1}$ kann zudem zu einem Verlust der Zellkontakte durch Abbau der Zonula occludens und der Adhärenzkontakte führen, die $\beta$-Catenin im Cytoplasma stabilisieren und somit nukleäre Translationsprozesse und die Expression von Matrix-Metalloproteinasen (MMP) modellieren (Masszi et al. 2003; Sun L et al. 2008). Somit nimmt TGF- $\beta$ Einfluss auf Invasivität und Metastasierung, die ebenfalls durch Interaktionen zwischen Tumor und Tumor-Stroma beeinflusst werden.

Im Metastasierungsprozess kommt darüber hinaus der Basalmembran eine besondere Rolle zu, da sie als Barriere der Tumorprogression gilt. Eine Beschädigung, ein Verlust bzw. ein Überwinden dieser Membran durch z. B. die o. g. Prozesse erleichtert eine Tumorinvasion und begünstigt einen sich anschließenden Metastasierungsprozess. Ein Schlüsselereignis dabei ist der epithelial-mesenchymale Übergang, bei dem epitheliale Zellen mesenchymale Eigenschaften gewinnen. Dieser Übergang wird auch als EpithelialeMesenchymale-Transition (EMT) bezeichnet.

\section{$1.4 \quad$ Epitheliale-Mesenchymale-Transition}

Die EMT ist ein bereits in der Embryologie auftretendes Ereignis (Typ 1 EMT), läuft aber auch bei Entzündungen und Fibrose (Typ 2 EMT) sowie bei Invasivitäts- und Metastasierungsprozessen (Typ 3 EMT) ab (Kalluri und Weinberg 2009). Hierbei gewinnen epitheliale Zellen (1) Motilität, (2) verändern die Zelladhäsion untereinander und (3) modellieren die extrazelluläre Matrix um (Curry et al. 2014). Epitheliale Zellverbände verlieren hierbei ihre stationäre Polarität und gewinnen mesenchymale Eigenschaften. 
Einleitung

Dadurch gewinnen Zellen der EMT eine gesteigerte Migrationsfähigkeit, eine verstärkte Invasivität und eine erhöhte Apoptose-Resistenz (Kalluri und Neilson 2003).

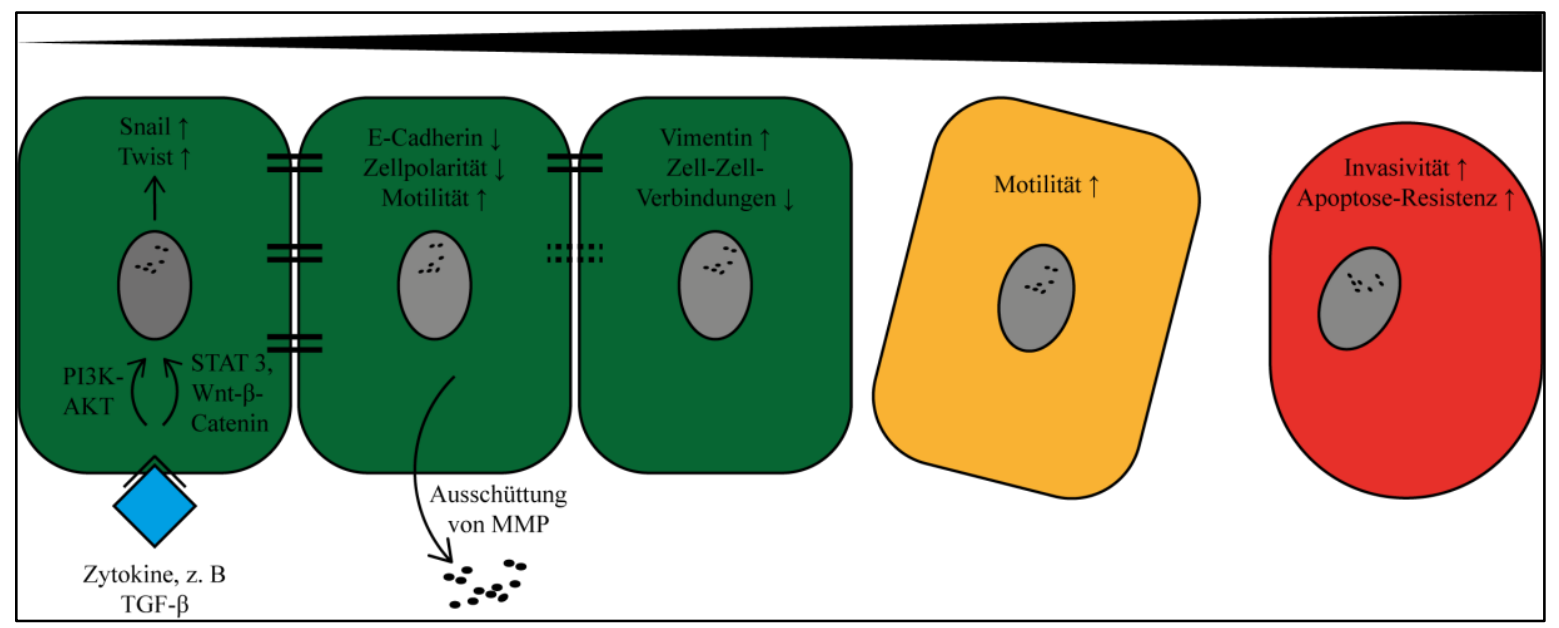

Abbildung 1: Prozess der Epithelialen-Mesenchymalen-Transition nach Kalluri und Weinberg (2009).

Im Rahmen von EMT assoziierten Prozessen zwischen Tumor und Stroma zeigen sich verschiedene proliferative und apoptotische Signalwege sowie Kaskaden beeinflusst (Böhrnsen et al. 2015). Beschreibend hierfür sind u. a. verschiedene Markerproteine.

\subsubsection{Die EMT-Marker Vimentin und E-Cadherin}

Vimentin ist ein Intermediärfilamentprotein und wird normalerweise in Zellen mesenchymalen Ursprungs wie z. B. Myofibroblasten, Chondrozyten, Makrophagen und Endothelzellen exprimiert (Korita et al. 2010). In mesenchymalen Zellen kommt Vimentin für eine Reihe von zellulären Funktionen wie Zelladhäsion, Migration und Signalübertragung eine entscheidende Bedeutung zu (Ivaska et al. 2007). Auch in Tumorgeweben kann Vimentin nachgewiesen werden (Satelli und Li 2011). Der Verlust von E-Cadherin und die Zunahme mesenchymaler Marker wie Vimentin werden als Kennzeichen der oben beschriebenen EMT gedeutet (Guo Y et al. 2013; Ozguven et al. 2011; Tiwari et al. 2012).

E-Cadherin ist ein Typ 1 Transmembran-Protein, das wichtig bei der Vermittlung der Zellpolarität und -integrität ist. Über extrazelluläre $\mathrm{Ca}^{2+}$-Bindungsstellen sorgt E-Cadherin für eine interzelluläre Stabilität und bildet eine epitheliale Barriere (van Roy 2014). In fortgeschrittenen Tumoren geht die E-Cadherin-Expression häufig verloren, was mit einer höheren Inzidenz von Metastasen und Rezidiven in Verbindung gebracht wird (Berx und van Roy 2009; Birchmeier und Behrens 1994). Zusammen mit $\beta$-Catenin bildet E-Cadherin einen Komplex auf der Zellmembran, der die Zell-Zell-Adhäsion fördert, zur Strukturbildung des geschichteten oralen Plattenepithels beiträgt und die Zelldissoziation 
Einleitung

verhindert. Eine Komplexauflösung fördert wiederum eine Zellmigration und -invasivität (Hulsken et al. 1994).

\subsubsection{Wnt-3 und $\beta$-Catenin}

Wnt-3 ist entscheidend an der Zellproliferation, -differenzierung, -adhäsion und -migration beteiligt. Dieses kann sowohl $\beta$-Catenin abhängig (kanonisch) als auch unabhängig (nicht-kanonisch) verlaufen (Anastas und Moon 2013). Hierbei spielt der Wnt- $\beta$-Catenin-Signalweg eine zentrale Rolle bei der Signalgebung der Embryonalentwicklung, wobei eine Überexpression des Signalweges in enger Beziehung zu den meisten Tumoren steht (Shukla et al. 2016). $\beta$-Catenin ist ein Protein, das je nach zellulärer Lokalisation unterschiedliche Funktionen erfüllt, die sich von Wechselwirkungen mit anderen zellulären Proteinen auf der Membran oder im Cytoplasma ableiten (Jamieson et al. 2012; Sharma et al. 2012). In nicht-stimulierten Zellen wird $\beta$-Catenin ständig abgebaut. Nach der Bindung von Wnt an einen Rezeptorkomplex kann sich $\beta$-Catenin in der Zelle stabilisieren und in den Nukleus gelangen. Hier wird es dann durch Transkriptionsfaktoren aufbereitet (Ramakrishnan und Cadigan 2017). In vielen Tumorarten konnten abnormale Aktivierungen bzw. Mutationen im kanonischen Wnt- $\beta$-CateninSignalweg nachgewiesen werden (Zhou und Hung 2005). Eine Aktivierung des Signalwegs bei PEK wirkt auf die Tumorzellen anti-apoptotisch und verstärkt dessen Invasivität (Yang F et al. 2006). Durch Wnt-3-Aktivierung können Zielgene wie z. B. Snail1 transkriptiert werden (ten Berge et al. 2008), was als ein entscheidender Schritt während einer EMT und im Metastasierungsprozesses angesehen wird (Cai et al. 2013).

\subsubsection{Snail1 und Twist}

Snail1 ist ein Transkriptionsfaktor, der Zellinvasivität durch Zytokinregulierung mediiert (Lyons et al. 2008). Externe Stimuli durch z. B. TGF- $\beta$ können die Snail1-Proteinaktivierung induzieren (Xu et al. 2010). Als EMT-Regulator fördert es die Überexpression von mesenchymalen Markern wie Vimentin und die Suppression epithelialer Marker wie E-Cadherin (Zeisberg und Neilson 2009) und schwächt bestehende Zell-Zell-Kontakte (Eastham et al. 2007). Snail1 ist in zahlreichen Tumortypen stark exprimiert und an der Tumorprogression, der Zellapoptose und der Zellmigration/-invasion beteiligt (Assani und Zhou 2019). Es konnte gezeigt werden, dass Snail gemeinsam mit Twist die PEK-Metastasierung synergistisch verstärkt (Yang MH et al. 2009)

Twist ist ein Basis Helix-Loop-Helix Protein, das eine wichtige Rolle bei der Embryonalentwicklung spielt, indem es die mensenchymale Zellspezifikation 
Einleitung

und -differenzierung reguliert (Qin et al. 2012). Postnatal wird Twist unter normalen physiologischen Bedingungen weder exprimiert noch inaktiviert. Zunehmende Evidenz zeigt eine starke Korrelation zwischen der Reaktivierung von Twist und sowohl dem Fortschreiten als auch der Malignität von Tumoren (Xue und Hemmings 2012). In allen drei Formen der EMT wird Twist aktiviert und in Tumormetastasen vermehrt exprimiert (Zeisberg und Neilson 2009). Bei PEK-Patienten korreliert die Twist-Expression u. a. auch mit Lymphknotenmetastasen (Ou et al. 2008). Im Rahmen einer fortschreiten EMT kommt es dann zu einer zunehmenden Desintegration, Motilität und Auflösung der interzelluären Adhäsion u. a. durch Matrix-Metalloproteinasen.

\subsubsection{MMP-14}

Matrix-Metalloproteinasen sind eine große Familie von Zink-abhängigen Endopeptidasen, die für die Remodellierung der extrazellulären Matrix von entscheidender Bedeutung sind (Egeblad und Werb 2002). Sie sind ebenso an der Aktivitätsmodulation von Signalmolekülen beteiligt und spielen eine große Rolle sowohl in normalen physiologischen, als auch in pathologischen Prozessen wie Metastasierung (Klein und Bischoff 2011). Insbesondere MMP-14 ist an vielen Zellprozessen beteiligt, $\mathrm{zu}$ denen Wundheilung, Angiogenese, Entzündungsprozesse, aber auch Tumorinvasion und Mestasierung gehören. Dies erfolgt durch Aktivierung von Wachstumsfaktoren oder Zytokinfreigabe aus der extrazellulären Matrix (Liotta und Kohn 2001; Mannello et al. 2005; Sternlicht und Werb 2001). Darüber hinaus spielt MMP-14 eine Schlüsselrolle bei der Tumorprogression und -dissemination (Deryugina und Quigley 2015). MMP-14 aktiviert MMP-2, dessen Expression oft mit einer erhöhten Tumoraggressivität und einer schlechteren Prognose verbunden ist (Bjorklund und Koivunen 2005; Mook et al. 2004).

\subsection{Regulierung von AKT-, Erk- und mTOR-Signalwegen im Rahmen der Tumorprogression}

Der Phosphoinositid-3 Kinase (PI3K)-AKT- und der Mammalian Target of Rapamycin (mTOR)-Signalweg sind sowohl unter physiologischen als auch unter pathologischen Bedingungen für viele Aspekte des Zellwachstums und -überlebens von entscheidender Bedeutung (Porta et al. 2014). Sie sind so miteinander verbunden, dass sie z. T. als ein einziger Signalweg angesehen werden können, der wiederum mit vielen anderen Signalwegen in starke Interaktion tritt (Abbildung 2). Dabei ist der PI3K-AKT-Signalweg 
Einleitung

ein Schlüsselregulator für das Überleben bei zellulärem Stress (Datta et al. 1999). Aus diesem Grund scheint die Rolle dieses Signalwegs bei Tumoren von entscheidender Bedeutung zu sein, wobei zelluläre Prozesse wie Zellproliferation, -überleben, -wachstum und -motilität reguliert werden. AKT 1/2 sind ubiquitär exprimierte Proteinkinasen, die über die 3-Phosphoinositid-abhängige Proteinkinase 1 (PDK1) aktiviert wird und dessen Aktivierung in vielen Krebsarten sowie als phosphoryliertes AKT in PEK des Kopf-HalsBereichs analysiert werden konnte (Brazil und Hemmings 2001; Engelman et al. 2006; Stegeman et al. 2012). Ein Antagonist des AKT-Signalweges ist das Phosphatase- und Tensin-Homolog (PTEN), das eine Lipidphosphatase ist und als wichtiger Tumorsuppressor gilt (Cully et al. 2006).

mTOR ist eine Kernkomponente der zwei makromolekularen Komplexe mTOR-Komplex (mTORC)-1 und mTORC2 (Wullschleger et al. 2006). Der mTORSignalweg ist bei der Regulierung des Zellwachstums, der Zellproliferation und des Zellmetabolismus beteiligt (Laplante und Sabatini 2012). Das AKT-Signal stimuliert mTORC1, die p70 S6 Kinase zu aktivieren und das 4E-Bindungsprotein 1 (4E-BP1) zu inhibieren (Laplante und Sabatini 2012). 4E-BP1 ist bei seiner Überexpression in der Lage, die Zellgröße zu verringern, den Zellzyklus zu hemmen und die Tumorpathogenität zu unterdrücken (Avdulov et al. 2004; Fingar et al. 2002; Fingar et al. 2004; Lynch et al. 2004). Dabei ist Proline-rich AKT substrate $40 \mathrm{kDa}$ (PRAS40) eine Komponente des mTORC1 (Vander Haar et al. 2007) und wird mit der Regulierung von Zellüberleben und Apoptose in Verbindung gebracht (Saito et al. 2004). Das Bcl-2-associated death promoter (Bad)-Protein ist ein pro-apoptotisches Mitglied der Bcl-2-Gen-Familie, das in die Initiierung der Apoptose involviert ist (Adachi und Imai 2002). Die Glykogensynthase-Kinase3 (GSK-3) besteht aus 2 Isoformen, GSK-3 $\alpha$ und GSK-3 $\beta$ (Mukai et al. 2002). Die Phosphorylierung von Bad, GSK-3 $\alpha$ und GSK-3 $\beta$ durch AKT inhibiert deren Funktionen und fördert so das Zellüberleben (Cross et al. 1995; Manning und Cantley 2007)

Im Rahmen einer gegenseitigen Regulation des AKT-Signalwegs (Abbildung 2) wird die extrazellulär signalregulierende Kinase (Erk)-Kaskade als ein entscheidender Regulator der Zellmotilität angesehen. Neben der Zellmotilität spielt der Erk-Signalweg auch eine entscheidende Rolle bei der Regulation verschiedener Zellfunktionen wie Zellproliferation, -differenzierung und -überleben als Reaktion auf extrazelluläre Signale (Johnson und Lapadat 2002; Nishida und Gotoh 1993). Weiterhin moduliert Erk direkt und indirekt die Expression und Funktion von Snail und Twist1 und induziert so die Expression von motilitätsfördernden und pro-invasiven Genen, die wiederum die Zellmortilität fördern 
Einleitung

(Ichikawa et al. 2015; Shin et al. 2010) Darüber hinaus nimmt Erk direkten Einfluss auf onkogene Transformationsvorgänge (Kyriakis et al. 1992; Pages et al. 1993; Rommel et al. 1999; Sun H et al. 1993). So wird zum Beispiel die ribosomale S6 Kinase 1 (RSK1) durch Erk1/2 aktiviert (Cargnello und Roux 2011; Roux und Blenis 2004). Diese phosphoryliert unter anderem das ribosomale Protein S6 und fördert somit Zellwachstum und Proliferation.

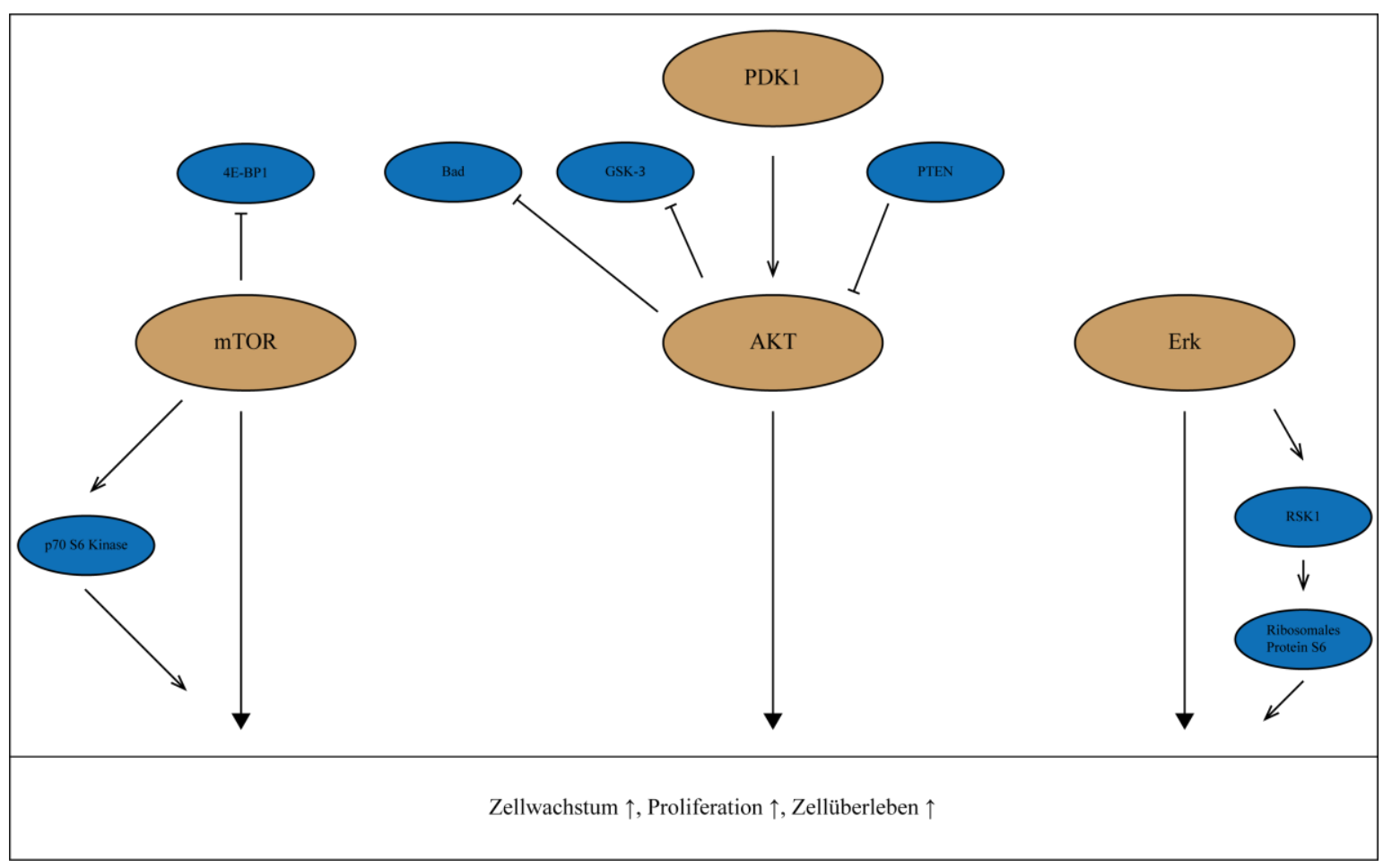

Abbildung 2: AKT-Signalweg und Erk-Kaskade nach Porta et al. (2014), Datta et al. (1999), Brazil und Hemmings (2001), Engelman et al. (2006), Stegeman et al. (2012), Cully et al. (2006), Wullschleger et al. (2006), Laplante und Sabatini (2012), Avdulov et al. (2004), Fingar et al. (2002), Lynch et al. (2004), Vander Haar et al. (2007), Saito et al. (2004), Adachi und Imai (2002), Mukai et al. (2002), Cross et al. (1995), Manning und Cantley (2007), Johnson und Lapadat (2002), Nishida und Gotoh (1993), Ichikawa et al. (2015), Shin et al. (2010), Kyriakis et al. (1992), Pages et al. (1993), Rommel et al. (1999), Sun H et al. (1993), Cargnello und Roux (2011), Roux und Blenis (2004).

\subsection{Tumor-Stroma-Analysen}

Die Komplexität einer Tumor-Mikroumgebung kann die klassische MonolayerDifferenzierung nur eingeschränkt wiedergeben. Humane Plattenepithelkarzinomzellen des Oropharynx wurden bereits mit anderen Zelllinien zur Simulation eines Tumor-Stromas kultiviert, wobei Änderungen in der Proliferation und der biologischen Aktivität gezeigt wurden (Ch'ng et al. 2006). Indirekte Ko-Kulturen, in denen MSC jeweils modellhaft als Tumor-Stroma dienten, wurden darüber hinaus mit natürlichen Killerzellen (Sotiropoulou et al. 2006) und Mammakarzinomzellen (Fierro et al. 2004) durchgeführt und konnten eine modifizierende Wirkung der MSC feststellen. Während im Monolayer-System ausschließlich eine Zellart kultiviert wird, können interzelluläre Aspekte der 
Einleitung

Tumormikroumgebung nur eingeschränkt analysiert werden. Die direkte oder indirekte KoKultur-Differenzierung bildet hier die Möglichkeit einer Ergänzung der MonolayerKultivierung (Böhrnsen et al. 2015; Boyera et al. 1993; Gache et al. 1998; Heneweer et al. 2005). Mit Hilfe der indirekten Ko-Kultur-/Transwelldifferenzierung können über eine semipermeable Membran (Porengröße: 0,4 $\mu \mathrm{m}$ ThinCerts) parakrine und Zell-ZellInteraktionen in Annäherung an ein Tumor-Stroma-Mikromilieu analysiert werden. Darüber hinaus lassen sich sowohl Tumorzellen (PCI-13) als auch MSC unkompliziert einzeln isolieren und unter definierten Bedingungen molekularbiologische Analysen durchführen. Störanfällige Trennverfahren können so umgangen werden (Goers et al. 2014). In dieser Arbeit wurde daher das etablierte Modell der indirekten Ko-Kultur zur Analyse und Auswertung der miteinander interagierenden Zelltypen unter molekularbiologischen Gesichtspunkten verwendet. 
Einleitung

\subsection{Zielsetzung der vorliegenden Arbeit}

Die Interaktionen zwischen Tumorgewebe und Tumor-Mikroumgebung beeinflussen das invasive Potential von PEK. MSC sind in der Lage, assoziierte Marker einer Epithelial-Mesenchymalen Transition (EMT) zu beeinflussen und einen suppressiven Einfluss auf die EMT der oralen Plattenepithelkarzinomzelllinie PCI-13 auszuüben. Die EMT steht jedoch unter dem Einfluss der Tumor-Mikroumgebung, die sich aus verschiedenen, auch nicht-tumorösen Zellen wie Fibroblasten, mesenchymalen Zellen, vaskulären Endothelzellen und Immunzellen gemeinsam mit der Extrazellulären Matrix zusammensetzt. Die Wechselwirkungen zwischen Tumor und Tumor-Stroma werden u. a. durch Wachstumsfaktoren beeinflusst, bei denen TGF- $\beta_{1}$ eine entscheidende Rolle spielt. Je nach zellulärem Kontext wird dabei dem Zytokin TGF- $\beta_{1}$ sowohl tumorproliferative als auch tumorsuppressive Wirkungen zugeschrieben.

Ziel dieser Arbeit war es daher die parakrinen, indirekten Wechselwirkungen zwischen Tumor und Stromazellen zu analysieren und den Einfluss von TGF- $\beta_{1}$ auf die Epitheliale-Mesenchymale-Transition und die Expression wichtiger EMT-Marker sowie den AKT-, mTOR- und Erk1/2-Signalweg zu untersuchen. Hierfür wurden human MSC isoliert, charakterisiert und im Rahmen von Monolayer- und Ko-Kulturen mit PCI-13 untersucht. Neben der Analyse von Proliferationscharakteristika der MSC und PCI-13 erfolgte die Untersuchung von Markern der EMT (E-Cadherin, Vimentin Wnt-3, $\beta$-Catenin, Snail1, Twist und MMP-14) mittels Immunfloureszenz und quantitative RT-qPCR Analysen. Genauere Betrachtung fanden auch die mit einer EMT assoziierten Signalwege von AKT, mTOR und Erk1/2 sowie deren nachgeschaltete Ziele S6, AMPK $\alpha$, PRAS40, GSK-3 $\alpha$, GSK-3 $\beta$, p70 S6, Bad, PTEN, PDK1, 4E-BP1 und RSK1. 
Material und Methoden

\section{Material und Methoden}

\subsection{Materialien und Geräte}

Tabelle 1: Verwendete Materialien und Geräte

\begin{tabular}{|c|c|}
\hline Autoklav Bioclav & Schütt-Biotech, Göttingen \\
\hline Chemiluminiszenz LAS 4000 & Fujifilm, Tokia, Japan \\
\hline Durchflusszytometer FACSCanto II & BD, Franklin Lakes, USA \\
\hline Eismaschine & Ziegra, Isernhagen \\
\hline Elektrische Pipettierhilfe Accu-Jet & Brand, Wertheim \\
\hline FluorPreserve & Merck, Darmstadt \\
\hline Gefrierschrank $-80^{\circ} \mathrm{C}$ & GFL, Burgwedel \\
\hline Glasplättchen (Ø $12 \mathrm{~mm})$ & Menzel, Braunschweig \\
\hline Imaging Chambers & Zell-Kontakt, Nörten-Hardenberg \\
\hline Kühlschrank $4^{\circ} \mathrm{C},-20^{\circ} \mathrm{C}$ & Liebherr, Ochsenhausen \\
\hline Latexhandschuhe Gentle Skin sensitive & Rösner-Mautby Meditrade, Kiefersfelden \\
\hline Mikroliterpipetten Eppendorf Reference $(10-1000 \mu \mathrm{l})$ & Eppendorf, Hamburg \\
\hline Mikroskop AxioVert $200 M$ & Carl Zeiss, Oberkochen \\
\hline Mikroskop AxioVert 35 & Carl Zeiss, Oberkochen \\
\hline Mikroskop Illuminator $H X P 120 C$ & Carl Zeiss, Oberkochen \\
\hline Orbital Shaker ThermoStar & BMG Labtech, Ortenberg \\
\hline Parafilm & American National Can, Chicago,USA \\
\hline PathScan Glasplatte & Cell Signaling Technology, Cambridge, UK \\
\hline PathScan Multi-Well-Abdichtung & Cell Signaling Technology, Cambridge, UK \\
\hline PCR 96-Well-Probenplatte & Bio-Rad Laboratories, Hercules, USA \\
\hline PCR iScript $^{\mathrm{TM}}$ cDNA Synthese Kit & Bio-Rad Laboratories, Hercules, USA \\
\hline PCR Kunststofffolie & Bio-Rad Laboratories, Hercules, USA \\
\hline PCR NanoDrop 1000 & Thermo Fisher Scientific, Waltham, USA \\
\hline PCR Real-Time-Thermocycler MyIQ & Bio-Rad Laboratories, Hercules, USA \\
\hline PCR RNase-Free DNase Set & Qiagen, Hilden \\
\hline PCR RNeasy ${ }^{\circledR}$ Mini Kit & Qiagen, Hilden \\
\hline PCR Thermocycler Mastercycler Gradient & Eppendorf, Hamburg \\
\hline PCR Werkbank Air clean 600 & Thermo Fisher Scientific, Waltham, USA \\
\hline Photometer SpectraMax M2 & Molucular Devices, Sunnyvale, USA \\
\hline Pipette Seriological Pipette $(10,25 \mathrm{ml})$ & Sarstedt, Nümbrecht \\
\hline Präzisionswaage $P M 460$ & Mettler-Toledo, Gießen \\
\hline Proteinanalyse Bio-Plex ${ }^{\mathrm{TM}}$ Cell Lysis Kit & Bio-Rad Laboratories, Hercules, USA \\
\hline Proteinanalyse PathScan ${ }^{\circledR}$ Antibody Array Kit & Cell Signaling Technology, Danvers, USA \\
\hline Proteinanalyse Pierce ${ }^{\mathrm{TM}} B C A$ Protein Assay Kit & Thermo Fischer Scientific, Waltham, USA \\
\hline Software AxioVision 4.8 & Carl Zeiss, Oberkochen \\
\hline Software BD FACSDiva & BD, Franklin Lakes, USA \\
\hline Software CORELDraw X6 & Corel, Ottawa, Canada \\
\hline Software Endnote X7.4 & Thomson Reuters, New York, USA \\
\hline Software FlowJo 10.1 & FlowJo, Ashland, USA \\
\hline Software GraphPad PRISM & GraphPad Software, La Jolla, USA \\
\hline Software ImageJ & NIH, Bethesda, USA \\
\hline Software Imagereader LAS-4000 & Fujifilm, Tokia, Japan \\
\hline Software $I Q 5$ & Bio-Rad Laboratories, Hercules, USA \\
\hline Software NanoDrop 1000 & Thermo Fisher Scientific, Waltham, USA \\
\hline Vortexer MS2 Minishaker & IKA-Werke, Staufen \\
\hline Wasserbad WB10 & Memmert, Schwabach \\
\hline Zellkultur 6-Well-Kulturplatte & Greiner Bio-One, Frickenhausen \\
\hline Zellkultur 6-Well-ThinCerts & Greiner Bio-One, Frickenhausen \\
\hline Zellkultur Eppendorf-Cup 1,5 ml & Sarstedt, Nümbrecht \\
\hline Zellkultur Falcon $(15,50 \mathrm{ml})$ & BD, Franklin Lakes, USA \\
\hline
\end{tabular}


Material und Methoden

\begin{tabular}{|l|l|}
\hline Zellkultur Gewebekulturflaschen $\left(25-175 \mathrm{~cm}^{2}\right)$ & Sarstedt, Nümbrecht \\
\hline Zellkultur Gewebekulturschale $(\varnothing 6 \mathrm{~cm})$ & Sarstedt, Nümbrecht \\
\hline Zellkultur Inkubator $\mathrm{CO}_{2}$-Incubator & Sanyo, Moriguchi, Japan \\
\hline Zellkultur Kryoröhrchen $(2 \mathrm{ml})$ & Sarstedt, Nümbrecht \\
\hline Zellkultur Mr. Frosty & Thermo Fisher Scientific, Waltham, USA \\
\hline Zellkultur Präparationsbesteck (steril) & Hu-Friedy, Frankfurt a. M. \\
\hline Zellkultur Werkbank $E N 12469$ & Clean Air Systems, Chennai, Indien \\
\hline Zellzählung CASY ${ }^{\circledR}$ Probenbecher & Roche, Basel, Schweiz \\
\hline Zellzählung CASY ${ }_{\text {-System Casy 1 Modell TT }}$ & Roche, Basel, Schweiz \\
\hline Zentrifuge Centrifuge $5415 R$ & Eppendorf, Hamburg \\
\hline Zentrifuge Centrifuge 5417 C & Eppendorf, Hamburg \\
\hline Zentrifuge Hermle Z400K & Hermle, Wehingen \\
\hline Zentrifuge Megafuge 1.0 & Thermo Fisher Scientific, Waltham, USA \\
\hline Zentrifuge Sigma 2 K15C & Sigma Laborzentrifugen, Osterode im Harz \\
\hline
\end{tabular}

\subsection{Allgemeine Zellkulturtechniken}

Alle verwendeten Zellen wurden bei $37^{\circ} \mathrm{C}$ und 5,5\% $\mathrm{CO}_{2}$-Begasung in einem Zellkulturinkubator ( $\mathrm{CO}_{2}$-Incubator, Sanyo, München) kultiviert. Es wurden stets autoklavierte, sterilisierte Materialien und Lösungen verwendet. Alle Arbeiten wurden unter sterilen Werkbänken (EN 12469, Clean Air Systems, Chennai, India) durchgeführt, wobei die Kultivierung der verwendeten Zellen auf Gewebekulturplastik (Sarstedt, Nümbrecht) erfolgte.

\subsubsection{Ablösen, Zentrifugieren und Passagieren}

Tabelle 2: Trypsin/EDTA

\begin{tabular}{|l|l|l|}
\hline $0,25 \%(\mathrm{v} / \mathrm{v})$ & Trypsin & Pan-Biotech, Aidenbach \\
\hline $0,02 \%(\mathrm{v} / \mathrm{v})$ & Ethylendiamintetraessigsäure (EDTA) & Pan-Biotech, Aidenbach \\
\hline \multicolumn{2}{|l}{$\begin{array}{l}\text { Trypsin und EDTA wurden in Dulbecco's Phosphat-gepufferte Salzlösung (DPBS, Pan-Biotech, Aidenbach) } \\
\text { gelöst und anschließend steril filtriert. }\end{array}$} \\
\hline
\end{tabular}

Bei 80-90 \%iger Zellkonfluenz wurden die verwendeten Zellen in die nächste Passage überführt. Das jeweilig verwendete Medium wurde vorsichtig abgesaugt und die Zellen zweimal mit DPBS gewaschen, um Mediumrückstände zu entfernen. Anschließend wurden die Zellen mit einem geringen Flüssigkeitsfilm Trypsin/EDTA (Tabelle 2) bedeckt und bei $37^{\circ} \mathrm{C}$ und 5,5\% $\mathrm{CO}_{2}$-Begasung für 10 min inkubiert. Das Abheben und Ablösen der Zellen vom Boden der Zellkulturflasche (Sarstedt, Nümbrecht) wurde unter einem Lichtmikroskop (Axiovert 35, Carl Zeiss, Oberkochen) kontrolliert. Mit serumhaltigem Medium wurde die Wirkung des Trypsins gestoppt, die Zellen mit Hilfe einer 10 ml-Pipette (Sarstedt, Nümbrecht) in ein $15 \mathrm{ml}$ Falcon (BD, Franklin Lakes, USA) überführt und anschließend 5 min bei 500 x $g$ zentrifugiert (Zentrifuge Sigma 2K15C, Osterode am Harz). 
Material und Methoden

Der Überstand wurde entfernt und das gebildete Zellpellet in $10 \mathrm{ml}$ Kultivierungsmedium resuspendiert. Im Anschluss erfolgte eine Zellzählung und die Zellen wurden entweder kryokonserviert oder in einer Zelldichte von $5 \times 10^{4}$ Zellen pro $\mathrm{cm}^{2}$ auf Gewebekulturflaschen ausplattiert.

\subsubsection{Kryokonservierung}

Die verwendeten Zellen wurden von der Gewebekulturoberfläche abgelöst, mit DPBS gewaschen, zentrifugiert und in $1 \mathrm{ml}$ Medium zur Kryokonservierung (10\% (v/v) Dimetylsulfoxid (DMSO) wurde in Kultivierungsmedium gelöst und anschließend steril filtriert) resuspendiert. Anschließend wurden die Zellen in ein Kryoröhrchen (Sarstedt, Nümbrecht) überführt und dieses zunächst bei $-80^{\circ} \mathrm{C}$ und im Anschluss zur Langzeitkryokonservierung in flüssigen Stickstoff $\left(-196^{\circ} \mathrm{C}\right)$ überführt.

Zur Überführung in die Zellkultur wurden kryokonservierte Proben im $37^{\circ} \mathrm{C}$ warmen Wasserbad (WB10, Memmert, Schwabach) zügig aufgetaut, in $10 \mathrm{ml}$ Kultivierungsmedium überführt und für 5 min bei 250 x g zentrifugiert. Anschließend wurde der Mediumüberstand verworfen und die Zellen in $10 \mathrm{ml}$ Kultivierungsmedium resuspendiert, sowie Zellzahl und -vitalität bestimmt. Die Zellen wurden im Anschluss in einer Dichte von 5 x $10^{4}$ Zellen pro $\mathrm{cm}^{2}$ auf Gewebekulturflaschen ausplattiert werden.

\subsection{Isolation und Kultivierung von MSC aus humanen Knochenmarkaspiraten}

Tabelle 3: MSC-Kultivierungsmedium

\begin{tabular}{|l|l|l|}
\hline $1000 \mathrm{ml}$ & DMEM & $\begin{array}{l}\text { Thermo Fisher } \\
\text { Waltham, USA }\end{array}$ \\
\hline $10 \%(\mathrm{v} / \mathrm{v})$ & Fetales Kälberserum (FKS) & Biochrom, Berlin \\
\hline $1 \%(\mathrm{v} / \mathrm{v})$ & MEM Non-Essential Amino Acids & PAN-Biotech, Aidenbach \\
\hline $1 \%(\mathrm{v} / \mathrm{v})$ & Penicillin/Streptomycin (Pen/Strep) & PAN-Biotech, Aidenbach \\
\hline $1 \%(\mathrm{v} / \mathrm{v})$ & $10 \mathrm{mM}$ 2-Mercaptoethanol & Sigma-Aldrich, St. Louis, USA \\
\hline
\end{tabular}

Die Isolation von MSC erfolgte aus der Spongiosa von Beckenkammpräparationen/-aspiraten von acht Patienten im Alter von 11 bis 61 Jahren. Eine jeweilige Einverständniserklärung der Patienten und das Votum der zuständigen Ethikkommision der Georg-August-Universität lagen vor (Nummer des Ethikantrags: 15/10/01). Es war von keinem der Patienten eine chronische Entzündung, Infektion, Tumorerkrankung oder sonstige Erkrankung des Knochenmarks bekannt. Die aus dem Knochenmark gewonnenen Proben wurden mit Hilfe der Dichtegradientenzentrifugation selektiert. Nach der Entnahme wurden die Proben mit 5000 i. E. Heparin (Rotexmedica, 
Material und Methoden

Trittau) pro ml Aspirat versetzt, 1:1 mit 0,9\%iger Natrium-Chlorid-Lösung ( $\mathrm{NaCl}$; B. Braun, Melsungen) verdünnt und $6 \mathrm{ml}$ dieser Verdünnung vorsichtig ohne Durchmischen über $3 \mathrm{ml}$ vorgelegtes Lymphoprep ${ }^{\mathrm{TM}}$ (Axis-Shield, Oslo, Norwegen) in einem $15 \mathrm{ml}$ Falcon überschichtet. Anschließend erfolgte die Zentrifugation für $20 \mathrm{~min}$ bei $800 \mathrm{x} g$ und Raumtemperatur. Die im Grenzbereich der lymphozytären und erythrozytären Phasen auftretende Interphase (Abbildung 3) wurde mittels 5 ml-Pipette ohne Vermischen der einzelnen Phasen abgezogen und mit $5 \mathrm{ml} \mathrm{NaCl}$ in ein neues Zentrifugenröhrchen überführt. Nach erneuter Zentrifugation für 10 min bei $250 \mathrm{x} g$ wurden der Überstand abgesaugt und die Zellen in einer 6-Well-Multiwell-Platte (Greiner Bio-One, Frickenhausen) mit $3 \mathrm{ml}$ MSC-Kultivierungsmedium (Tabelle 3) pro Well ausplattiert. Nach 24 Stunden wurde das Medium gewechselt, weitere Mediumwechsel erfolgten alle 48 bis 72 h. Bei Erreichen einer 80-90 \%igen Zellkonfluenz wurden die MSC-Isolate gepoolt und in die Folgekultur überführt oder für eine spätere Verwendung kryokonserviert.

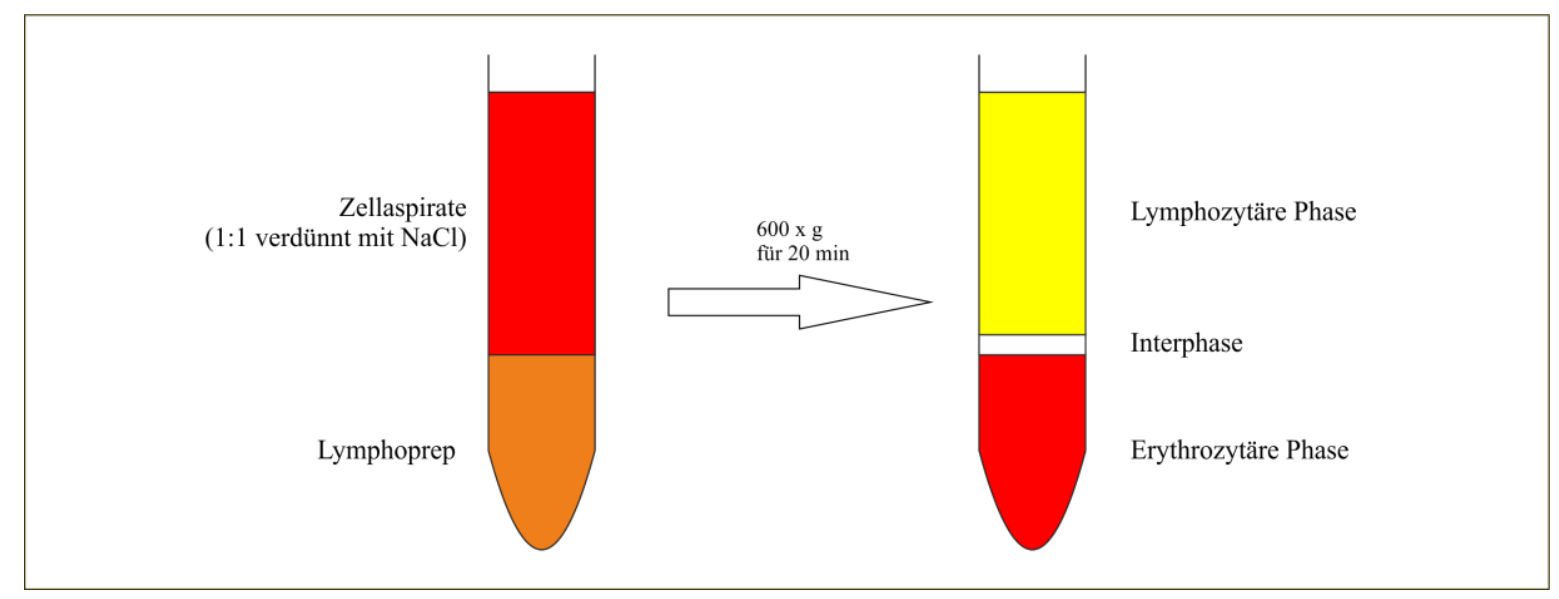

Abbildung 3: Darstellung der Dichtegradientenzentrifugation.

Die Kultivierung der MSC erfolgte im MSC-Kultivierungsmedium im Zellkulturinkubator bei $37^{\circ} \mathrm{C}$ unter Begasung mit 5,5\% $\mathrm{CO}_{2}$. Hierfür wurden die MSC von der 6-Well-Oberfläche abgelöst, zentrifugiert, resuspendiert, gezählt und mit einer Dichte von $5 \times 10^{4}$ pro $\mathrm{cm}^{2}$ in einer Zellkulturflasche ausplattiert. Die Anzucht der Zellen erfolgte über Nacht, nach spätestens $24 \mathrm{~h}$ konnte mikroskopisch eine Zelladhärenz festgestellt werden. Zellproliferation und -morphologie wurden täglich kontrolliert, ein Mediumwechsel erfolgte alle 48 bis 72 h, im selben Zeitraum konnten auch erste Koloniebildungen (colony forming units) beobachtet werden. Nach ca. 10 bis $14 \mathrm{~d}$ erreichten die Zellen innerhalb der Kulturflasche eine 80-90 \%ige Zellkonfluenz und konnten bei genügender Zellzahl für die Versuche verwendet werden. 
Material und Methoden

\subsection{Kultivierung der humanen PEK-Zelllinie PCI-13}

Tabelle 4: PCI-13 Kultivierungsmedium

\begin{tabular}{|l|l|l|}
\hline $1000 \mathrm{ml}$ & DMEM & $\begin{array}{l}\text { Thermo Fisher Scientific, } \\
\text { Waltham, USA }\end{array}$ \\
\hline $10 \%(\mathrm{v} / \mathrm{v})$ & FKS & Biochrom, Berlin \\
\hline $1 \%(\mathrm{v} / \mathrm{v})$ & MEM Non-Essential Amino Acids & PAN-Biotech, Aidenbach \\
\hline $1 \%(\mathrm{v} / \mathrm{v})$ & Pen/Strep & PAN-Biotech, Aidenbach \\
\hline
\end{tabular}

Die Zellen der etablierten humanen Plattenepithelkarzinomlinie PCI-13 (Heo et al. 1989) wurden verwendet. Nach Auftauen aus der Kryokonservierung erfolgte die Proliferation der Zellen im PCI-13-Kultivierungsmedium (Tabelle 4) im Zellkulturinkubator bei $37^{\circ} \mathrm{C}$ unter Begasung mit 5,5\% $\mathrm{CO}_{2}$. Nach spätestens 24 Stunden konnte mikroskopisch eine Zelladhärenz festgestellt werden. Zellproliferation und -morphologie wurden täglich kontrolliert, ein Mediumwechsel erfolgte alle 48 bis 72 Stunden. Nach ca. 7 bis 10 d erreichten die Zellen innerhalb der Kulturflasche eine 80-90\%ige Zellkonfluenz und konnten bei genügender Zellzahl für die Versuche verwendet werden.

\subsection{Differenzierung isolierter, humaner MSC}

\subsubsection{Osteogene und adipogene Differenzierung im Monolayer}

Tabelle 5: Medium zur osteogenen Induktion

\begin{tabular}{|l|l|l|}
\hline $0,1 \mu \mathrm{M}$ & Dexamethason & Merk, Darmstadt \\
\hline $10 \mathrm{mM}$ & $\beta$-Glycerophosphat & Sigma, München \\
\hline $300 \mu \mathrm{M}$ & Vitamin C (steril) & Sigma, München \\
\hline \multicolumn{2}{|l}{} \\
Die genannten Zusätze wurden in MSC-Kultivierungsmedium gelöst. \\
\hline
\end{tabular}

Tabelle 6: Medium zur adipogenen Induktion

\begin{tabular}{|l|l|l|}
\hline $2 \mu \mathrm{M}$ & Insulin & Sigma, München \\
\hline $500 \mu \mathrm{M}$ & IBMX & Sigma, München \\
\hline $1 \mu \mathrm{M}$ & Dexamathason & Merk, Darmstadt \\
\hline $200 \mu \mathrm{M}$ & Indomethacin & Sigma, München \\
\hline \multicolumn{2}{|l}{} \\
\multicolumn{2}{|l}{ Die genannten Zusätze wurden in MSC-Kultivierungsmedium gelöst. } \\
\hline
\end{tabular}

Tabelle 7: Medium zum Erhalt der adipogenen Differenzierung

\begin{tabular}{|l|l|l|}
\hline $2 \mu \mathrm{M}$ & Insulin & Sigma, München \\
\hline & \\
Insulin wurde in MSC-Kultivierungsmedium gelöst. & \\
\hline
\end{tabular}

Zur Charakterisierung der MSC erfolgte die osteogene und adipogene Differenzierung im klassischen Monolayer (Meirelles Lda und Nardi 2003; Pittenger et al. 1999; Tropel et al. 2004). Die MSC wurden auf Gewebekulturschalen (Ø 6 cm, Sarstedt, 
Material und Methoden

Nümbrecht) für die RNA-Isolierung und Imaging Chambers (Zell-Kontakt, NörtenHardenberg) für die histochemischen und immunhistochemischen Färbungen kultiviert. Die spezifische Induktion der MSC wurde ab einer Zellkonfluenz von 70-80 \% durchgeführt. Für die osteogene Induktion wurden das Kultivierungsmedium durch das Medium zur osteogenen Induktion (Tabelle 5) ersetzt und die Zellen über einen Zeitraum von 25 Tagen differenziert. Ein Wechsel des osteogenen Induktionsmediums erfolgte alle vier Tage.

Für die adipogene Induktion wurde das Kultivierungsmedium durch das Medium zur adipogenen Induktion (Tabelle 6) ersetzt. Nach 3 Tagen Induktion folgte eine Stabilisierung der adipogenen Differenzierung durch eine Kultivierung mit dem Medium zum Erhalt der adipogenen Differenzierung (Tabelle 7) für 4 Tage. Die Induktions- und Stabilisierungsphase wurden jeweils zweimal wiederholt, abschließend erfolgte eine viertägige Differenzierung der MSC im Medium zum Erhalt der adipogenen Differenzierung.

Im Rahmen aller Differenzierungsversuche wurden nach 25 Tagen Proben für histochemische und immunhistochemische Färbungen entnommen.

\subsubsection{Chondrogene Differenzierung im Micro-Mass-Body}

Tabelle 8: Medium zur chondrogenen Differenzierung

\begin{tabular}{|l|l|l|}
\hline $1 \%$ & IST+ Premix & B\&D, Heidelberg \\
\hline $0,1 \mu \mathrm{M}$ & Dexamethason & Merk, Darmstadt \\
\hline $1 \mathrm{mM}$ & L-Prolin & Sigma, München \\
\hline $10 \mathrm{ng} / \mathrm{ml}$ & TGF- $\beta_{1}$ & PeproTech, Rocky Hill/NJ, USA \\
\hline $300 \mu \mathrm{M}$ & Vitamin C (steril) & Sigma, München \\
\hline \multicolumn{2}{|l}{} \\
Die genannten Zusätze wurden in MSC-Kultivierungsmedium gelöst. \\
\hline
\end{tabular}

Zur Charakterisierung erfolgte die chondrogene Differenzierung der MSC im klassischen Micro-Mass-Body (MMB; (Johnstone et al. 1998);

Abbildung 4) in Gegenwart von Serum und TGF- $\beta_{1}$. Undifferenzierte Stammzellen wurden wie beschrieben von den Gewebekulturoberflächen abgelöst und in Medium zur chondrogenen Induktion (Tabelle 8) resuspendiert. Aliquotes von $0,5 \mathrm{ml} \mathrm{mit} \mathrm{je} 2 \times 10^{5}$ Zellen wurden in $15 \mathrm{ml}$ Falcons überführt und für 10 min bei $65 \mathrm{x} g$ zentrifugiert. Diese wurden im Anschluss bei $37^{\circ} \mathrm{C}$ und unter Begasung mit $5 \% \mathrm{CO}_{2}$ im Inkubator inkubiert. Um einen guten Sauerstoffaustausch zu gewährleisten sowie externe Kontaminationen zu vermeiden, behielten die Röhrchen eine sterile luftdurchlässige Schutzkappe. Innerhalb von 24 Stunden nach Inkubation wurde ein Zellaggregat sichtbar, das im Verlauf der Differenzierung keine Adhärenz zur Wand des Röhrchens zeigte. Im Verlauf des Differenzierungszeitraums von 
Material und Methoden

25 Tagen wurden das chondrogene Induktionsmedium alle vier Tage erneuert und Proben zur Erstellung von histologischen Kryopräparaten entnommen.

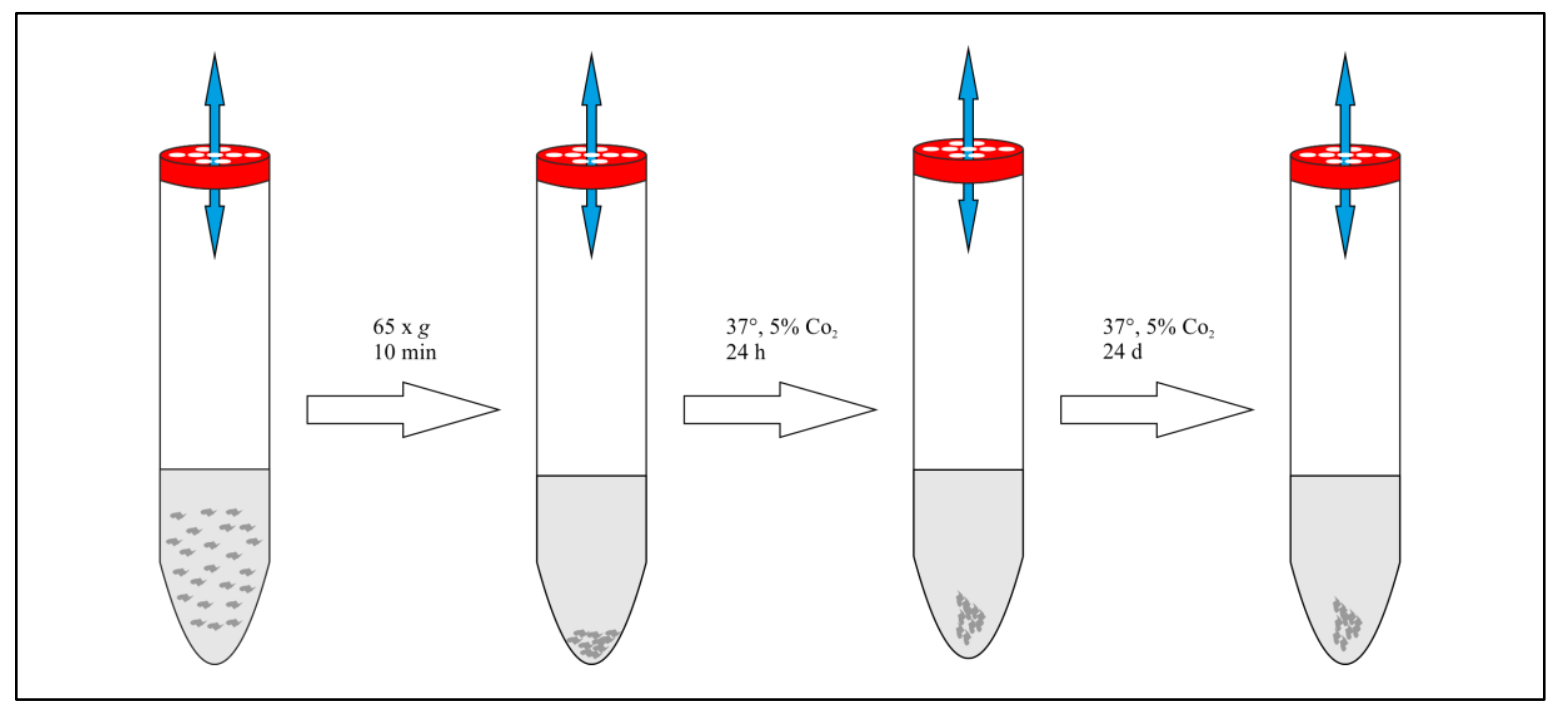

Abbildung 4: Chondrogene Differenzierung von MSC im Micro-Mass-Body.

\subsection{Histochemische Analysen zur Charakterisierung der Differenzierung von humanen MSC}

\subsubsection{Osteogene Differenzierung}

Der Nachweis einer osteogenen Differenzierung erfolgte histologisch durch die Auswertung der Expression alkalischer Phosphatase (AP, Sigma, München).

Tabelle 9: Citrat-Formaldehyd-Fixierlösung

\begin{tabular}{|l|l|l|}
\hline $2,5 \mathrm{ml}$ & Citrat-Lösung & Sigma, München \\
\hline $6,5 \mathrm{ml}$ & Aceton & Roth, Karlsruhe \\
\hline $0,8 \mathrm{ml}$ & Formaldehyd 37\% & Merck, Darmstadt \\
\hline
\end{tabular}

Tabelle 10: Naphtol-Färbelösung

\begin{tabular}{|l|l|l|}
\hline $125 \mu \mathrm{l}$ & Natrium-Nitrit-Lösung & Sigma, München \\
\hline $125 \mu \mathrm{l}$ & Alkalische Phosphatase-Lösung & Sigma, München \\
\hline $125 \mu \mathrm{l}$ & Naphthol-Lösung & Sigma, München \\
\hline $5,63 \mathrm{ml}$ & Aqua destillata & Merck, Darmstadt \\
\hline
\end{tabular}

Durch doppeltes Waschen der Zellen mit DPBS wurden zunächst alle Mediumrückstände entfernt und die Zellen anschließend mit der Citrat-FormaldehydFixierlösung (Tabelle 9) fixiert. Durch gründliches Spülen mit Aqua destillata wurde die Fixierlösung entfernt und die Probe für 15 min bei Raumtemperatur im Dunkeln mit Naphthol-Färbelösung (Tabelle 10) inkubiert. Nach der Inkubation wurde die Färbelösung rückstandslos abgesaugt und die Präparate mit Aqua destillata gewaschen. Die 
Material und Methoden

Gegenfärbung der Präparate erfolgte mit Hämatoxylin. Abschließende wurden diese gewaschen und mit FluorPreserve ${ }^{\mathrm{TM}}$ (Merck, Darmstadt) eingedeckt und bei $4^{\circ} \mathrm{C}$ gelagert.

\subsubsection{Sudan-III-Färbung zur Darstellung der adipogenen Differenzierung}

Die Visualisierung intrazellulärer Lipidvakuolen wurde mit Sudan-III realisiert. Sudan-III ist ein in Kohlenwasserstoffen, Ölen, Fetten und Wachsen löslicher Azofarbstoff.

Tabelle 11: Sudan-III-Färbelösung

\begin{tabular}{|l|l|l|}
\hline $0,3 \%(w / v)$ & Sudan-III & Sigma, München \\
\hline \multicolumn{2}{|l}{ Sudan-III wurde in $70 \%$ igem Ethanol gelöst, 15 min auf $60^{\circ} \mathrm{C}$ erhitzt und anschließend steril filtriert. } \\
\hline
\end{tabular}

Durch doppeltes Waschen der Zellen mit DPBS wurden zunächst alle Mediumrückstände entfernt und anschließend die Sudan-III-Färbelösung (Tabelle 11) aufgebracht. Der Färbevorgang wurde unter dem Mikroskop beobachtet und kontrolliert. Nach 3 min wurde die Färbelösung abgesaugt und Rückstände restlos mit DPBS entfernt. Abschließend wurde das Präparat mit FluorPreserve ${ }^{\mathrm{TM}}$ eingedeckt und bei $4^{\circ} \mathrm{C}$ gelagert.

\subsubsection{Alcianblau-Färbung zur Darstellung der chondrogenen Differenzierung}

Zur Darstellung knorpelspezifischer Proteoglykane wurde der wasserlösliche Phthalocyaninfarbstoff Alcianblau (AB) verwendet.

Tabelle 12: AB-Färbelösung

\begin{tabular}{|l|l|l|}
\hline $154 \mathrm{mM}$ & $\mathrm{NaCl}$ & Merck, Darmstadt \\
\hline $134 \mathrm{mM}$ & $\mathrm{MgCl}$ & Merck, Darmstadt \\
\hline $0,05 \%(\mathrm{w} / \mathrm{v})$ & Alcianblau 8GX & Sigma, München \\
\hline $\begin{array}{l}\text { Die gennanten Additive wurden in 3\%iger Essigsäure gelöst und anschließend auf einen pH-Wert 1,5 } \\
\text { eigestellt. }\end{array}$
\end{tabular}

Durch doppeltes Waschen der Zellen mit DPBS wurden zunächst alle Mediumrückstände entfernt und die Präparate für 30 min mit $3,7 \%$ (v/v) Formaldehydlösung fixiert. Im Anschluss wurden die Präparate erneut gewaschen und über Nacht bei Raumtemperatur mit AB-Färbelösung (Tabelle 12) gefärbt. Am nächsten Morgen wurde die Färbelösung abgenommen, die Zellen mit DPBS gewaschen und mit FluorPreserve $\mathrm{TM}^{\mathrm{TM}}$ eingedeckt. Die Lagerung erfolgte bei $4^{\circ} \mathrm{C}$. 
Material und Methoden

2.7 Charakterisierung isolierter MSC mittels Durchflusszytometrie

Tabelle 13: Verwendete Antikörper der durchflusszytometrischen MSC-Charakterisierung

\begin{tabular}{|l|l|l|l|}
\hline $\begin{array}{l}\text { Oberflächen- } \\
\text { eigenschaft }\end{array}$ & Name & Gekoppelt & Hersteller \\
\hline \hline CD 34 & gp105-120 & PE gekoppelt & Miltenyi Biotech, Bergisch Gladbach \\
\hline CD 45 & $\begin{array}{l}\text { leukocyte } \\
\text { common antigen }\end{array}$ & PE gekoppelt & BioLegend, San Diego, USA \\
\hline CD 73 & $\begin{array}{l}\text { ecto-5'- } \\
\text { nucleotidase }\end{array}$ & PE gekoppelt & BD, Franklin Lakes, USA \\
\hline CD 90 & Thy-1 & PE gekoppelt & BioLegend, San Diego, USA \\
\hline CD 105 & endoglin & PE gekoppelt & BioLegend, San Diego, USA \\
\hline
\end{tabular}

Eine Oberflächencharakterisierung der MSC erfolgte mittels Durchflusszytometrie (fluorescence activated cell sorting, FACS). Hierzu wurden die zu analysierenden Zellen wie beschrieben von ihrer Gewebekulturoberfläche abgelöst und mit DPBS eine Zellsuspension von 1 x $10^{5}$ Zellen pro $100 \mu 1$ hergestellt. Im weiteren Verlauf wurden jeweils $100 \mu 1$ dieser Zellsuspension mit je $2 \mu 1$ eines monoklonalen Antikörpers Phycoerythrin (PE; BD, Franklin Lakes, USA) für 10 min bei $4^{\circ} \mathrm{C}$ inkubiert. Die Expression der in Tabelle 13 aufgelisteten Antikörper wurde untersucht. Für die FACS-Untersuchung wurden anschließend alle Proben mit DPBS auf ein einheitliches Volumen von $500 \mu$ l eingestellt und im Durchflusszytometer FACSCanto II (BD, Franklin Lakes, USA) analysiert. Die nachfolgende Auswertung erfolgte mit der Software BD FACSDiva (BD, Franklin Lakes, USA). Es wurden mindestens 10.000 Events aufgezeichnet und mittels eines einparametrischen Analyseprotokolls ausgewertet (FL1). Zelluläre Aggregate und Zellfragmente wurden durch Anpassen des Messfensters (FSC/SSC dotplot) ausgeschlossen. Die Erstellung der jeweiligen Histogramme erfolgte mit der Software FlowJo (FlowJo, Ashland, USA).

\subsection{TGF- $\beta_{1}$ induzierte Transwell-Ko-Kultur-Differenzierung}

\subsubsection{Transwell-Ko-Kultur von MSC und PCI-13}

Tabelle 14: Reduktionsmedium

\begin{tabular}{|l|l|l|}
\hline $1 \%$ & FKS & Biochrom, Berlin \\
\hline $1 \%$ & Pen/Strep & PAN-Biotech, Aidenbach \\
\hline \multicolumn{2}{|l}{} \\
Die genannten Additive wurden in DMEM gelöst. \\
\hline
\end{tabular}


Material und Methoden

Tabelle 15: Transwell-Ko-Kultur-Medium

\begin{tabular}{|l|l|l|}
\hline $20 \mathrm{ng} / \mathrm{ml}$ & TGF- $\beta_{1}$ & PeproTech, Rocky Hill/NJ, USA \\
\hline $1 \%$ & Pen/Strep & PAN-Biotech, Aidenbach \\
\hline
\end{tabular}

Die genannten Additive wurden in Panserin 401 (serumfrei; Pan-Biotech, Aidenbach) gelöst.

Die Ko-Kultur erfolgte in 6-Well-Multiwell-Platten mit Membran-Ko-Kultureinsätzen (ThinCerts; Greiner Bio-One, Frickenhausen). Dabei wurden die PCI-13-Zellen auf dem Plattenboden und die MSC auf dem ThinCert-Boden jeweils als Monolayerkultur kultiviert. Über die semipermeable Membran (Porengröße: 0,4 $\mu \mathrm{m}$ ) der ThinCerts war ein freier Austausch von Medium und Mediumbestandteilen zwischen Schalenboden und Einsatz gewährleistet (Abbildung 5).

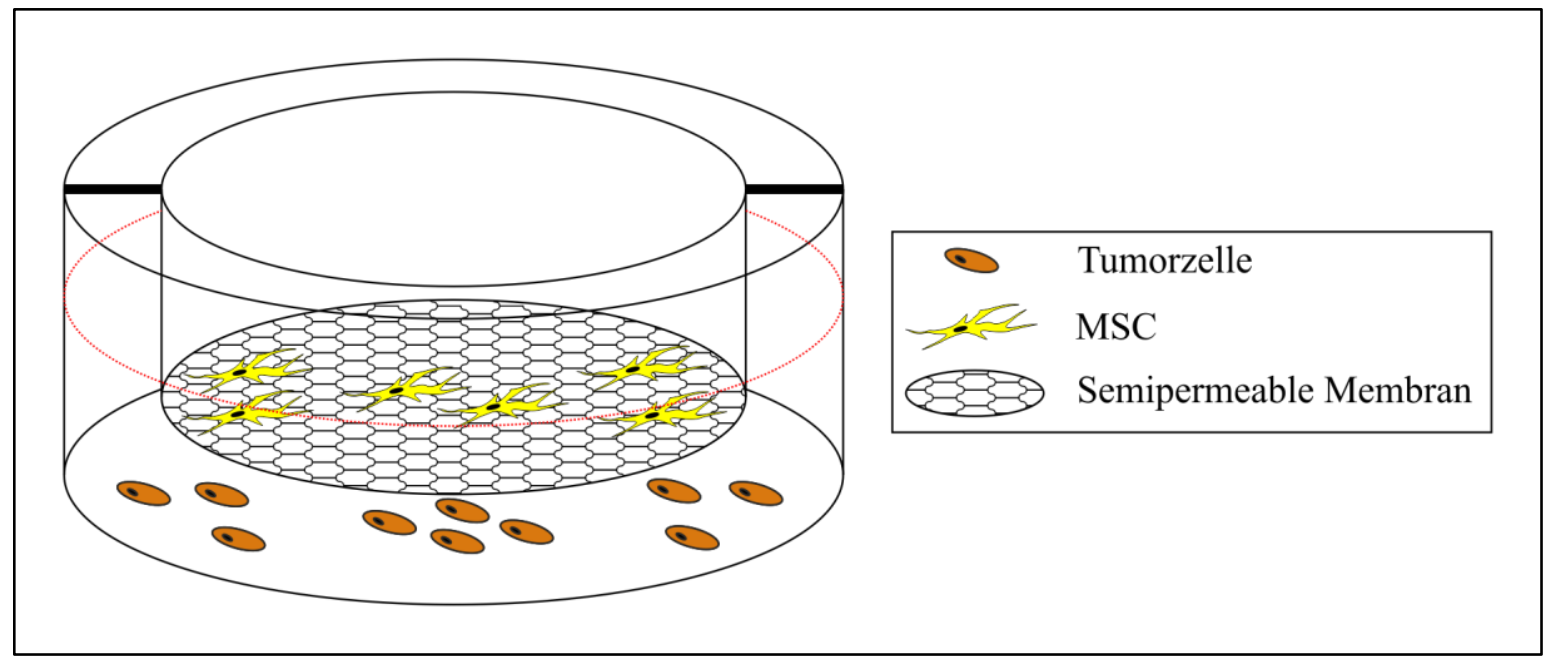

Abbildung 5: Ausschnitt einer Multiwell-Platte mit Transwell-Ko-Kultur-Einsatz.

Jeweils vor den Versuchen wurden MSC und PCI-13 für 8 bis 10 Tage getrennt voneinander kultiviert und in MSC- bzw. PCI-13-Kultivierungsmedium kultiviert, um eine ausreichende Zellzahl gewährleisten zu können. Vier Tage vor Versuchsbeginn wurden die Zellen wie beschrieben vom Schalenboden abgelöst und in die Ko-Kultur mit MSC-Kultivierungsmedium überführt. Einen Tag vor Versuchsbeginn erfolgte eine Mediumumstellung der Ko-Kultur auf Reduktionsmedium (Tabelle 14) für $24 \mathrm{~h}$. Am Versuchsstart wurden die Ausgangsproben genommen und die restlichen Ko-Kulturen auf Transwell-Ko-Kultur-Medium (Tabelle 15) umgestellt, wobei durch die generelle Serumfreiheit des Panserin 401 gewährleistet wurde, dass nur die Zugabe des TGF- $\beta_{1}$ auf die ko-kultivierten Zellen wirken konnte. Weitere Probennahmen erfolgten an Tag 3 und 6. 
Material und Methoden

\subsection{Analyse der Proliferationscharakteristika von MSC und PCI-13}

Die Evaluation der Proliferations- und Wachstumseigenschaften erfolgte mit Hilfe des Verdopplungsfaktors (V-Faktor). Für die Berechnung wurde folgende Formel zu Grunde gelegt:

$$
\mathrm{v}=100 /\left(\mathrm{K}_{\mathrm{n}} / \mathrm{K}_{0}-1\right)^{\mathrm{n}}
$$

$\mathrm{K}_{\mathrm{n}} \quad=$ Zellzahl nach dem Kultivierungszeitraum $\mathrm{n}$

$\mathrm{K}_{0} \quad=$ Initial plattierte Zellzahl

$\mathrm{n} \quad=$ Kultivierungszeitraum in Tagen

$\mathrm{v} \quad=\mathrm{V}$-Faktor, Auflösung der Gleichung nach $\mathrm{v}$

Der V-Faktor wurde an verschiedenen Zeitpunkten während der Kultivierung bestimmt, quantifiziert und statistisch ausgewertet. Er beschreibt die Zunahme der Zellpopulationen als Verdopplungsfaktor innerhalb von 24 Stunden. Die Zellzählung erfolgte durch das vollautomatische, nicht-invasive CASY®-System Casy 1 Modell TT (150 $\mu \mathrm{m}$ Messkapillare, Roche, Basel, Schweiz). Hierfür wurden $100 \mu 1$ der Zellsuspension in 10 $\mathrm{ml}$ der isotonen Elektrolytlösung CasyTon (Roche, Basel, Schweiz) in einem speziellen Casy Probenbecher (Roche, Basel, Schweiz) suspendiert. Anschließend konnte eine dreifache Zellzahlbestimmung nach dem Widerstandsmessprinzip vorgenommen werden. Beim Eindringen einer Zelle in die Messkapillare entstand durch Widerstandsänderung ein elektrischer Impuls, wobei die Anzahl der gemessenen Impulse der Zellzahl entsprach.

\subsection{Darstellung zelltypspezifischer Proteinexpression mittels direkter Immunfluoreszenzfärbung}

Tabelle 16: Methanol-/Aceton-Fixierlösung

\begin{tabular}{|l|l|l|}
\hline $70 \mathrm{ml}$ & Methanol & Merck, Darmstadt \\
\hline $30 \mathrm{ml}$ & Aceton & Merck, Darmstadt \\
\hline
\end{tabular}

Tabelle 17: BSA-Blocking-Reagenz

\begin{tabular}{|l|l|l|}
\hline $7,5 \%(\mathrm{w} / \mathrm{v})$ & Bovines Serum Albumin (BSA) in DPBS & Biochrom, Berlin \\
\hline
\end{tabular}

Tabelle 18: Anti-Vimentin Antikörper (EPR3776)

\begin{tabular}{|l|l|l}
\hline $0,2 \mathrm{mg} / \mathrm{ml}$ & Antikörper Anti-Vimentin (1:100 in BSA) & Abcam, Cambridge, UK \\
\hline
\end{tabular}

Tabelle 19: Anti-E-Cadherin Antikörper (612130)

\begin{tabular}{|l|l|l|}
\hline $0,25 \mathrm{mg} / \mathrm{ml}$ & Antikörper Anti-E-Cadherin (1:50 in BSA) & BD, Franklin Lakes, USA \\
\hline
\end{tabular}

Tabelle 20: Fluoreszenzfarbstoff DAPI

\begin{tabular}{|l|l|l|l}
\hline $20 \mathrm{mg} / \mathrm{ml}$ & 4',6-Diamidin-2-phenylindol (DAPI) (1:1000 in BSA) & Sigma-Aldrich, St. Louis, USA \\
\hline
\end{tabular}


Material und Methoden

Die Immunfluoreszenzfärbung (IF) ist eine Methode hoher Auflösung, mit der die zelltypspezifische Proteinexpression dargestellt werden kann (Coons 1954). Bei der direkten Methode bindet ein fluoreszenzmarkiertes Immunglobulin unmittelbar an ein zellspezifisches Protein und markiert es so. Die Anregung der jeweiligen Alexa-Fluor- bzw. Fluorescein (FITC)-Fluoreszenz durch ultraviolettes Licht charakteristischer Wellenlängen führte zur spezifischen Illumineszenz des Antikörpers.

Die Zellen wurden zweimal mit DPBS gewaschen und anschließend für 5 min bei $-20^{\circ} \mathrm{C}$ mit Methanol-/Aceton-Fixierlösung (Tabelle 16) fixiert. Nach erneut gründlichem Waschen mit DPBS wurden die Zellen in eine feuchte Kammer überführt. Alle folgenden Inkubationsschritte wurden in einer Dunkelkammer bei $37^{\circ} \mathrm{C}$ durchgeführt. Um die freien, unspezifischen Antikörperbindungsstellen zu binden, erfolgte für 30 min eine Blockung mit 7,5\% BSA-Blocking-Reagenz (Tabelle 17). Anschließend wurden die Proben mit $100 \mu \mathrm{l}$ der jeweiligen Antikörperlösung (Tabelle 18, Tabelle 19) für $1 \mathrm{~h}$ inkubiert. Nach erneuter gründlicher Spülung mit DPBS erfolgte zur Darstellung intranukleärer DNA eine Inkubation mit DAPI (Tabelle 20) für 15 min. Abschließend wurden die Zellen gründlich mit DPBS gewaschen und mit FluorPreserve ${ }^{\mathrm{TM}}$ auf einem Objektträger fixiert. Die Analyse und Auswertung der Proteinexpression erfolgte mittels Fluoreszenzmikroskopie (Zeiss Axiovert 200M mit Zeiss Illuminator HXP 120C; Carl Zeiss, Oberkochen).

\subsection{Darstellung zelltypspezifischer Genexpression mittels RT-qPCR}

Mittels quantitativer Reverser Transkriptase Polymerase-Ketten-Reaktion (RT-qPCR) wurde die Expression zelltypspezifischer messenger Ribonukleinsäuren (mRNA) nachgewiesen. Die aus MSC und PCI-13 isolierte RNA wurde aufgereinigt und mit Hilfe einer reversen Transkription in komplementäre DNA (cDNA) umgeschrieben. Die Amplifikation des primerspezifischen Genabschnitts erfolgte im Verlauf der PCR nach Anlagerung (Annealing) sequenzspezifischer Primerpaare an die cDNA. Die spezifische Genexpression wurde quantitativ bestimmt und statistisch ausgewertet.

\subsubsection{Sequenzspezifisches Primerdesign}

Mit Hilfe der Internetplattform des National Center for Biotechnology Information (NCBI, Bethesda, USA, http:// http://www.ncbi.nlm.nih.gov; 27.08.2020) wurden die Sequenzen der zu untersuchenden Gene identifiziert. Die Primer wurden so gewählt, dass sie mindestens eine Intronsequenz voneinander getrennt waren, um kontaminierende 
Material und Methoden

genomische DNA von spezifischen Amplifikationen unterscheiden zu können. Die Primer wurden anschließend von Thermo Fisher Scientific (Waltham, USA) hergestellt. Eine detaillierte Beschreibung der verwendeten Primer und der primerspezifischen Reaktionsbedingungen findet sich in Tabelle 21.

Tabelle 21: Verwendete Primer für die RT-qPCR

\begin{tabular}{|c|c|c|c|}
\hline Gen & $\begin{array}{l}\text { Forward Primer 5'-3' } \\
\text { Reverse Primer 5'-3', }\end{array}$ & $\begin{array}{l}\text { Größe } \\
\text { (Basepairs, bp) }\end{array}$ & Accessionnumer \\
\hline GAPDH & $\begin{array}{l}\text { 5'- GAGTCAACGGATTTGGTCGT -3' } \\
\text { 5'- GACAAGCTTCCCGTTCTCAG -3' }\end{array}$ & $185 \mathrm{bp}$ & NM_002046.5 \\
\hline E-Cadherin & $\begin{array}{l}\text { 5'- CGGAGAAGAGGACCAGGACT -3' } \\
\text { 5'- GGTCAGTATCAGCCGCTTTC -3' }\end{array}$ & $185 \mathrm{bp}$ & NM_004360.4 \\
\hline Vimentin & $\begin{array}{l}\text { 5'- GGCTCGTCACCTTCGTGAAT -3' } \\
\text { 5'- GAGAAATCCTGCTCTCCTCGC -3' }\end{array}$ & $110 \mathrm{bp}$ & NM_003380.3 \\
\hline WNT3 & $\begin{array}{l}\text { 5'- GGCTGTGACTCGCATCATAA -3' } \\
\text { 5'- CAGCAGGTCTTCACCTCACA -3' }\end{array}$ & $245 \mathrm{bp}$ & NM_030753.4 \\
\hline$\beta$-Catenin & $\begin{array}{l}\text { 5'- GAAACGGCTTTCAGTTGAGC -3' } \\
\text { 5'- CTGGCCATATCCACCAGAGT -3' }\end{array}$ & $166 \mathrm{bp}$ & NM_001904.3 \\
\hline Snail1 & $\begin{array}{l}\text { 5'- CAGTGCCTCGACCACTATGC -3' } \\
\text { 5'- TGCTGGAAGGTAAACTCTGGATTA - } \\
\text { 3' }\end{array}$ & $114 \mathrm{bp}$ & NM_005985.3 \\
\hline Twist & $\begin{array}{l}\text { 5'- TTCTCGGTCTGGAGGATGGA -3' } \\
\text { 5'- CAATGACATCTAGGTCTCCGGC -3' }\end{array}$ & $102 \mathrm{bp}$ & NM_000474.3 \\
\hline MMP-14 & $\begin{array}{l}\text { 5'- GAGCTCAGGGCAGTGGATAG -3' } \\
\text { 5'- GGTAGCCCGGTTCTACCTTC -3' }\end{array}$ & $172 \mathrm{bp}$ & NM_004995.3 \\
\hline
\end{tabular}

\subsubsection{RNA-Isolation}

Tabelle 22: RNeasy ${ }^{\circledR}$ Mini Kit

\begin{tabular}{|l|l|}
\hline Puffer RLT & Qiagen, Venlo, Netherlands \\
\hline Puffer RW1 & Qiagen, Venlo, Netherlands \\
\hline Puffer RPE & Qiagen, Venlo, Netherlands \\
\hline
\end{tabular}

Tabelle 23: RNase-Free DNase Set

\begin{tabular}{|l|l|}
\hline DNAse-I-Lyophilisat (in 1,5 ml RNase \& DNase freiem H2O) & Qiagen, Venlo, Netherlands \\
\hline Puffer RDD & Qiagen, Venlo, Netherlands \\
\hline \multicolumn{2}{|l}{ Das DNAse-I-Lyophilisat wurde mit 1,5 ml RNase- und DNase-freiem $\mathrm{H}_{2} \mathrm{O}$ (B. Braun, Melsungen) versetzt. } \\
\hline
\end{tabular}

Die Isolation zelltypspezifischer RNA erfolgte mit dem RNeasy ${ }^{\circledR}$ Mini Kit (Tabelle 22) und dem RNase-Free DNase Set (Tabelle 23) entsprechend den Herstellerempfehlungen. Die für die RNA-Isolation differenzierten Zellen wurden zweimal mit DPBS gewaschen, mit $350 \mu 1$ RLT-Puffer und 2-Mercaptoethanol (Sigma-Aldrich, St. Louis, USA; Verhältnis 100:1) lysiert und die zellulären RNasen so denaturiert. Anschließend wurde das Lysat unter Verwendung steriler, RNase-freier Pipettierhilfen in ein Eppendorfgefäß überführt und entweder bei $-80^{\circ} \mathrm{C}$ eingefroren oder direkt der RNA-Isolation zugeführt. Zur Aufbereitung wurde das Lysat mit $350 \mu 170$ \%igem Ethanol (Merck, Darmstadt) versetzt, durchmischt 
Material und Methoden

und unmittelbar auf die RNeasy ${ }^{\circledR}$ Mini-Säule gegeben. Über die Membran der RNeasy ${ }^{\circledR}$ Mini-Säule erfolgte die Aufreinigung der RNA-Probe. Verunreinigungen durch an die Membran gebundene DNA wurden durch Inkubation mit RNase-freier DNase für 15 min entfernt. Die Zugabe von $350 \mu$ l RW1-Puffer beendete den DNase-Verdau. Waschschritte mit $700 \mu \mathrm{l}$ RW1-Puffer und $500 \mu \mathrm{l}$ RPE-Puffer führten zur Aufreinigung der an der Membran gebundenen RNA. Diese wurde abschließend durch Zugabe von $40 \mu \mathrm{l}$ RNase-freiem $\mathrm{H}_{2} \mathrm{O}$ in ein RNase-freies Eppendorfgefäß eluiert. Die Gesamtkonzentration und Reinheit der RNA wurde spektralphotometrisch bei $260 \mathrm{~nm}$ und $280 \mathrm{~nm}$ ermittelt (NanoDrop 1000, Thermo Fisher Scientific, Waltham, USA).

\subsection{3 cDNA-Synthese mittels reverser-Transkriptase-Lösungen}

Tabelle 24: iScript ${ }^{\mathrm{TM}}$ cDNA Synthese Kit

\begin{tabular}{|l|l|}
\hline $5 \mathrm{X}$ iScript reaction mix & Bio-Rad Laboratories, Hercules, USA \\
\hline iScript reverse transcriptase & Bio-Rad Laboratories, Hercules, USA \\
\hline
\end{tabular}

Die cDNA Synthese mittels reverser-Transkriptase-Reaktion erfolgte mit dem

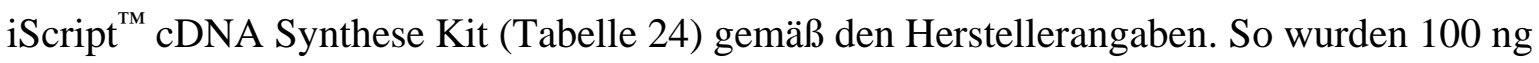
der isolierten RNA mit $4 \mu 1$ XX iScript reaction mix, $1 \mu 1$ iScript reverse transcriptase und RNase- und DNase-freiem $\mathrm{H}_{2} \mathrm{O}$ auf ein Endvolumen von $20 \mu \mathrm{l}$ eingestellt. Die Inkubation erfolgte in einem Thermocycler (Eppendorf, Hamburg). Die entstandene cDNA wurde bei $-20^{\circ} \mathrm{C}$ eingefroren oder direkt in einer Qualitativen reverse Transkriptase PolymeraseKetten-Reaktion (qRT-PCR) vervielfältigt.

\subsection{4 qRT-PCR}

Durch die Wiederholung von DNA-Denaturierung, Anlagerung von sequenzspezifischen Primern an die DNA (Annealing) und komplementärer Strangsynthese durch eine thermostabile DNA-Polymerase (Extension) erfolgt durch die PCR eine exponentielle Vervielfältigung eines durch den sequenzspezifischen Primer eingegrenzten Genabschnitts.

Tabelle 25: qRT-PCR Reagenz

\begin{tabular}{|l|l|l|}
\hline & 2X SensiFAST ${ }^{\mathrm{TM}} \mathrm{SYBR}^{\circledR} \&$ Fluorescein mix & Bioline, London, UK \\
\hline $10 \mu \mathrm{M}$ & Primer forward & Siehe Tabelle 21 \\
\hline $10 \mu \mathrm{M}$ & Primer reverse & Siehe Tabelle 21 \\
\hline
\end{tabular}

Die Durchführung der qRT-PCR erfolgte gemäß den Herstellerangaben (Tabelle 25). Dabei wurden die Proben auf Eis in 96-Well-Probenplatten (Bio-Rad Laboratories, Hercules, USA) verarbeitet. Für jeden Ansatz wurden $2 \mu 1$ cDNA durch $10 \mu 12$ X Sensifast 
Material und Methoden

SYBR Green, 0,8 $\mu 1$ forward Primer, 0,8 $\mu 1$ reverse Primer und 6,4 $\mu 1$ RNase-, DNase-freies $\mathrm{H}_{2} \mathrm{O}$ vervollständigt. Die cDNA-Proben wurden jeweils als Triplikate eingesetzt. Als Referenzgen diente Glycerinaldehyd-3-Phosphat-Dehydrogenase (GAPDH). Die Proben wurden in den PCR-Thermocycler überführt und für 2 min bei $95^{\circ} \mathrm{C}$ zur PolymeraseAktivierung erhitzt. Anschließend durchliefen die Proben 45 Zyklen, in denen die nachfolgend genannten Schritte wiederholt wurden:

- 10 s Denaturierung der Proben bei $95^{\circ} \mathrm{C}$

- 30 s Annealing der Primer und Extension des komplementären DNA-Strangs bei $60^{\circ} \mathrm{C}$

- Fluoreszenzmessung

Nach Abkühlung auf $4^{\circ} \mathrm{C}$ wurden die Proben bei $-20^{\circ} \mathrm{C}$ gelagert.

\subsection{Darstellung zelltypspezifischer Proteinexpression mittels Antibody Array}

\subsubsection{Protein-Isolation und Aufreinigung}

Tabelle 26: Bio-Plex ${ }^{\mathrm{TM}}$ Cell Lysis-Kit

\begin{tabular}{|l|l|}
\hline Bio-Plex $^{\mathrm{TM}}$ Cell Wash Buffer & Bio-Rad Laboratories, Hercules, USA \\
\hline Bio-Plex $^{\mathrm{TM}}$ Cell Lysis Buffer & Bio-Rad Laboratories, Hercules, USA \\
\hline Bio-Plex $^{\mathrm{TM}}$ Cell Lysis Buffer, Factor 1 (250x) & Bio-Rad Laboratories, Hercules, USA \\
\hline Bio-Plex $^{\mathrm{TM}}$ Cell Lysis Buffer, Factor 2 & Bio-Rad Laboratories, Hercules, USA \\
\hline
\end{tabular}

Die Isolation zelltypspezifischer Proteine erfolgte mit dem Bio-Plex ${ }^{\mathrm{TM}}$ Cell Lysis Kit (Tabelle 26) entsprechend den Herstellerempfehlungen. Die für die Isolation differenzierten Zellen wurden mit DPBS und Bio-Plex ${ }^{\mathrm{TM}}$ Cell Wash Buffer gewaschen. Anschließend erfolgte die Lysierung mit $200 \mu \mathrm{l}$ einer Zell-Lysis-Lösung $\left(5 \mathrm{ml}\right.$ Bio-Plex Cell ${ }^{\mathrm{TM}}$ Lysis Buffer, $20 \mu$ Bio-Plex ${ }^{\mathrm{TM}}$ Cell Lysis Buffer Factor 1, $10 \mu 1$ Bio-Plex ${ }^{\mathrm{TM}}$ Cell Lysis Buffer Factor 2, $20 \mu$ Phenylmethylsulfonylfluorid (Sigma-Aldrich, St. Louis, USA; PMSF)) für 20 min bei $4^{\circ} \mathrm{C}$ auf einem Orbital-Shaker (BMG Labtech, Offenburg). Danach konnte das Lysat eines Wells mittels Eppendorf-Pipette in ein Eppendorf-Cup überführt werden, um dann bei $4.500 \mathrm{x} \mathrm{g}$ bei $4^{\circ} \mathrm{C}$ zentrifugiert zu werden. Bis zur weiteren Verwendung wurden die Proben bei $-80^{\circ} \mathrm{C}$ eingelagert.

\subsubsection{Quantifizierung des Proteingehalts mittels Bicinchoninic Acid Assay (BCA)}

Tabelle 27: Pierce ${ }^{\mathrm{TM}}$ BCA Protein Assay Kit

\begin{tabular}{|l|l|}
\hline BCA Reagent A & Thermo Fischer Scientific, Waltham, USA \\
\hline BCA Reagent B & Thermo Fischer Scientific, Waltham, USA \\
\hline Albumin Standard Ampullen $(2 \mathrm{mg} / \mathrm{ml})$ & Thermo Fischer Scientific, Waltham, USA \\
\hline
\end{tabular}


Material und Methoden

Zur kalorimetrischen Detektion und Quantifizierung des Gesamt-Proteingehalts wurde das Pierce ${ }^{\mathrm{TM}}$ BCA Protein Assay Kit (Tabelle 27) verwendet. $25 \mu 1$ des Lysats und des Standards wurden in eine 96-Well-Multiwell-Platte (Greiner Bio-One, Frickenhausen) pipettiert, $200 \mu \mathrm{l}$ BCA Working Reagent (Verhältnis Reagent A zu Reagent B 50:1) hinzugegeben und auf einem Orbital Shaker (ThermoStar, BMG Labtech, Offenburg) für 30 $\mathrm{s}$ bei Raumtemperatur vermischt. Anschließend wurde bei $37^{\circ} \mathrm{C}$ für $30 \mathrm{~min}$ inkubiert. Nachdem die Platte wieder auf Raumtemperatur abgekühlt war, erfolgte die kalorimetrische Detektion und Quantifizierung des Gesamt-Proteingehalts bei einer Wellenlänge von 562 nm im Photometer (SpectraMax M2 Multi-Mode Microplate Reader, Sunnyvale, USA).

\subsubsection{Untersuchung des AKT-Signalwegs mittels PathScan ${ }^{\circledR}$}

Tabelle 28: PathScan® AKT Signaling Antibody Array Kit

\begin{tabular}{|l|l|}
\hline 20X Array Wash Buffer (AWB) & Cell Signaling Technology, Danvers, USA \\
\hline Array Blocking Buffer (ABB) & Cell Signaling Technology, Danvers, USA \\
\hline Array Diluent Buffer (ADB) & Cell Signaling Technology, Danvers, USA \\
\hline 10X Detection Antibody Cocktail (DAC) & Cell Signaling Technology, Danvers, USA \\
\hline 10X HRP-linked Streptavidin & Cell Signaling Technology, Danvers, USA \\
\hline 20X LumiGLO ${ }^{\circledR}$ Reagent A & Cell Signaling Technology, Danvers, USA \\
\hline 20X Peroxid Reagent B & Cell Signaling Technology, Danvers, USA \\
\hline
\end{tabular}

Die Darstellung zelltypspezifischer Proteinexpression innerhalb des AKT-Signalweges wurde mittels PathScan ${ }^{\circledR}$ AKT Signaling Antibody Array Kit (Tabelle 28) gemäß den Herstellerangaben durchgeführt. Hierfür wurde die Multi-Well-Abdichtung (Cell Signaling Technology, Cambridge, UK) so auf der Glasplatte (Cell Signaling Technology, Cambridge, UK) fixiert, dass die Nitro-Cellulose Felder in das Innere der Wells zeigten. Jedes Well wurde dann mit $100 \mu \mathrm{ABB}$ für 15 min bei Raumtemperatur auf einem Orbitalshaker (THERMOstar ${ }^{\circledR}$; BMG Labtech, Offenburg) inkubiert. Nachdem der Puffer vorsichtig ausgeklopft worden war, wurden $75 \mu$ des gewonnenen Lysats (2.12.1) in je ein Well gegeben und bei Raumtemperatur für $2 \mathrm{~h}$ auf einem Orbitalshaker inkubiert. Der WellInhalt wurde verworfen und es erfolgte eine gründliche Waschung mit $1 \mathrm{X}$ AWB $(150 \mu 1$ 10X $A W B$ verdünnt in $1350 \mu \mathrm{l} A D B)$. Anschließend wurden $75 \mu \mathrm{l} 1 \mathrm{X} D A C$ (150 $\mu \mathrm{l} 10 \mathrm{X} D A C$ verdünnt in $1350 \mu \mathrm{l} A D B$ ) in jedes Well gegeben und für $1 \mathrm{~h}$ bei Raumtemperatur inkubiert. Es erfolgte eine erneute gründliche Waschung mit $A W B$. Nachdem der Well-Inhalt verworfen wurde, wurden $75 \mu \mathrm{l}$ 1X HRP-linked Streptavidin (150 $\mu 1$ 10X HRP-linked Streptavidin verdünnt in $1350 \mu \mathrm{l} A D B$ ) in die Wells pipettiert und für $30 \mathrm{~min}$ bei Raumtemperatur inkubiert. Anschließend wurde erneut mit $A W B$ gründlich gewaschen. Die Multi-Well-Abdeckung wurde entfernt und die Glasplatte in einem Bad aus $A W B$ gespült. Anschließend wurden 0,5 $\mathrm{ml}$ 20X LumiGLO ${ }^{\circledR}$ und 0,5 $\mathrm{ml}$ 20X Peroxid in $9 \mathrm{ml}$ deionisiertem 
Wasser gelöst und die Glasplatte damit überdeckt. Die Glasplatte wurde unmittelbar danach in einer Kunststoff-Folie fixiert und der Chemiluminiscence-Auswertung überführt (LAS 4000, Fujifilm, Tokio, Japan).

\subsection{Statistische Auswertung}

Es wurden insgesamt drei Versuche $(n=3)$ bei jeweils dreifacher Messwiederholung durchgeführt. Die erhobenen Zellzählungs-Triplikate für jeden Beobachtungstag wurden sowohl für MSC als auch für PCI-13 gemittelt. Die statistischen Analysen wurden mit Hilfe der Software GraphPad Prism (GraphPad Software, La Jolla, USA) durchgeführt und visualisiert. Die Expressionverhältnisse der qRT-PCR wurden über das $\Delta \Delta \mathrm{Ct}$ des mathematischen Modells zur relativen Quantifizierung bestimmt (Livak und Schmittgen 2001). Unterschiede in der Genexpression wurden durch einen Kruskal-Wallis-Test bestimmt und multiple Vergleiche durch einen Dunn's Vergleichstest mit einem Alpha von 0,05 durchgeführt. Unterschiede in der relativen Proteinexpression der IF wurden mittels two-way Anova bestimmt. Die relative Proteinexpression der Antibody-Arrays wurde nach dem Student's-t-Test berechnet. 
Ergebnisse

\section{Ergebnisse}

\subsection{Charakterisierung humaner MSC mittels Durchflusszytometrie}

Die durchgeführte Charakterisierung der gewonnenen humanen MSC mittels FACS ergab nach Auswertung gemittelt in mehr als $90 \%$ eine homogene Positivität für die mesenchymalen Antigene CD73, CD90 und CD105. Als Kontrollantigene der hämatogenen Reihe ergab die Auswertung in mehr als $95 \%$ eine homogene Negativität für die Antigene CD34 und CD45 (Abbildung 6).

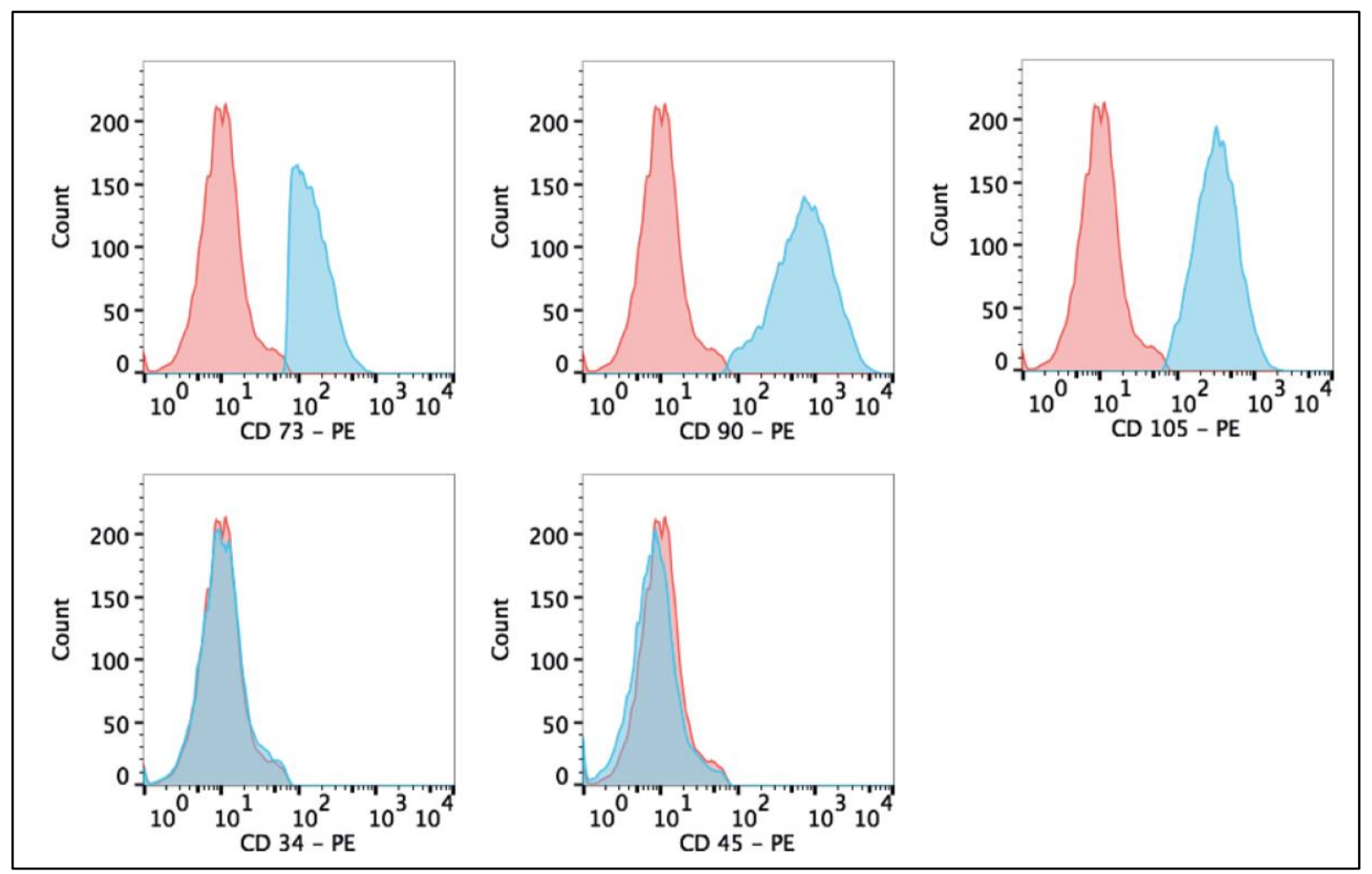

Abbildung 6: Eine repräsentative, durchflusszytometrische Analyse isolierter humaner MSC. Die Isotyp-Kontrollfärbung humaner Antikörper ist in hellrot, die spezifischen Marker sind in hellblau dargestellt.

\subsection{Osteogene, adipogene und chondrogene Differenzierung humaner MSC}

Die klassische osteogene, adipogene und chondrogene Differenzierung humaner MSC erfolgte im Monolayer- (2.5.1) bzw. MMB-System (2.5.2). Die Applikation des Mediums zur osteogenen Induktion führte in allen im klassischen Monolayer differenzierten MSC nach 25 Tagen zu einer positiven Alkalische-Phosphatase-Färbung (Abbildung 7A). Nach Applikation des Mediums zur adipogenen Induktion und des Mediums zum Erhalt der 
Ergebnisse

adipogenen Induktion zeigten alle im klassischen Monolayer differenzierten MSC nach 25 Tagen eine positive Färbung für Sudan-III (Abbildung 7B). Nach Applikation des Mediums zur chondrogenen Induktion zeigten alle im klassischen MMB- System differenzierten MSC nach 25 Tagen eine positive Färbung für AB (Abbildung 7C).

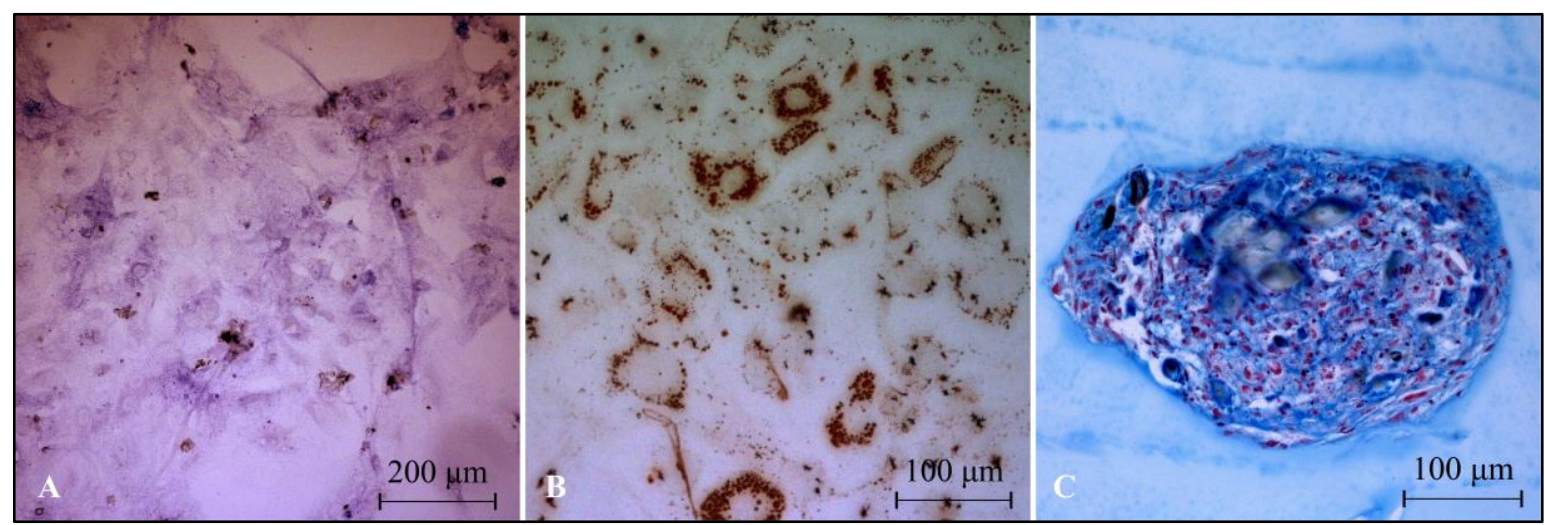

Abbildung 7: Osteogene, adipogene und chondrogene Differenzierung humaner MSC. (A) AP-Färbung. (B) Sudan-III-Färbung. (C) AB-Färbung.

\subsection{Proliferationscharakteristika von MSC und PCI-13}

MSC und PCI-13 demonstrierten stabile Proliferations- und Verdopplungseigenschaften in vitro. Ko-Kultivierung oder TGF- $\beta_{1}$-Induktion führte bei den MSC zu keiner signifikanten Veränderung der Proliferationseigenschaften. Hingegen zeigten die PCI-13 Ko-Kulturen eine signifikante Reduktion der Proliferation $(\mathrm{p}=0.0001)$, die jedoch unter TGF- $\beta_{1}$ Einfluss aufgehoben wurde.

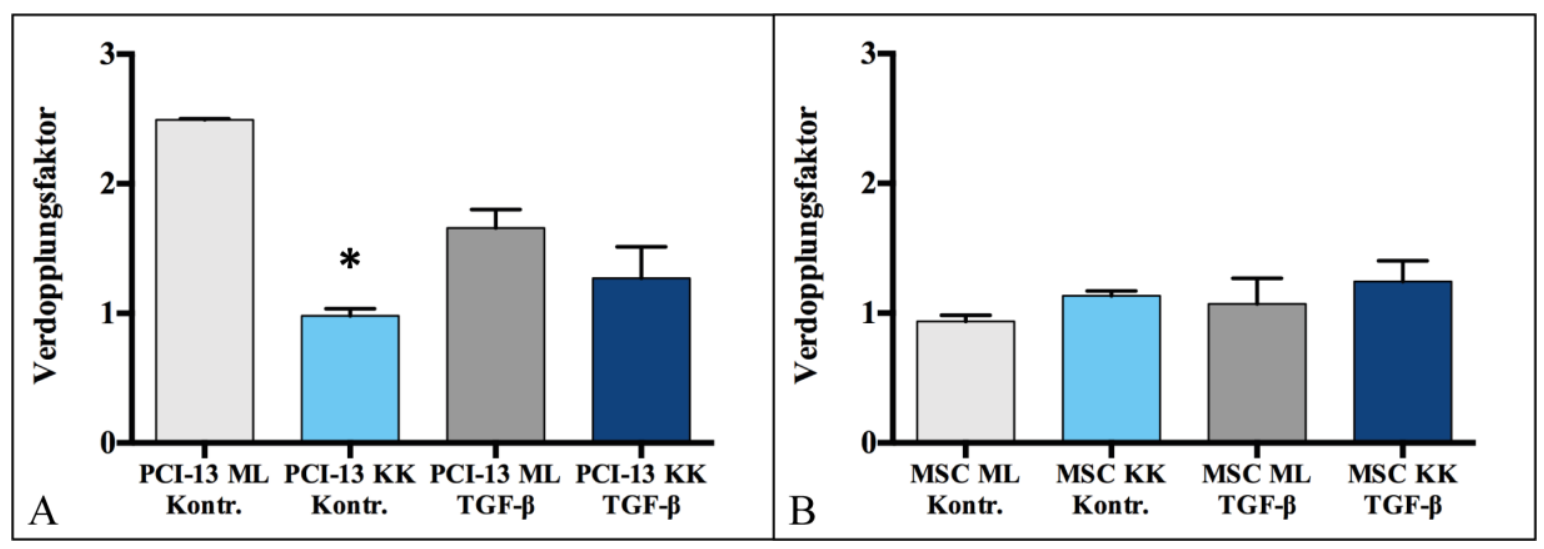

Abbildung 8: Täglicher Verdopplungsfaktor der PCI-13 und MSC. (A) Im Monolayer (ML) sowie in Ko-Kultur (KK) kultivierte PCI-13 und (B) im Monolayer sowie in Ko-Kultur kultivierte MSC $(*=p \leq 0.0001)$. 
Ergebnisse

\subsection{Monolayer-Differenzierung humaner MSC und PCI-13-Zellen unter dem Einfluss von TGF- $\beta_{1}$}

\subsubsection{IF-Proteinexpression von Vimentin und E-Cadherin in im Monolayer kultivierten $\underline{\text { PCI-13 und MSC }}$}

In den PCI-13 Monolayer-Kulturen wurde über den gesamten Zeitraum der sechstägigen Differenzierung eine kontinuierliche Expression von Vimentin in allen Kulturen festgestellt. Die durchgeführte Quantifizierung ergab keine signifikanten Unterschiede zwischen den mit TGF- $\beta_{1}$ induzierten PCI-13 und der Kontrollgruppe (Abbildung 9A). Eine kontinuierliche Expression des Transmembran-Proteins E-Cadherin konnte ebenfalls über den gesamten Zeitraum der sechstägigen Differenzierung gezeigt werden. (Abbildung 9B).

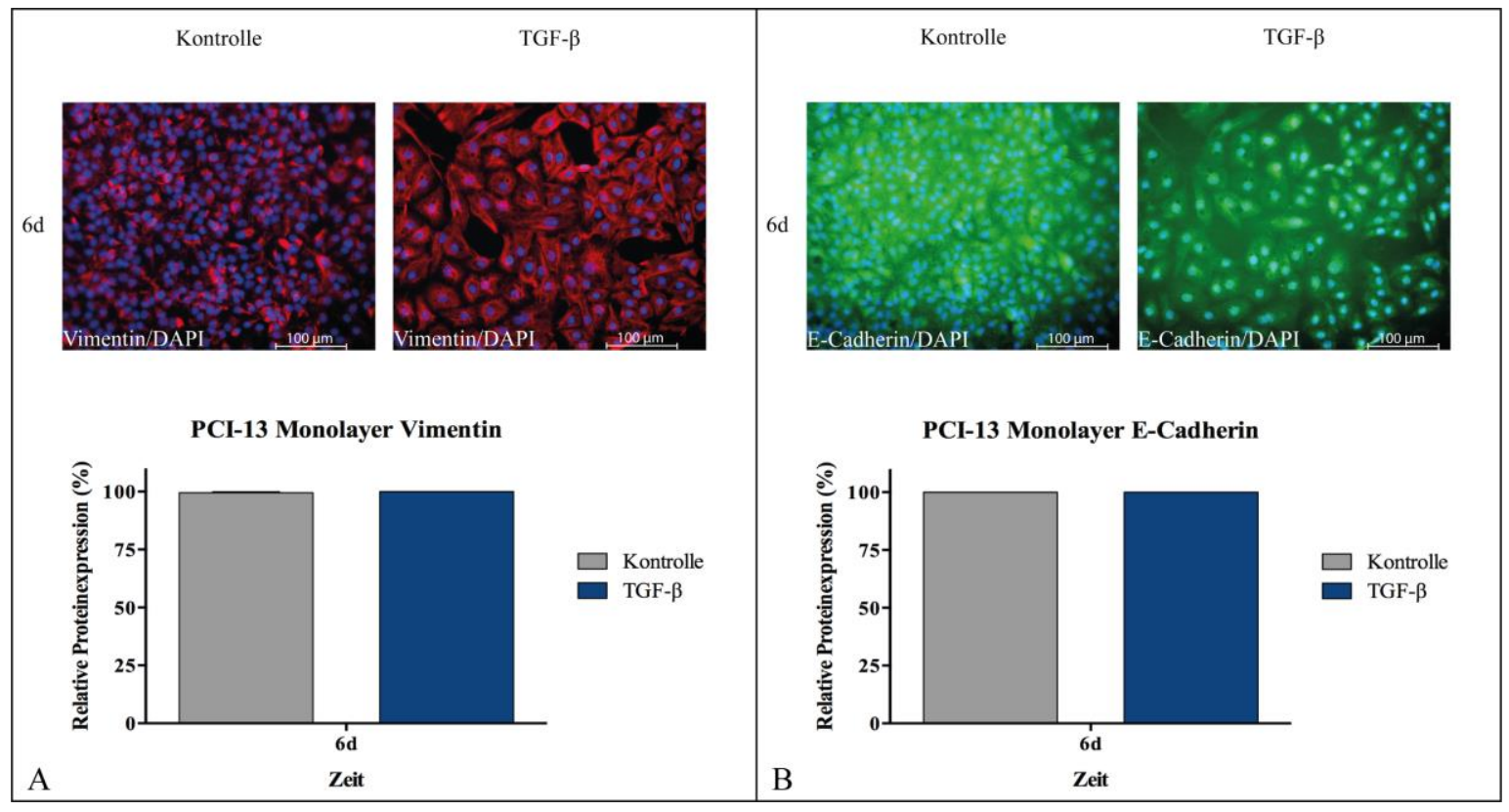

Abbildung 9: IF-Proteinexpression der PCI-13 Monolayer-Kulturen. Vimentin (A) ist mit Alexa Fluor 594 (rot), E-Cadherin (B) ist mit FITC (grün) und die Zellkerne sind mit DAPI (blau) dargestellt. Relative Proteinexpression in \% (Bohrnsen et al. 2017). Die Verwendung erfolgt mit freundlicher Genehmigung des Elsevier-Verlags. 
Ergebnisse

In den MSC Monolayer-Kulturen wurde über den gesamten Zeitraum der sechstägigen Differenzierung eine kontinuierliche Vimentin-Expression in allen Kulturen festgestellt. Die durchgeführte Quantifizierung ergab keine signifikanten Unterschiede zwischen der mit TGF- $\beta_{1}$ induzierten Gruppe und der Kontrollgruppe (Abbildung 10A). Auch in den MSC Monolayer-Kulturen konnte eine kontinuierliche E-Cadherin-Expression über den gesamten Zeitraum der sechstägigen Differenzierung gezeigt werden (Abbildung 10B).

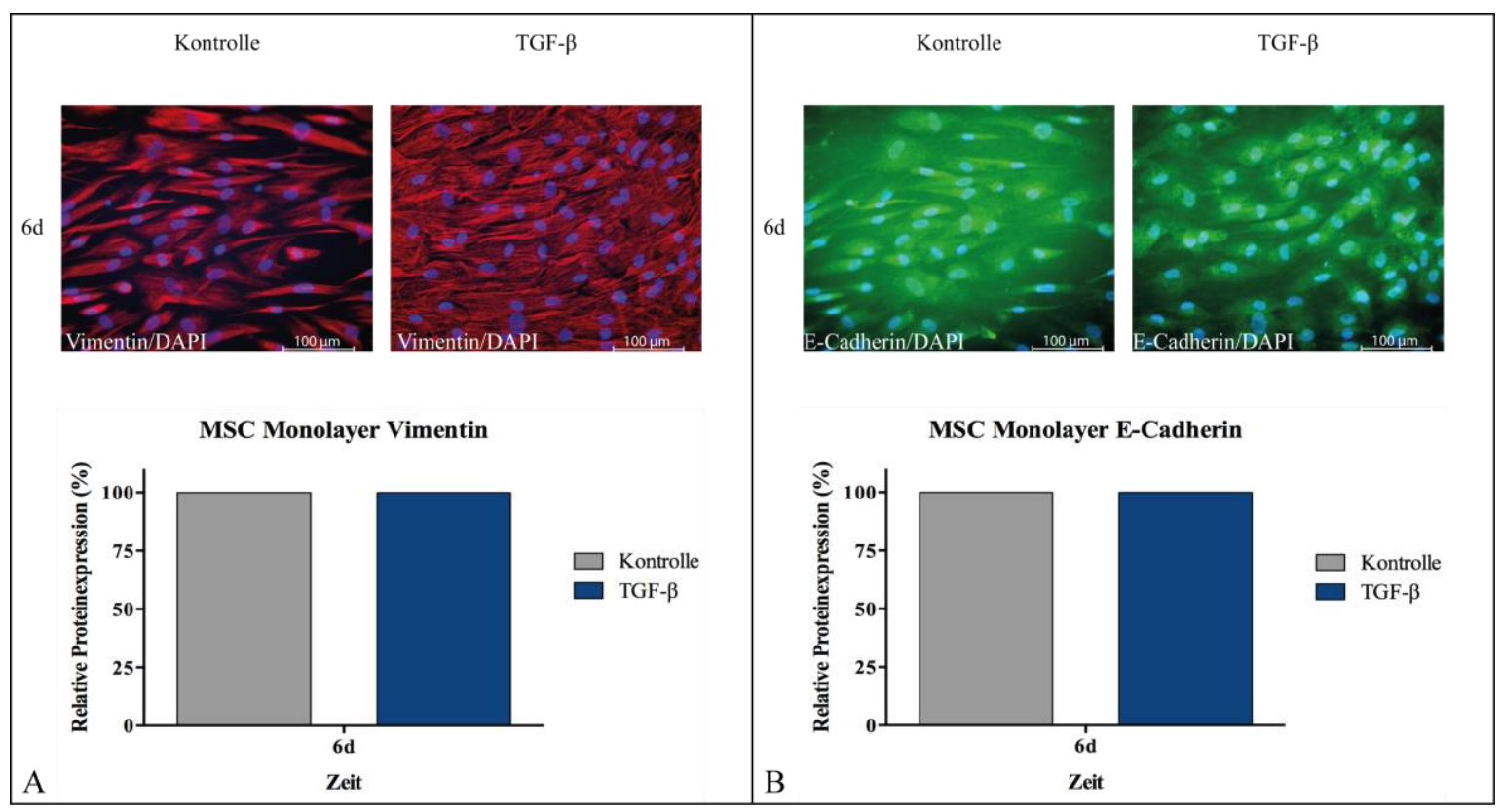

Abbildung 10: IF-Proteinexpression der im Monolayer kultivierten MSC. Vimentin (A) ist mit Alexa Fluor 594 (rot), E-Cadherin (B) ist mit FITC (grün) und die Zellkerne sind mit DAPI (blau) dargestellt. Relative Proteinexpression in \% (Bohrnsen et al. 2017). Die Verwendung erfolgt mit freundlicher Genehmigung des Elsevier-Verlags. 
Ergebnisse

\subsubsection{Genexpression von Mediatoren der Tumor-Stroma-Interaktion in im Monolayer kultivierten PCI-13 und MSC}

In den PCI-13 Monolayer-Kulturen zeigte sich nach sechstägiger Differenzierung mit TGF- $\beta_{1}$ die Expression von MMP-14 signifikant erhöht $(\mathrm{p}=0.01)$. Weitere Analysen innerhalb der PCI-13 Monolayer-Kulturen ergaben jedoch keine signifikanten Unterschiede in der Expression von E-Cadherin, Vimentin, Wnt-3, $\beta$-Catenin, Snail1 und Twist (Abbildung 11).

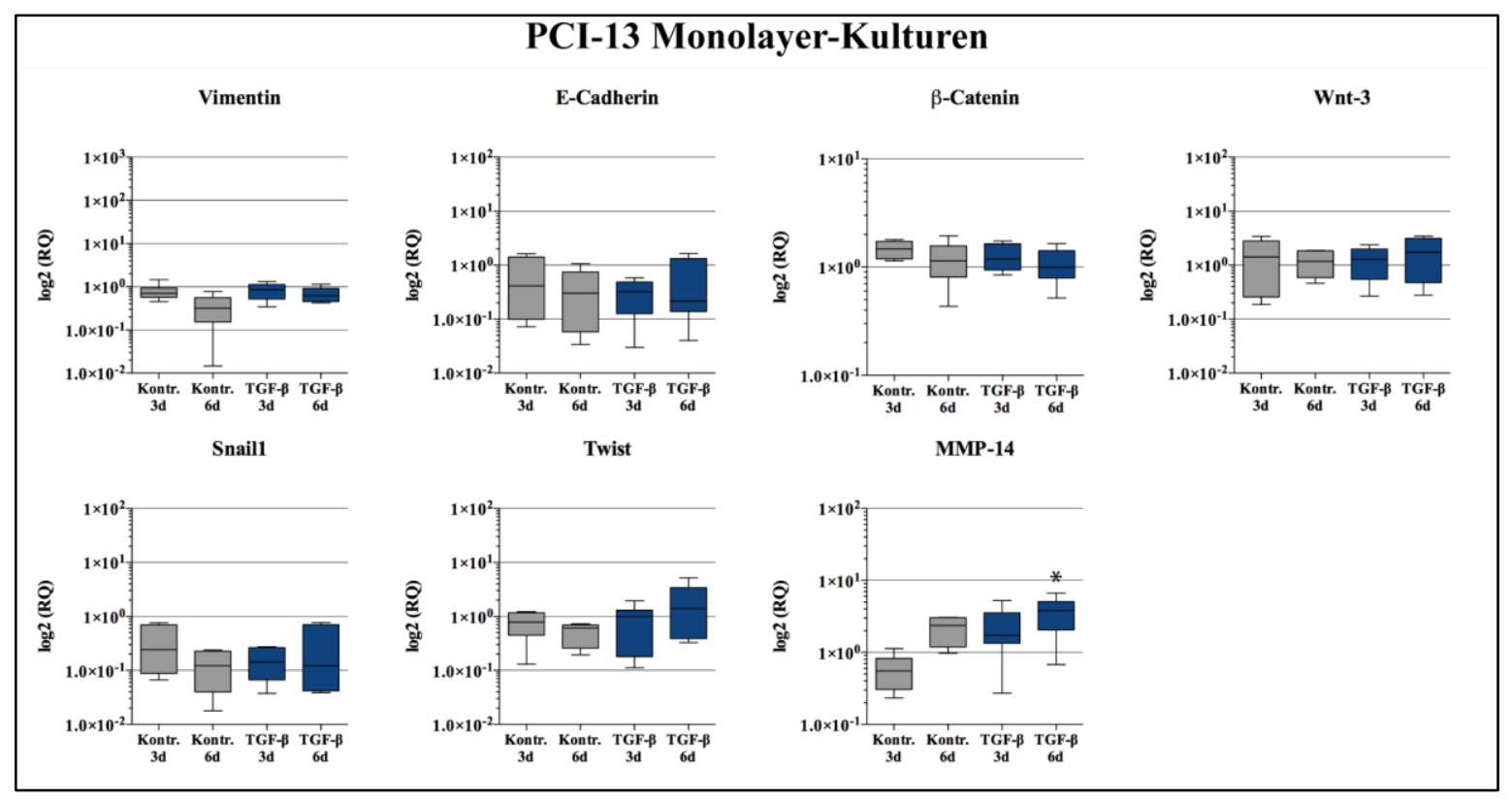

Abbildung 11: qRT-PCR Analyse der im Monolayer kultivierten PCI-13 ( $*=p \leq 0.01$ ) (Bohrnsen et al. 2017). Die Verwendung erfolgt mit freundlicher Genehmigung des Elsevier-Verlags. 
Ergebnisse

In den MSC Monolayer-Kulturen zeigte sich eine signifikante Reduzierung der Vimentin-Expression in den mit TGF- $\beta_{1}$ kultivierten Monolayer-Kulturen $(\mathrm{p}=0.04)$. Darüber hinaus war die Snail1-Expression in den mit TGF- $\beta_{1}$ kultivierten Kulturen signifikant erhöht $(\mathrm{p}=0.007)$. In der Expression von E-Cadherin, Wnt-3, $\beta$-Catenin, Snail1, Twist und MMP-14 konnten keine signifikanten Unterschiede beobachtet werden (Abbildung 12).

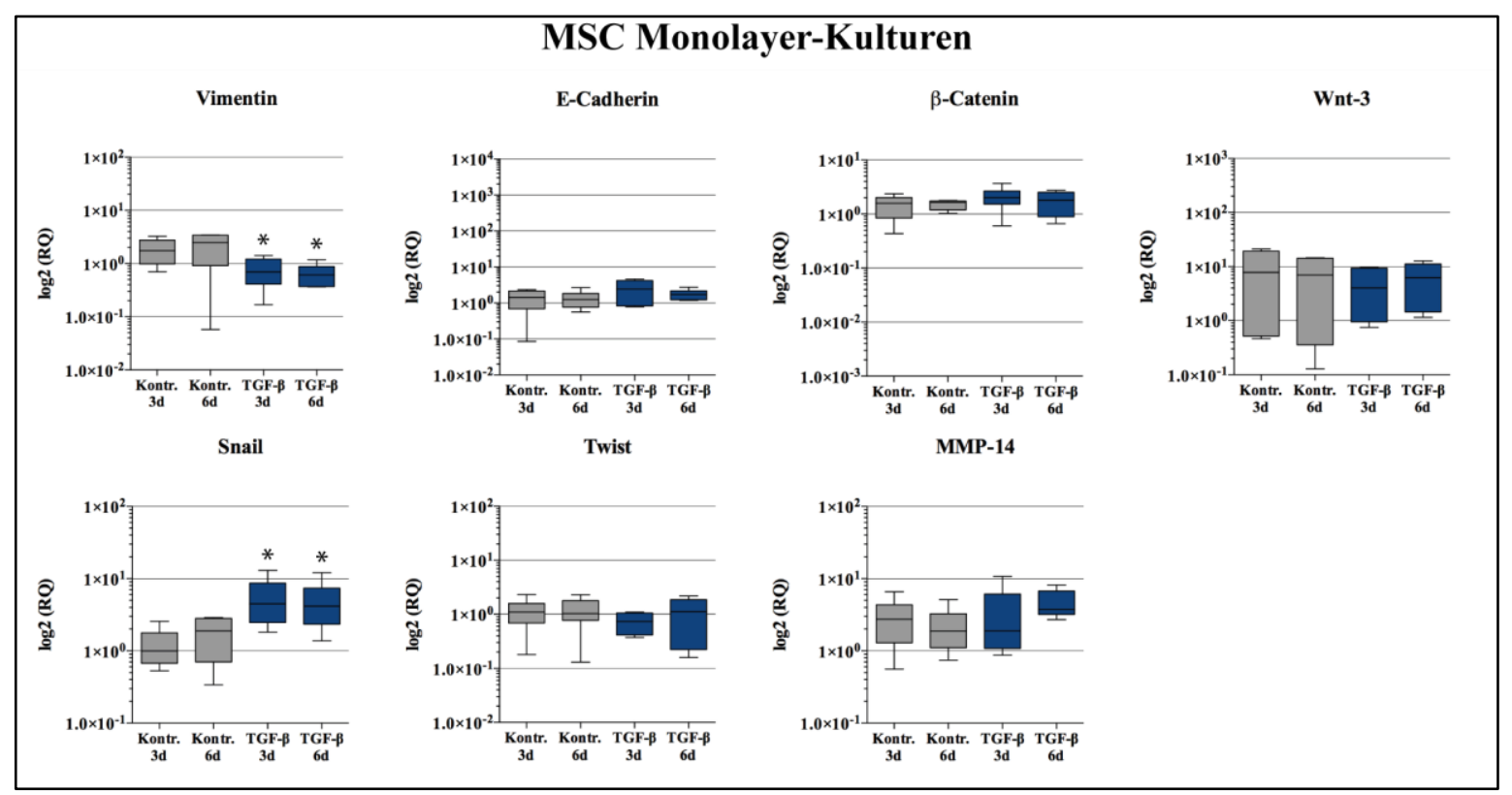

Abbildung 12: qRT-PCR Analyse der im Monolayer kultivierten MSC ( $*=p \leq 0.04$ ) (Bohrnsen et al. 2017). Die Verwendung erfolgt mit freundlicher Genehmigung des Elsevier-Verlags.. 
Ergebnisse

3.4.3 Proteinanalyse des AKT-Signalwegs, der Apoptose und des Erk-Signalwegs in im Monolayer kultivierten PCI-13 und MSC

In den PCI-13 Monolayer-Kulturen konnten durch die Proteinanalysen am Ende der Beobachtungszeit signifikante Unterschiede in der phosphorylierten Proteinaktivität festgestellt werden. So war die Expression von AKT $(\mathrm{p}=0.006)$, S6 $(\mathrm{p}=0.02)$, $\operatorname{AMPK} \alpha(\mathrm{p}=0.01), \operatorname{PRAS} 40(\mathrm{p}=0.02), \mathrm{p} 70$ S6 $(\mathrm{p}=0.049), \operatorname{Bad}(\mathrm{p}=0.04)$ und Erk1/2 ( $\mathrm{p}=0.006)$ in den mit TGF- $\beta_{1}$ induzierten Tumorzellen signifikant geringer als in der entsprechenden nicht-induzierten Kontrollgruppe (Abbildung 13).

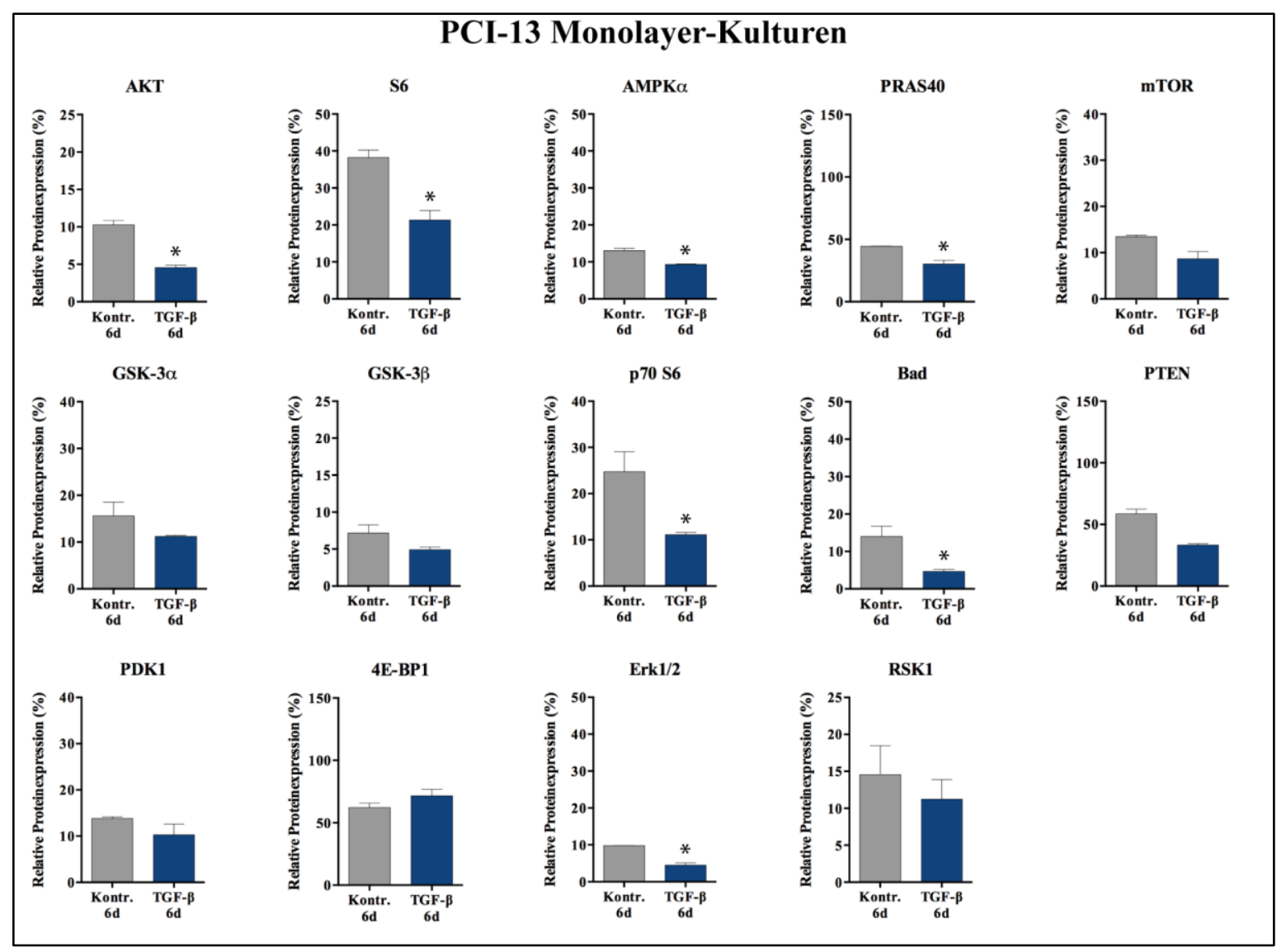

Abbildung 13: Die Proteinlevelanalysen mittels Pathscan der im Monolayer kultivierten PCI-13 $(*=p \leq 0.049)$ (Bohrnsen et al. 2017). Die Verwendung erfolgt mit freundlicher Genehmigung des ElsevierVerlags. 
Ergebnisse

In den MSC Monolayer-Kulturen konnten durch die Proteinanalysen ebenfalls am

Ende der Beobachtungszeit signifikante Unterschiede in der phosphorylierten Proteinaktivität festgestellt werden. So waren S6 $(p=0.01)$, mTOR $(p=0.02)$ und GSK-3 $\beta$ $(\mathrm{p}=0.002)$ in den mit TGF- $\beta_{1}$ induzierten Kulturen signifikant erhöht. Darüber hinaus konnte in den mit TGF- $\beta_{1}$ induzierten Kulturen eine signifikante Reduzierung der 4E-BP1 Expression gezeigt werden ( $\mathrm{p}=0.01$; Abbildung 14).

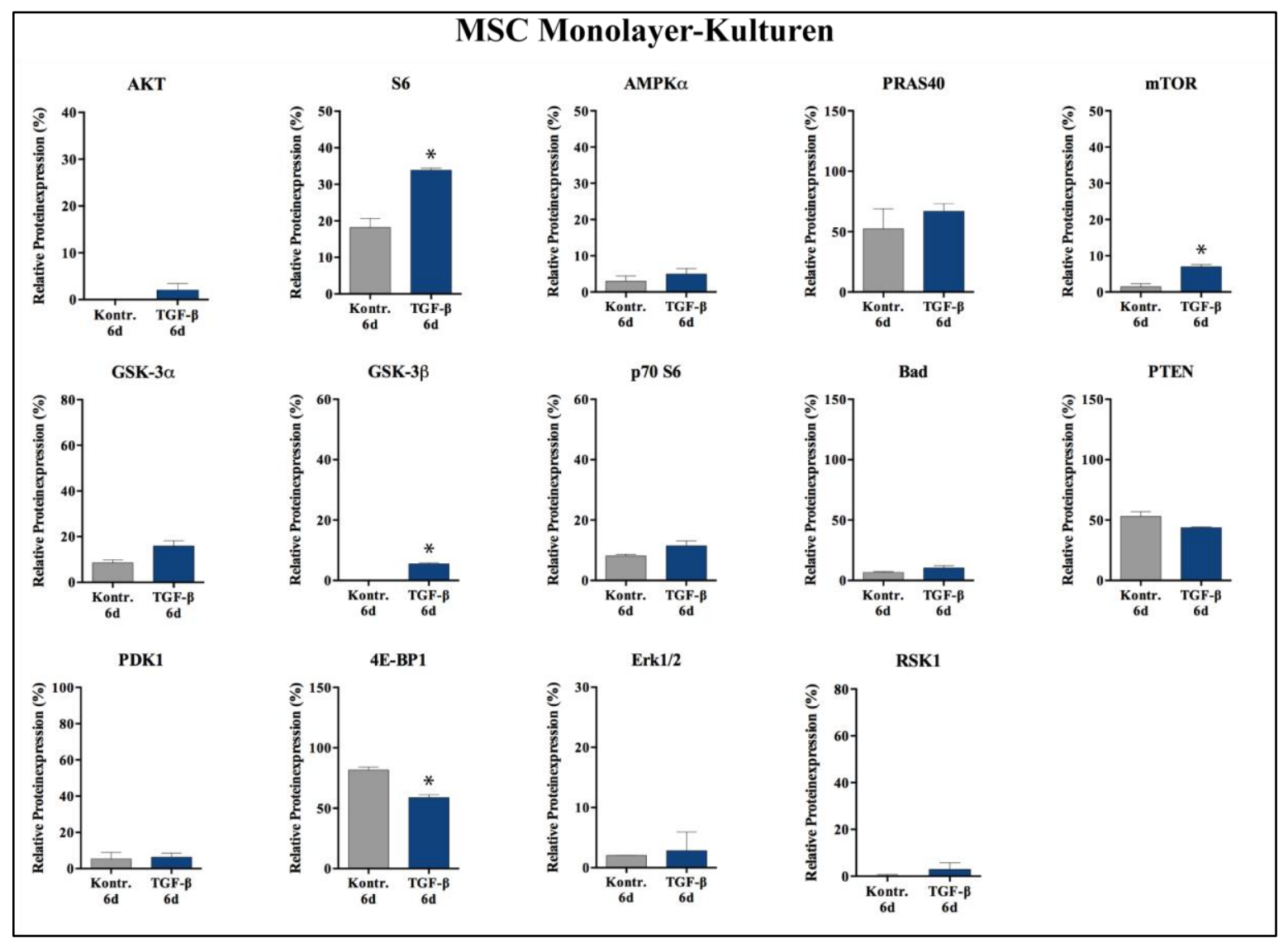

Abbildung 14: Die Proteinlevelanalysen mittels Pathscan der im Monolayer kultivierten MSC $(*=p \leq 0.02)$ (Bohrnsen et al. 2017). Die Verwendung erfolgt mit freundlicher Genehmigung des Elsevier-Verlags. 
Ergebnisse

\subsection{Ko-Kultur-Differenzierung humaner MSC und PCI-13-Zellen unter Einfluss von TGF- $\beta_{1}$}

\subsubsection{IF-Proteinexpression von Vimentin und E-Cadherin in ko-kultivierten PCI-13 und $\underline{\mathrm{MSC}}$}

In den PCI-13 Ko-Kulturen wurde über den gesamten Zeitraum der sechstägigen Differenzierung eine kontinuierliche Expression von Vimentin in allen Kulturen festgestellt, dessen Expressionsniveau jedoch im Vergleich zu den Monolayer-Kulturen signifikant geringer war $(p=0.02)$. Eine Induktion der Ko-Kultur mit TGF- $\beta$ führte zu einer signifikant erhöhten Vimentin-Expression ( $\mathrm{p}=0.0001$; Abbildung 15A). In den ko-kultivierten PCI-13 konnte darüber hinaus eine kontinuierliche E-Cadherin-Expression über den gesamten Zeitraum der sechstägigen Differenzierung gezeigt werden. Hier zeigte die durchgeführte Quantifizierung keine signifikanten Unterschiede zwischen den Vergleichs- und Kontrollgruppen (Abbildung 15B).

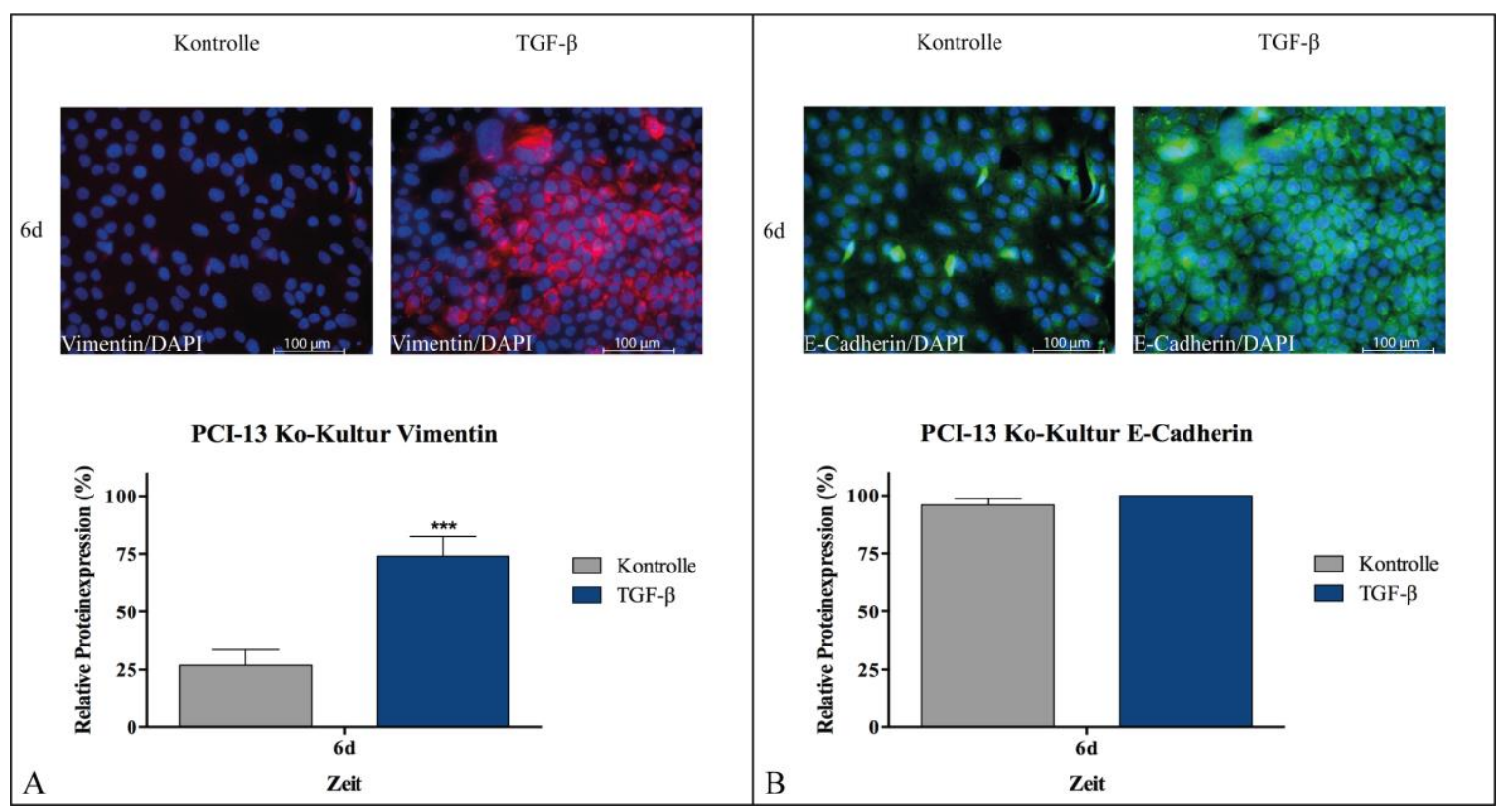

Abbildung 15: IF-Proteinexpression der ko-kultivierten PCI-13. Vimentin (A) ist mit Alexa Fluor 594 (rot), ECadherin (B) ist mit FITC (grün) und die Zellkerne sind mit DAPI (blau) dargestellt. Relative Proteinexpression in $\%(* * *=p \leq 0.0001)$ (Bohrnsen et al. 2017). Die Verwendung erfolgt mit freundlicher Genehmigung des Elsevier-Verlags. 
Ergebnisse

In den MSC Ko-Kulturen konnte die Expression des mesenchymalen Markers Vimentin (Abbildung 16A) und des epithelialen Markers E-Cadherin (Abbildung 16B) gezeigt werden. Dabei wurde über den gesamten Zeitraum der sechstägigen Differenzierung eine kontinuierliche Expression dieser Marker in allen Kulturen festgestellt. Die durchgeführte Quantifizierung ergab keine signifikanten Unterschiede zwischen den Vergleichs- und Kontrollgruppen. Wie schon in den Monolayer-Kulturen zeigte sich eine vergleichbare Veränderung der MSC-Zellmorphologie.

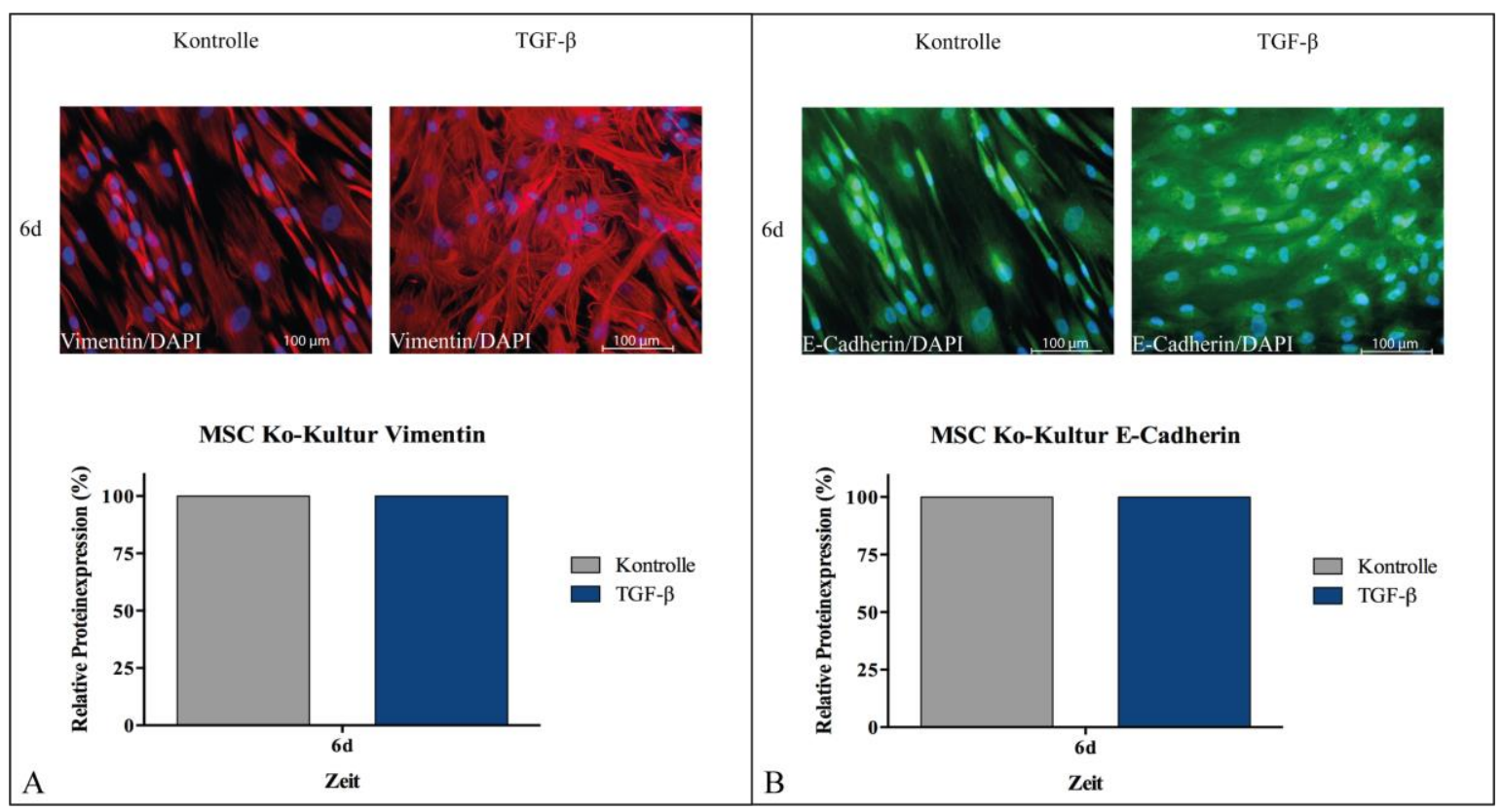

Abbildung 16: IF-Proteinexpression der ko-kultivierten MSC. Vimentin (A) ist mit Alexa Fluor 594 (rot), ECadherin (B) ist mit FITC (grün) und die Zellkerne sind mit DAPI (blau) dargestellt. Relative Proteinexpression in \% (Bohrnsen et al. 2017). Die Verwendung erfolgt mit freundlicher Genehmigung des Elsevier-Verlags. 
Ergebnisse

\subsubsection{Genexpression von Mediatoren der Tumor-Stroma-Interaktion in ko-kultivierten PCI-13 und MSC}

In den PCI-13 Ko-Kulturen zeigten die mit TGF- $\beta_{1}$ induzierten Zellen signifikant höhere Expressionen von Vimentin $(\mathrm{p}=0.003)$, E-Cadherin $(\mathrm{p}=0.004)$ und MMP-14 $(\mathrm{p}=0.002)$. Darüber hinaus waren die Expressionsniveaus von Snail $(\mathrm{p}=0.01)$, Twist ( $\mathrm{p}=0.04)$ und MMP-14 ( $\mathrm{p}=0.003)$ unter Ko-Kultur-Bedingungen im Vergleich zu den Monolayer-Kulturen signifikant erhöht. Keine Expressions-Unterschiede wurden bei Wnt-3 und $\beta$-Catenin festgestellt (Abbildung 17).

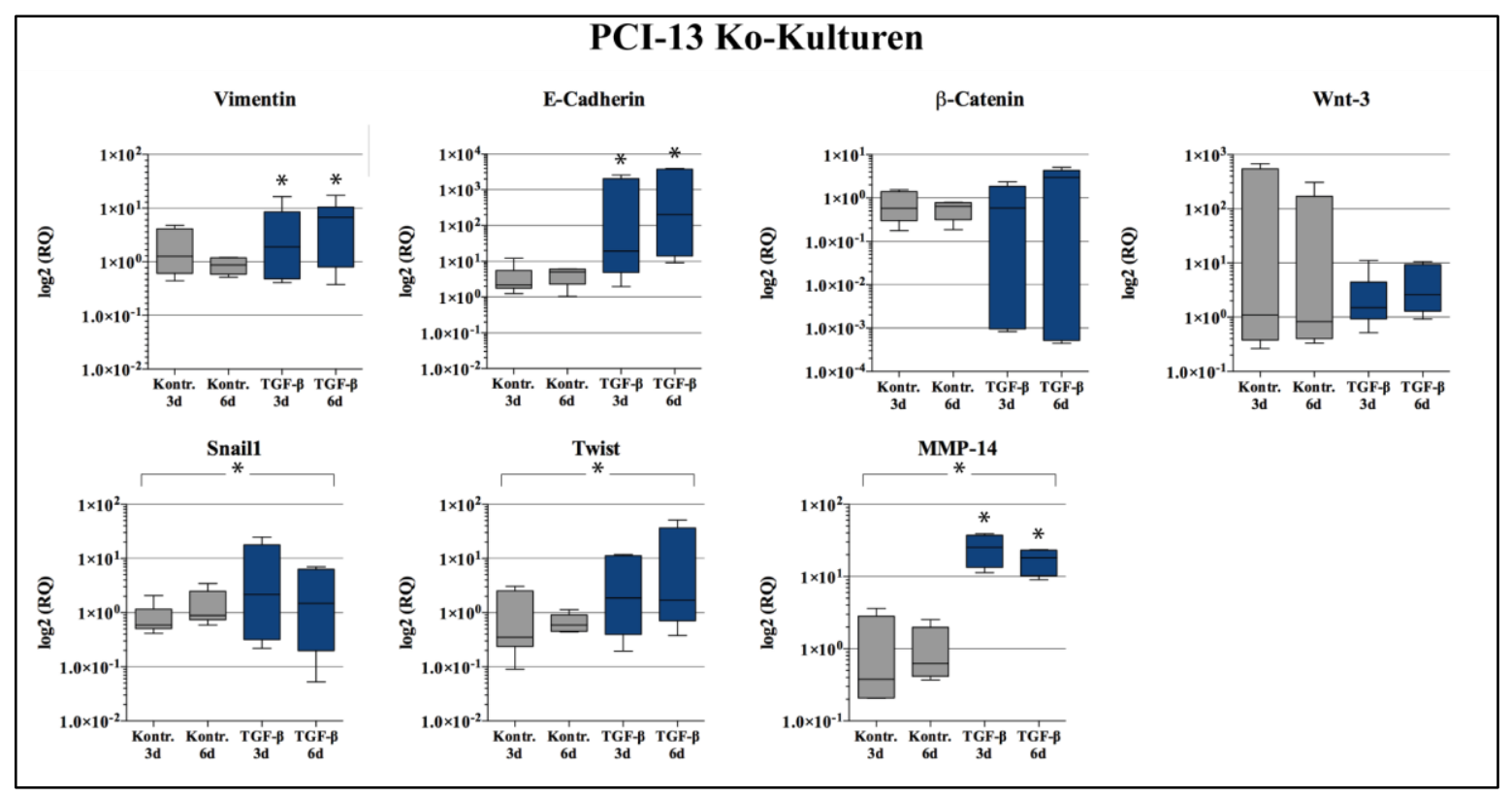

Abbildung 17: qRT-PCR Analyse der ko-kultivierten PCI-13 ( $*=p \leq 0.04$ ) (Bohrnsen et al. 2017). Die Verwendung erfolgt mit freundlicher Genehmigung des Elsevier-Verlags. 
Ergebnisse

In den MSC-Ko-Kulturen konnten die Analysen der qRT-PCR eine signifikante Erhöhung der E-Cadherin-Expression in den mit TGF- $\beta_{1}$ induzierten Kulturen zeigen $(p=0.003)$. Darüber hinaus war die Snail1-Expression in den mit TGF- $\beta_{1}$ induzierten Kulturen wie schon in den Monolayer-Kulturen signifikant erhöht $(\mathrm{p}=0.002)$. Die in den Monolayer-Kulturen noch beobachtete signifikante Reduzierung von Vimentin $(p=0.04)$ wurde in den Ko-Kulturen nicht länger festgestellt. Ebenso verblieben die Expressionen von Wnt-3, $\beta$-Catenin, Twist und MMP-14 ohne signifikante Unterschiede (Abbildung 18).

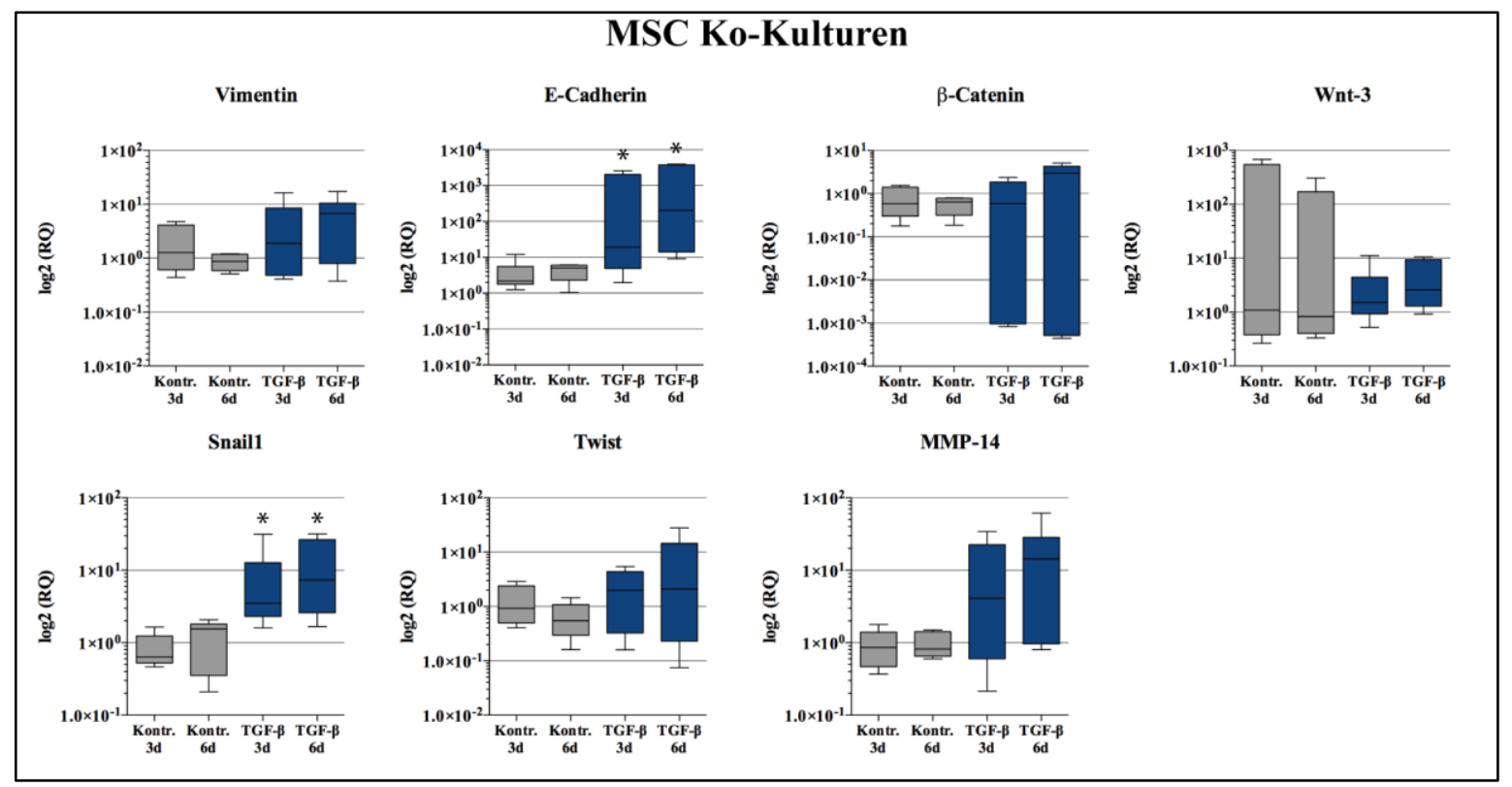

Abbildung 18: qRT-PCR Analyse der ko-kultivierten MSC ( $*=p \leq 0.04)$ (Bohrnsen et al. 2017). Die Verwendung erfolgt mit freundlicher Genehmigung des Elsevier-Verlags. 
Ergebnisse

\subsubsection{Proteinanalyse des AKT-Signalwegs, der Apoptose und des Erk-Signalwegs in} ko-kultivierten PCI-13 und MSC

In den PCI-13 Ko-Kulturen zeigten sich die Expressionen von AMPK $\alpha(\mathrm{p}=0.04)$, PRAS40 ( $\mathrm{p}=0.04), \operatorname{GSK}-3 \alpha(\mathrm{p}=0.045)$ und 4E-BP1 $(\mathrm{p}=0.006)$ in den mit TGF- $\beta_{1}$ induzierten Tumorzellen signifikant erhöht. Das Expressionsniveau von AMPK $\alpha$ $(\mathrm{p}=0.0001), \operatorname{GSK}-3 \alpha(\mathrm{p}=0.0003), \operatorname{Bad}(\mathrm{p}=0.002)$, PTEN $(\mathrm{p}=0.002)$ und ERK1/2 ( $\mathrm{p}=0.006)$ war im Vergleich zu den Monolayer-Kulturen in den Ko-Kulturen signifikant höher. Das Expressionsniveau von S6 ( $\mathrm{p}=0.02)$ war in den Ko-Kulturen signifikant niederiger als in den Monolayer-Kulturen (Abbildung 19).

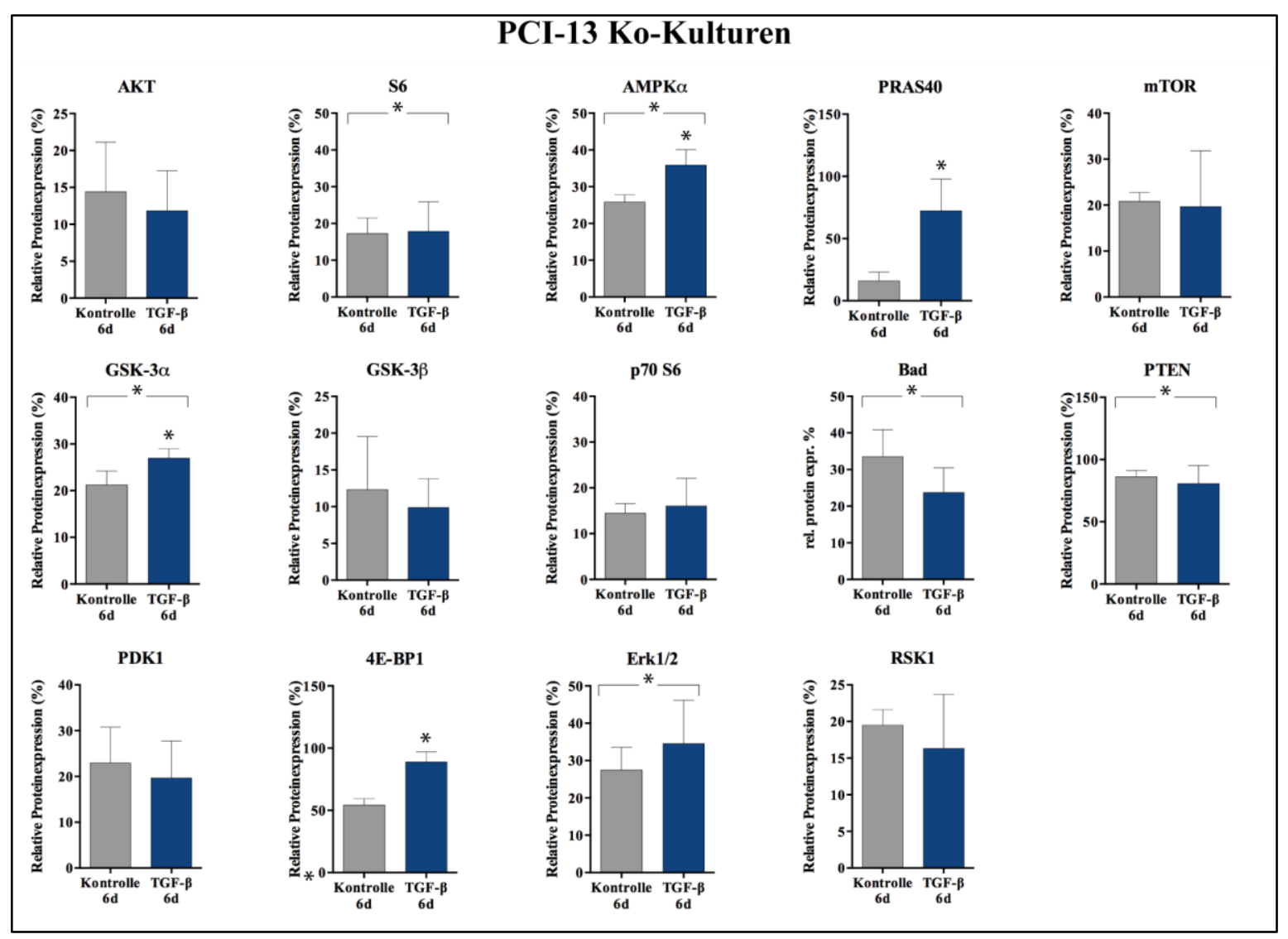

Abbildung 19: Die Proteinlevelanalysen mittels Pathscan der ko-kultivierten PCI-13. Relative Proteinexpression in $\%(*=p \leq 0.045)$ (Bohrnsen et al. 2017). Die Verwendung erfolgt mit freundlicher Genehmigung des Elsevier-Verlags. 
In den MSC Ko-Kulturen konnte durch die Proteinanalysen gezeigt werden, dass die Aktivität von PRAS40 ( $\mathrm{p}=0.0002)$, GSK-3 $\alpha(\mathrm{p}=0.01)$ und GSK-3 $\beta(\mathrm{p}=0.01)$ ebenso wie $\operatorname{Bad}(\mathrm{p}=0.008)$, PDK1 $(\mathrm{p}=0.001)$ und 4E-BP1 $(\mathrm{p}=0.0002)$ in TGF- $\beta_{1}$ induzierten Ko-Kulturen signifikant erhöht wurden. Auch in den MSC Ko-Kulturen konnten Unterschiede im Expressionsniveau beobachtet werden. So war das Expressionsniveau in den Ko-Kulturen von AKT ( $p=0.0009)$, AMPK $\alpha(p=0.0006)$, mTOR $(p=0.002)$, GSK-3 $\alpha$ $(\mathrm{p}=0.0002), \operatorname{GSK}-3 \beta(\mathrm{p}=0.0005), \operatorname{Bad}(\mathrm{p}=0.0001)$, PTEN $(\mathrm{p}=0.0001)$, PDK1 $(\mathrm{p}=0.0001)$ und RSK1 $(\mathrm{p}=0.01)$ im Vergleich zu den Monolayer-Kulturen signifikant höher (Abbildung 20).

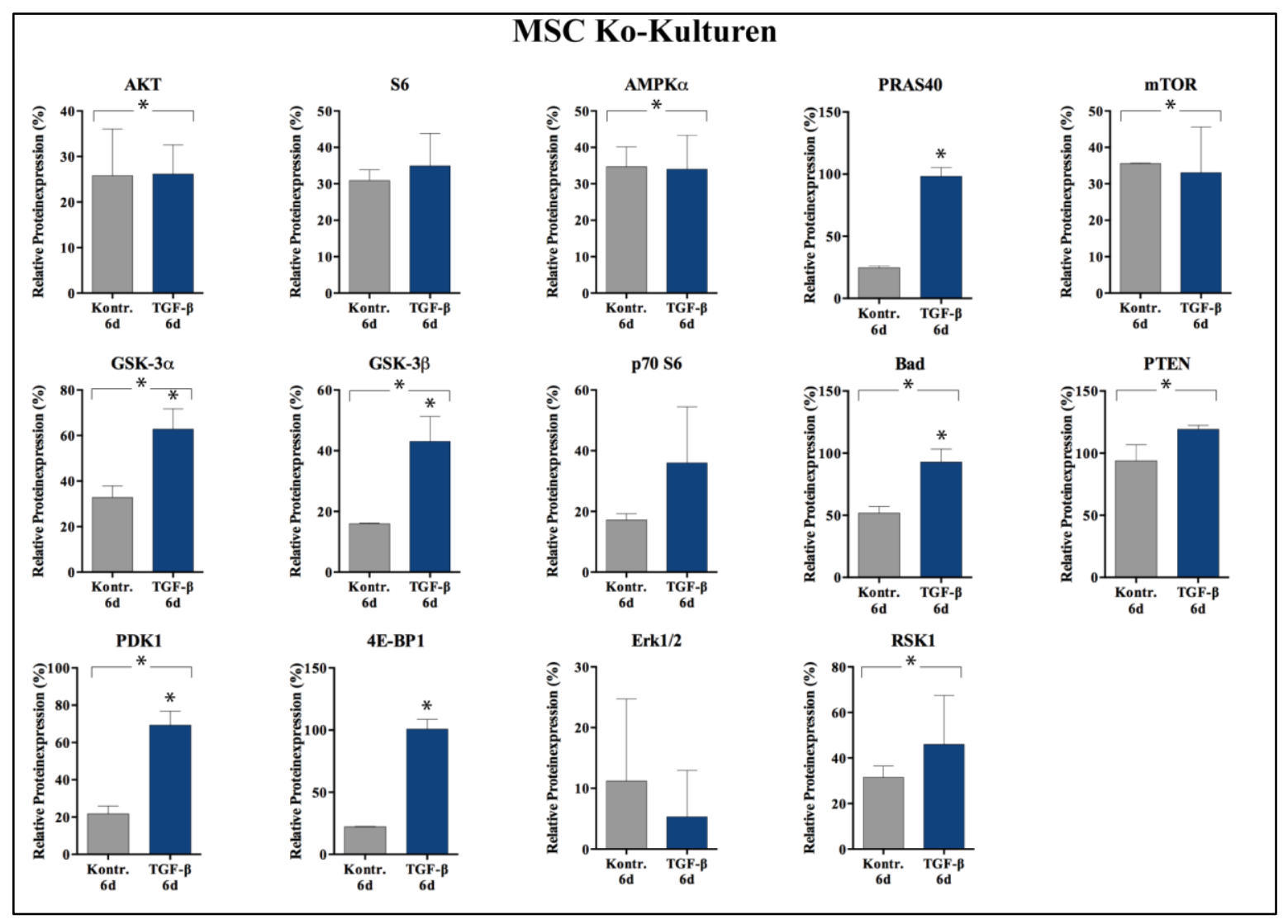

Abbildung 20: Die Proteinlevelanalysen mittels Pathscan der ko-kultivierten MSC. Relative Proteinexpression in $\%(*=p \leq 0.01)$ (Bohrnsen et al. 2017). Die Verwendung erfolgt mit freundlicher Genehmigung des Elsevier-Verlags. 
Ergebnisse

Zur besseren Darstellung verdeutlicht Tabelle 29 die unterschiedlichen ProteinExpressionsniveaus. Es werden die ko-kultivierten Zellen im Vergleich zu den Zellen, die im Monolayer kultiviert wurden in Relation gesetzt. $\mathrm{Zu}$ erkennen sind hierbei auch Unterschiede zwischen mit TGF- $\beta_{1}$ induzierten und nicht-induzierten Zellen.

Tabelle 29: Proteinlevel-Expressionsniveau der im Monolayer kultivierten Zellen im Vergleich zur Ko-Kultur.

\begin{tabular}{|c|c|c|c|c|}
\hline Protein & $\begin{array}{c}\text { PCI-13 } \\
\text { Kontrolle }\end{array}$ & $\begin{array}{c}\text { PCI-13 } \\
\text { TGF- } \beta_{1}\end{array}$ & $\begin{array}{c}\text { MSC } \\
\text { Kontrolle }\end{array}$ & $\begin{array}{c}\text { MSC } \\
\text { TGF- } \beta_{1}\end{array}$ \\
\hline AKT & $=$ & $=$ & $\uparrow$ & $\uparrow$ \\
\hline S6 & $\downarrow$ & $=$ & $\uparrow$ & $=$ \\
\hline AMPK $\alpha$ & $\uparrow$ & $\uparrow$ & $\uparrow$ & $\uparrow$ \\
\hline PRAS40 & $\downarrow$ & $=$ & $\uparrow$ & $\uparrow$ \\
\hline mTOR & $\uparrow$ & $\uparrow$ & $\uparrow$ & $\uparrow$ \\
\hline GSK-3 $\alpha$ & $=$ & $\uparrow$ & $\uparrow$ & $\uparrow$ \\
\hline GSK-3 $\beta$ & $=$ & $=$ & $\uparrow$ & $=$ \\
\hline P70 S 6 & $=$ & $\uparrow$ & $=$ & $\uparrow$ \\
\hline Bad & $=$ & $\uparrow$ & $=$ & $\uparrow$ \\
\hline PTEN & $\uparrow$ & $=$ & $\downarrow$ & $=$ \\
\hline PDK1 & $=$ & $=$ & $=$ & $=$ \\
\hline 4E-BP1 & $=$ & $\uparrow$ & $\uparrow$ & $=$ \\
\hline Erk1/2 & $=$ & $=$ & $\uparrow$ & $\uparrow$ \\
\hline RSK1 & $=$ & & $\uparrow$ & $\uparrow$ \\
\hline
\end{tabular}

Legende: =: Keine Unterschiede im Expressionsniveau messbar; $\uparrow:$ Ko-kultivierte Zellen weisen im Vergleich zu den im Monolayer kultivierten Zellen ein höheres Expressionsniveau auf; $\downarrow$ : Ko-kultivierte Zellen weisen im Vergleich zu den im Monolayer kultivierten Zellen ein niedrigeres Expressionsniveau auf. 


\section{Diskussion}

\subsection{Tumor-Stroma-Interaktionen beeinflussen die Proliferation der PCI-13 Ko-Kulturen}

Durch Interaktionen eines Tumors mit der Tumor-Mikroumgebung kann das invasive Potential der Tumorzellen beeinflusst werden (Curry et al. 2014). Die TumorMikroumgebung wird u. a. aus MSC gebildet (Hanahan und Coussens 2012). Interaktionen zwischen MSC und Tumorzellen finden sich oftmals in diesen Bereichen der Tumorproliferationszonen am invasiven Rand des Tumors (Routray et al. 2014). Diese progressiven, interzellulären Aktionen können Einfluss auf die Immunantwort und -reaktion der gesunden Tumorumgebung nehmen und so zur Bildung von Tumorsuppressorzellen und regulatorischen T-Zellen führen (Turley et al. 2015). So kann die Effizienz von Mechanismen der autologen Antitumorabwehr zur Eliminierung neoplastischer Zellen beeinflusst werden (Poggi et al. 2014; Turley et al. 2015). Durch parakrine Cross-Talk-Mechanismen, die inter- und intrazelluläre Signalwege modellieren, nehmen MSC Einfluss auf die Tumor- und Stromazellproliferation (Böhrnsen et al. 2015; Curry et al. 2014) und können pleomorphe Fähigkeiten der Tumorzellen aktivieren (Weinberg 2008). So werden Faktoren wie MMPs sezerniert, die zusätzlich zur Invasivität des Tumors beitragen. Hierdurch kann eine neue, metabolische Umgebung des Tumors geschaffen werden, die den hohen Energie- und anabolen Anforderungen des Tumors entspricht (Paget 1989).

Die Auswirkungen der MSC auf Tumorzellen und deren Progression werden in der Literatur jedoch differenziert beschrieben. Einige Studien berichten, dass durch den Einfluss der MSC die Größe der Tumorzellen zunimmt und die Fähigkeit zur Metastasierung erhöht wird (Luo et al. 2014; Roorda et al. 2010). Andere Quellen wiederum schildern, dass die Tumorzellproliferation durch direkten Zell-Zell-Kontakt, aber auch durch parakrine Signalwege reduziert werden kann (Böhrnsen et al. 2015; Chao et al. 2012; Kucerova et al. 2013).

Im Tumor-Stroma finden sich neben mesenchymalen Stromazellen auch Fibroblasten, vaskuläre Endothelzellen, Immunzellen und die extrazelluläre Matrix (Hanahan und Coussens 2012). Eine besondere Stellung in der Tumormikroumgebung nehmen Tumor assoziierte Fibroblasten oder Cancer associated Fibroblasts (CAF) ein (Bhome et al. 2015). Sie sind aktive Teilnehmer im Prozess der Tumorentstehung, da sie 
Diskussion

Wachstum und Metastasierung der Tumorzellen fördern (Wheeler et al. 2014). Obwohl die Mehrzahl der CAF im Tumor-Stroma von stromalen Fibroblasten abstammen, stammt auch ein signifikanter Anteil der CAF in Tumoren von MSC aus dem Knochenmark ab (Chan et al. 2019). Durch die Sekretion von Zytokinen wie z. B. TGF- $\beta$ können CAF pro-tumoröse Signale senden, die dann durch Stimulierung der Tumorzellproliferation und Angiogenese sowie Metastasenbildung durch die Verstärkung des Migrations- und Invasivitätspotentials der Tumorzellen zu einem erhöhten Tumorwachstum führen (Leef und Thomas 2013).

\subsubsection{Die Ko-Kultur zwischen PCI-13 und MSC ohne TGF- $\beta$ verringert die Proliferation $\underline{\text { der PCI-13 }}$}

In dieser Studie war die Proliferation der ko-kultivierten, nicht-induzierten PCI-13 signifikant verringert. Hier scheinen die MSC ohne den Einfluss von TGF- $\beta_{1}$ in der Ko-Kultur einen suppressiven Einfluss auf die Proliferation der Tumorzellen zu nehmen. Dieses ist vergleichbar mit Ergebnissen, in denen die parakrinen Einflüsse von MSC in der Lage waren, eine Tumorzellproliferation zu reduzieren (Böhrnsen et al. 2015; Poggi et al. 2014; Turley et al. 2015). Die Induktion mit dem Zytokin TGF- $\beta_{1}$ hob den suppressiven Einfluss der Ko-Kultur auf die Proliferation der PCI-13 jedoch wieder auf. Insbesondere durch Chemokine und Wachstumsfaktoren werden die Tumor-Stroma-Interaktionen und die zelluläre Kommunikation beeinflusst. Als Wachstumsfaktor reguliert TGF- $\beta_{1}$ abhängig von Zelltyp und Wirkdauer Proliferation, Differenzierung, Migration und Apoptose (Oshimori und Fuchs 2012). Je nach zellulärem Kontext kann TGF- $\beta_{1}$ als Tumorsuppressor aber auch als Tumorpromotor fungieren (Massague 2012). So kann es in physiologischen Epithelzellen hemmend auf Zellproliferation, Differenzierung und Motilität wirken und eine Apoptose fördern (Leef und Thomas 2013; Massague 2012). In Karzinomen jedoch wirkt die vermehrte Sezernierung von TGF- $\beta$ tumorproliferativ (Molinolo et al. 2009), indem Invasivität und Metastasierung gefördert werden (Nagaraj und Datta 2010).

\subsection{TGF- $\beta$-Einfluss auf die Expression wichtiger EMT-Marker}

Ein Schlüsselereignis während der Tumorprogression ist die EpithelialeMesenchymale-Transition (EMT), bei der epitheliale Zellen mesenchymale Eigenschaften gewinnen (Kalluri und Weinberg 2009). Zu diesen Eigenschaften gehören eine gesteigerte Motilität, eine veränderte Zelladhäsion und die Fähigkeit, die extrazelluläre Matrix zu modellieren (Curry et al. 2014). Durch die EMT gewinnen Zellen eine gesteigerte 
Migrationsfähigkeit, eine verstärkte Invasivität und eine erhöhte Apoptose-Resistenz (Kalluri und Neilson 2003). Am invasiven Rand eines Tumors versuchen Tumorzellen, zelluläre und biochemische Regulationsmechanismen $\mathrm{zu}$ überwinden, die sie an einer weiteren Proliferation hindern (Poggi et al. 2014; Turley et al. 2015). Der mehrstufige Prozess der Invasion und Metastasierung wird häufig als Invasions-MetastasierungsKaskade bezeichnet (Fidler 2003; Talmadge und Fidler 2010): Es kommt zu einer Abfolge zellbiologischer Veränderungen, beginnend mit einem lokalen invasiven Wachstum und einer Intravasation von Tumorzellen in nahegelegene Blut- und Lymphgefäße. Im Rahmen der EMT verlieren Tumorzellen ihre interzellulären Verbindungen. So wird ein Transport einzelner, sich vom Haupttumor gelöster Tumorzellen durch das lymphatische und hämatogene System möglich. Gefolgt von einem Entweichen der Tumorzellen aus dem Lumen solcher Gefäße in das Parenchym von entfernten Geweben (Extravasation), erlangen die Tumorzellen durch den zur EMT reversen Prozess der Mesenchymalen-EpithelialenTransition (MET) an dieser Stelle ihren epithelialen Phänotyp zurück, bilden erneut feste Zell-Zell-Verbindungen aus und schränken ihre Beweglichkeit somit wieder ein. Durch die Bildung kleiner Gruppen von Tumorzellen (Mikrometastasen) und schließlich das Wachstum mikrometastatischer Läsionen zu makroskopischen Tumoren entsteht im Folgenden ein sekundärer Tumor (Gupta und Massague 2006). Signalwege und regulatorische Elemente der EMT sind aktueller Gegenstand der Untersuchungen (Nieto 2011). So konnte gezeigt werden, dass eine Aktivierung des EMT-Programms einen kritischen Mechanismus für die Etablierung eines malignen Phänotyps epithelialer Karzinome darstellt und dieser durch proliferative und apoptotische Signalwege sowie Kaskaden beeinflusst wird (Böhrnsen et al. 2015).

Verschiedene Signalmoleküle und Zytokine wie TGF- $\beta_{1}$ (Yingling et al. 2004) beeinflusen diesen beschriebenen Metastasierungsprozess (Lamouille et al. 2014). Bei TGF- $\beta_{1}$ handelt es sich um einen Wachstumsfaktor, der je nach Zelltyp und Wirkdauer spezifische zelluläre Effekte wie Proliferation, Differenzierung, Migration und Apoptose reguliert (Oshimori und Fuchs 2012). Hierbei kann TGF- $\beta_{1}$ sowohl als Tumorsuppressor, als auch als Tumorpromotor agieren (Massague 2012).

\subsubsection{TGF- $\beta$-Induktion nimmt einen progressiven Einfluss auf die EMT}

Wie die Ergebnisse der IF-Proteinanalysen und der qRT-PCR zeigen, führte die Induktion mit TGF- $\beta_{1}$ in den PCI-13 Ko-Kulturen zu einem Anstieg der VimentinExpression. Für E-Cadherin konnte zwar in den IF-Analysen keine Expressionsunterschiede 
Diskussion

beobachtet werden, die qRT-PCR-Analysen zeigten jedoch einen signifikanten Anstieg der E-Cadherin-Expression in den mit TGF- $\beta_{1}$ induzierten PCI-13- und MSC-Ko-Kulturen. Vimentin ist ein klassischer mesenchymaler Marker und E-Cadherin ein Marker für zelluläre Verbindungen (Satelli und Li 2011; van Roy 2014). In Tumorzellen sind ein Verlust von E-Cadherin und ein Anstieg von Vimentin die klassischen Marker der EMT (Eriksson et al. 2009; Zeisberg und Neilson 2009). In primären PEK-Tumoren wird eine geringe E-Cadherin-Expression und eine hohe Vimentin-Expression mit einem Anstieg ferner Metastasen assoziiert (Nijkamp et al. 2011). Eine Reduktion der E-Cadherin-Expression ist häufig assoziiert mit einer schlechten klinischen Prognose bei Patienten mit Kopf-HalsTumoren (Xing et al. 2013). Obwohl eher ein Verlust von E-Cadherin eine beginnende EMT nahelegt, ist seine Expression heterogen und kann sich in verschiedenen Teilen desselben Tumors unterscheiden (Casarsa et al. 2011; Hung et al. 2006; Smith et al. 2013). Darüber hinaus gibt es Hinweise darauf, dass viele invasive und metastasierende Tumoren ein hohes Maß der E-Cadherin-Expression beibehalten (Christiansen und Rajasekaran 2006). So hemmt die Überexpression von E-Cadherin in der humanen Brustkrebszelllinie MDA-MB-435 die Zellmotilität und die invasive Kapazität nicht signifikant (Nieman et al. 1999). In ähnlicher Weise korreliert die hohe Expression von E-Cadherin positiv mit dem invasiven Wachstum und der Infiltration von Prostatakrebszellen (Putzke et al. 2011). Zudem zeigen Studien, dass die verstärkte Motilität und Invasion in Tumoren mit hoher E-Cadherin-Expression auf der Ko-Expression anderer Cadherine wie P-Cadherin (Ribeiro et al. 2013) und N-Cadherin (Hazan et al. 2000) beruht. So fördert die Überexpression von N-Cadherin oder P-Cadherin die Motilität und Invasion von Tumorzellen unabhängig der E-Cadherin-Expression (Ribeiro et al. 2013).

Wiederum war die Ko-Kultur aus PCI-13 und MSC ohne TGF- $\beta_{1}$ Einfluss in der Lage, einen eher EMT-hemmenden Einfluss zu nehmen, indem die Expression von Vimentin und E-Cadherin unverändert blieb. Die Induktion mit TGF- $\beta_{1}$ hob diesen Effekt jedoch auf und führte zu einer eher EMT-progressiven Wirkung, in dem die Expression der wichtigen EMT Marker Vimentin und E-Cadherin angehoben wurde. Die Abnahme der VimentinExpression in den MSC Monolayer-Kulturen unterstreicht den EMT-fördernden Einfluss der TGF- $\beta_{1}$-Induktion. In PEK kann TGF- $\beta_{1}$ eine EMT fördern, indem die Transformation zu einem mesenchymalen Phänotyp und darüber hinaus die Expression von EMT-assoziierten Proteinen wie Snail1 und Twist gefördert werden (Massague 2012).

Snail1 und Twist beeinflussen E-Cadherin und Vimentin, indem Snail1 die Überexpression mesenchymaler Marker und die Suppression epithelialer Marker wie neben 
Diskussion

E-Cadherin auch u. a. Claudine, Okkludine und Zytokeratine fördert (Zeisberg und Neilson 2009). Snail1 ist ein Transkriptionsfaktor, der in frühen Phasen einer EMT induziert wird (Sanchez-Tillo et al. 2012). Dabei werden Snail und Twist jedoch nur in $35 \%$ der HNSCC und in $40 \%$ des umgebenden Stromas exprimiert (Smith et al. 2013). In den Primärtumoren von PEK-Patienten korreliert die Snail1-Expression stark mit Metastasen und einer verschlechterten klinischen Prognose. Darüber hinaus geht die Snail1-Expression mit einem verstärkten histologischen Grading und einer starken Invasivität einher (Hayry et al. 2010), was $\mathrm{zu}$ einer niedrigeren Differenzierung des Tumors, lymphovaskulär-invasivem Wachstum und regionalen Metastasen führt (Mendelsohn et al. 2012). In MSC ist Snail1 für die Aufrechterhaltung eines undifferenzierten Zustands erforderlich, was ebenfalls durch TGF- $\beta_{1}$ gefördert werden kann (Batlle R et al. 2013). Die Induktion mit TGF- $\beta_{1}$ führte sowohl in den MSC-Monolayer-, als auch in MSC Ko-Kulturen zu einem Anstieg der Snail1-Expression. Darüber hinaus zeigten die Analysen der qRT-PCR ein signifikant höheres Expressionsniveau von Snail1 in den PCI-13 Ko-Kulturen im Vergleich zu den Monolayer-Kulturen. In den MSC verstärkt TGF- $\beta_{1}$ die Aufrechterhaltung eines undifferenzierten Zustands und wirkt damit tumorprogressiv auf das reine Tumor-Stroma (Batlle R et al. 2013). In Ko-Kultur mit PCI-13 konnte dieser Effekt wiederum aufgehoben werden. Das höhere Expressionsniveau von Snail1 in den PCI-13 Ko-Kulturen spricht für einen Progressionsbeginn innerhalb der ko-kultivierten Zellen. Dieser scheint jedoch durch den Einfluss der MSC auf die PCI-13 eingegrenzt zu werden.

Neben Snail1 gilt Twist als einer der wesentlichen Transkriptionsfaktoren, die eine EMT aktivieren können. Dieses geschieht entweder durch eine E-Cadherin-Suppression oder eine Interaktion mit anderen Transkriptionsfaktoren wie Snail (Batlle E et al. 2000; Sanchez-Tillo et al. 2012). Unter physiologischen Bedingungen wird Twist nicht exprimiert. Es konnte jedoch eine starke Korrelation zwischen der Reaktivierung von Twist und sowohl dem Fortschreiten als auch der Malignität von Tumoren festgestellt werden (Xue und Hemmings 2012). Twist wird vermehrt in Tumormetastasen exprimiert (Zeisberg und Neilson 2009), wobei eine Reduktion der Expression von Twist mit Hemmung der Invasivität oraler PEK in vitro assoziiert wird (da Silva et al. 2014). So korreliert bei PEK-Patienten die Twist-Expression u. a. auch mit Lymphknotenmetastasen (Ou et al. 2008). Die Ko-Kultur zwischen PCI-13 und MSC führte in den Tumorzellen zu einem erhöhten Expressionsniveau von Twist im Vergleich zu den Monolayer-Kulturen. Wiederum könnte dieser Anstieg auf einen Progressionsbeginn innderhalb der ko-kultivierten Zellen hindeuten, der jedoch durch den hemmenden Einfluss der MSC auf die PCI-13 wie bei 
Diskussion

Snail1 noch zurückgehalten wird. Im Rahmen einer unter vermehrter Snail1 und Twist Expression fortschreitenden EMT, kommt es zu einer zunehmenden Desintegration, Motilität und Auflösung der interzelluären Adhäsion u. a. durch Matrix-Metalloproteinasen. So könnte Twist auch zu den beobachteten Veränderungen der MMP-14-Expression beigetragen haben.

\subsubsection{TGF- $\beta$-Induktion führt zu Veränderung der MMP-14-Expression}

Bereits 1995 konnte die Expression von MMP-14 in PEK als eine der ersten Tumorentitäten gezeigt werden (Okada et al. 1995). Insgesamt ist in 75-100 \% aller PEK MMP-14 nachweisbar (Birkedal-Hansen et al. 2000; Kurahara et al. 1999). Zusätzlich ist MMP-14 als ein Mitglied der membranständigen MMP-Familie in der Lage, MMP-2 zu aktivieren und so den Abbau der extrazellulären Matrix während der EMT zu fördern (Radisky und Radisky 2010). MMP-14 beeinflusst die Tumorinvasivität und Metastasierung entscheidend, in dem es das Durchtreten der Tumorzellen durch die Basalmembran indiziert (Jacob und Prekeris 2015). So korreliert ein höheres Niveau der MMP-14-Expression mit entfernten Metastasen und einer kürzeren Patienten-Überlebenszeit (Wang et al. 2014). Sowohl in den PCI-13, als auch in den MSC wurde die Expression von MMP-14 nachgewiesen. Sowohl in PCI-13 Monolayer-, als auch in PCI-13 Ko-Kulturen führte die Induktion mit TGF- $\beta_{1}$ zu signifikanten Anstiegen der MMP-14-Expression. Diese durch TGF- $\beta_{1}$ ausgelösten Expressionsanstiege können als Anzeichen für eine mögliche gesteigerte Invasivität und einer Korrelation zur Malignität angesehen werden (Jacob und Prekeris 2015).

\subsection{Veränderung von Wnt-, AKT-, Erk- und mTOR-Signalwegen in MSC- und PCI Ko-Kulturen}

\subsubsection{Wnt-Signalweg in PCI-13 und MSC}

Der kanonische Wnt-Weg beginnt mit dem Empfang von Signalmolekülen auf der Zellmembran. Bei aktivem Wnt-Signal wird GSK-3 $\beta$ zu einer inaktiven Form phosphoryliert. Als Folge hiervon wird funktionelles $\beta$-Catenin im Cytosol akkumuliert und dann weiter in den Zellkern transportiert. Hier bindet es an die Promotorregion eines Zielgens wie z. B. Snail1 und aktiviert dessen Transkription (Easwaran et al. 1999; ten Berge et al. 2008). Zwischen dem Wnt- und TGF- $\beta$-Signalweg gibt es in vielen Bereichen Überschneidungen, die eine EMT fördern können (Zhang et al. 2016). So kann unter 
Diskussion

TGF- $\beta$-Stimulation der WNT-Signalweg durch Small mothers against decapentaplegic(SMAD) unabhängige Signalwege aktiviert werden. In humanen Lungen-Fibroblasten inaktiviert TGF- $\beta_{1}$ das GSK-3 $\beta$, indem es ERK phosphoryliert (Caraci et al. 2008). GSK-3 $\beta$ wiederum beeinflusst den TGF- $\beta$-Signalweg durch SMAD3-Phosphorylierung und löst seinen Abbau bei fehlendem intrazellulärem TGF- $\beta$ Signal aus (Guo X et al. 2008).

Die Expression von Wnt-3 und $\beta$-Catenin als wichtige Marker des WNT-Signalweges zeigte sich in den vorliegenden Untersuchungen unverändert und konnte somit auch keinen Einfluss auf nachgeschaltete Ziele wie Snail1 nehmen. Auch wenn in vielen Tumorarten abnormale Aktivierungen bzw. Mutationen im kanonischen Wnt- $\beta$-Catenin-Signalweg nachgewiesen wurden (Zhou und Hung 2005), hatte weder die verwendete Kultivierungsmethode, noch die Induktion mit TGF- $\beta_{1}$ einen Einfluss auf den Wnt-Signalweg. Neben dem Wnt-Signalweg sind aber auch noch andere Signalwege wie die AKT-, Erk- und mTOR-Signalwege während der Tumorprogression relevant.

\subsubsection{AKT-Signalweg wird durch TGF- $\beta_{1}$-Induktion und Ko-Kultivierung in PCI-13 und $\underline{\text { MSC aktiviert }}$}

Eine Aktivierung des PI3K-AKT-Signalwegs wurde in Tumoren des Kopf-HalsBereichs festgestellt (Engelman et al. 2006), erhöht das Überleben von Tumorzellen in vitro (Kim et al. 2005) und wird mit der Induktion einer EMT in Verbindung gebracht (Bruzzese et al. 2011). Darüber hinaus werden Veränderungen dieses Signalwegs mit einer Tumorprogression und einem kürzeren Gesamtüberleben von Patienten mit PEK assoziiert (Kovacina et al. 2003; Theocharis et al. 2014; Wiza et al. 2012). So zeigten sich in den mit TGF- $\beta_{1}$ induzierten PCI-13 Monolayer-Kulturen signifikante Abnahmen der Expressionen von AKT, AMPK $\alpha$ und Bad. In den PCI-13 Ko-Kulturen führte die Induktion mit TGF- $\beta_{1}$ jedoch zu einer erhöhten Expression von AMPK $\alpha$, GSK-3 $\alpha$. Die TGF- $\beta_{1}$-Induktion führte sowohl in den MSC Monolayer-Kulturen als auch in den MSC Ko-Kulturen dazu, dass GSK-3 $\beta$ erhöht wurde. Darüber hinaus zeigte sich in den MSC Ko-Kulturen die Expression von GSK-3 $\alpha$, Bad sowie PDK1 signifikant erhöht. In phosphorylierter Form konnte AKT in PEK des Kopf-Hals-Bereichs nachgewiesen werden (Brazil und Hemmings 2001; Engelman et al. 2006; Stegeman et al. 2012). Das Protein Bad ist als pro-apoptotisches Mitglied der Bcl-2 Gen-Familie in die Initiierung einer Apoptose involviert (Adachi und Imai 2002). Über die Bedeutung von AMPKa in PEK ist aktuell Gegenstand wissenschaftlicher Untersuchungen. Den Energiehaushalt der Zellen regulierend, sind Untereinheiten von AMPK $\alpha$ in verschiedenen Tumoren vermehrt exprimiert (Monteverde et al. 2015). Die 
Diskussion

Phosphorylierung von Bad inhibiert seine Funktionen und fördert so das Zell-Überleben (Cross et al. 1995; Manning und Cantley 2007). Die Phosphorylierung von GSK-3 fördert das Zell-Überleben, indem es die eigenen Funktionen inhibiert (Cross et al. 1995; Manning und Cantley 2007). PDK1 aktiviert AKT und fördert damit eine Tumorprogression (Brazil und Hemmings 2001). Auch die höheren Expressionsniveaus in den PCI-13 Ko-Kulturen von AMPK $\alpha$, GSK-3a, Bad, PTEN ( $\mathrm{p}=0.006)$ deuten ebenfalls darauf hin, dass es zu vermehrten Aktivitäten im AKT-Signalweg kommt. Die höheren Expressionsniveaus in den MSC Ko-Kulturen von AKT, AMPK $\alpha$, GSK-3 $\alpha / \beta$, Bad, PTEN und PDK1 unterstreichen diese Annahme.

\subsubsection{Erk-Signalweg wird durch TGF- $\beta_{1}$-Induktion und Ko-Kultivierung in PCI-13 und $\underline{\text { MSC beeinflusst }}$}

Die Erk-Kaskade wird im Rahmen einer gegenseitigen Regulation des AKT-Signalwegs als ein entscheidender Regulator der Zellmotilität angesehen. Neben der Zellmotilität spielt der ERK-Signalweg auch eine entscheidende Rolle bei der Regulation verschiedener Zellfunktionen wie Zellproliferation, -differenzierung und -überleben als Reaktion auf extrazelluläre Signale (Johnson und Lapadat 2002; Nishida und Gotoh 1993). Erk1/2 ist direkt mit der Induktion von Zellproliferation und einer onkogenen Transformation assoziiert (Kyriakis et al. 1992; Pages et al. 1993; Sun H et al. 1993). So wird zum Beispiel die RSK1 durch Erk1/2 aktiviert (Cargnello und Roux 2011; Roux und Blenis 2004). Diese phosphoryliert unter anderem das ribosomale Protein S6 und fördert somit Zellwachstum und Proliferation. Die mit TGF- $\beta_{1}$ induzierten PCI-13 MonolayerKulturen zeigten jedoch signifikante Abnahmen der Expressionen von Erk1/2 und S6. Die TGF- $\beta_{1}$-Induktion der MSC Monolayer-Kulturen führte dazu, dass S6 erhöht wurden. Die höheren Expressionsniveaus von Erk 1/2 (p = 0.006) in den PCI-13 Ko-Kulturen und die höheren Expressionsniveaus von RSK1 in den MSC Ko-Kulturen deuten wiederum ähnlich zum AKT-Signalweg darauf hin, dass es durch TGF- $\beta_{1}$-Induktion und Ko-Kultivierung zu einem Beginn in der Aktivität der Erk-Kaskade kommt.

\subsection{4 mTOR-Signalweg in PCI-13 und MSC}

Der mTOR-Signalweg reguliert Zellwachstums, Zellproliferation und Zellmetabolismus (Laplante und Sabatini 2012). Dabei ist mTOR eine Kernkomponente der zwei makromolekularen Komplexe mTORC 1 und mTORC 2 (Wullschleger et al. 2006). Veränderungen der mTOR-Expression wurden mit einer Tumorprogression und einer kürzeren Gesamtüberlebenszeit von 126 PEK-Patienten in Verbindung gebracht (Wiza et al. 
2012). Insbesondere die Verbindungen zwischen mTOR und AKT-Signalwegen machen die Interkonnektivität und Komplexität der Tumor-Stroma-Interaktionen deutlich. Indem PRAS40 den AKT- und den mTOR-vermittelten-Signalweg verbindet, reguliert es zelluläres Wachstum und den zellulären Metabolismus. So geht eine verringerte Thr246-Phosphorylierung mit einer erhöhten Empfindlichkeit der Zellen auf proapoptotische Stimuli einher (Madhunapantula et al. 2007). Das AKT-Signal stimuliert mTORC1, die p70 S6 Kinase zu aktivieren (Laplante und Sabatini 2012). 4E-BP1 ist bei seiner Überexpression in der Lage, die Zellgröße zu verringern, den Zellzyklus zu hemmen und die Tumorpathogenität zu unterdrücken (Avdulov et al. 2004; Fingar et al. 2002; Fingar et al. 2004; Lynch et al. 2004). Die mit TGF- $\beta_{1}$ induzierten PCI-13 Monolayer-Kulturen zeigten signifikante Abnahmen der Expressionen von PRAS40 und p70 S6. In den PCI-13 Ko-Kulturen führte die Induktion mit TGF- $\beta_{1}$ jedoch zu einer erhöhten Expression von PRAS40 und 4E-BP1. Die TGF- $\beta_{1}$-Induktion der MSC Monolayer-Kulturen führte dazu, dass mTOR erhöht wurde. In den MSC Ko-Kulturen war die Expression von PRAS40 und 4E-BP1 signifikant erhöht. Wie schon im AKT- und im Erk-Signalweg, deutet auch das höhere Expressionsniveaus von mTOR in den PCI-13 Ko-Kulturen darauf hin, dass es durch TGF- $\beta_{1}$-Induktion und Ko-Kultivierung $\mathrm{zu}$ einem Beginn in der Aktivität des mTOR-Signalweges kommt. 


\subsection{Fazit}

Aus den vorliegenden Untersuchungen lassen sich abschließend folgende Resultate beschreiben:

MSC scheinen in Ko-Kultur mit PCI-13 einen suppressiven Einfluss auf die Proliferation der Tumorzellen zu nehmen. Die Induktion mit dem Zytokin TGF- $\beta_{1}$ hebt diesen suppressiven Einfluss der Ko-Kultur auf die Proliferation der PCI-13 jedoch wieder auf.

Die Induktion mit TGF- $\beta_{1}$ führte zu einer EMT-progressiveren Wirkung, in dem der Wachstumsfaktor einen direkten Einfluss auf die Expression wichtiger EMT-Marker wie Vimentin, E-Cadherin, Snail1 und Twist nimmt.

Die Analyse der AKT-, Erk- und mTOR-Signalwege zeigt eine progressive Aktivierung dieser Signalwege durch TGF- $\beta_{1}$. So scheint der AKT-Signalweg durch TGF- $\beta_{1}$-Induktion und Ko-Kultivierung in PCI-13 und MSC aktiviert zu werden, was in den vorliegenden Untersuchungen u. a. zu einem Beginn des Erk- und mTOR-Signalwegs führen kann. 


\section{$5 \quad$ Zusammenfassung}

Tumoren des Kopf-Hals-Bereichs gehören mit weltweit jährlich mehr als 500.000 Neuerkrankungen zu den zehn häufigsten Tumoren, wobei es sich bei mehr als 9 von 10 Tumoren um PEK handelt. Beeinflusst wird das invasive Potential eines Tumors $u$. a. durch Interaktionen mit der Tumormikroumgebung, die u. a. auch aus mesenchymalen Stromazellen (MSC) besteht. Um ihre Wirkung zu entfalten, produzieren MSC u. a. eine Vielzahl von Zytokinen, zu denen auch Transforming Growth Factor beta 1 (TGF- $\beta_{1}$ ) zählt. TGF- $\beta_{1}$ ist ein Wachstumsfaktor, der je nach Zelltyp und Wirkdauer spezifische zelluläre Effekte wie Proliferation, Differenzierung, Migration und Apoptose reguliert. So können MSC weiter Einfluss auf die Interaktion zwischen Tumor und Tumor-Stroma gewinnen. Es konnte gezeigt werden, dass der Einfluss von MSC und die Interaktionen zwischen Tumorgewebe und Tumor-Mikroumgebung das invasive Potential von Plattenepithelkarzinomen (PEK) hemmen können.

Zentrale Prozesse wie invasives Wachstum und Metastasierung sind entscheidende Schritte während der Tumorprogression und können durch den Prozess einer InvasivitätsMetastasierungs-Kaskade beschrieben werden. Ein Schlüsselereignis im Metastasierungsprozess ist der epithelial-mesenchymale Übergang, bei dem epitheliale Zellen mesenchymale Eigenschaften gewinnen. Dieser Übergang wird auch als EpithelialeMesenchymale-Transition (EMT) bezeichnet.

Die Analysen der vorliegenden Dissertation untersuchen, welchen Einfluss das Zytokin TGF- $\beta_{1}$ auf die Wechselwirkungen zwischen Tumor und Tumor-Stroma hat, wie sich diese auf die Tumorzellproliferation auswirken, wie wichtige EMT-Marker wie Vimentin, E-Cadherin, Snail1, Twist und Matrix-Metalloproteinase (MMP)-14 beeinflusst und wie die Marker des Wingless-type MMTV integration site family member (Wnt)-, AKT-, Erk- und Mammalian Target of Rapamycin (mTOR)-Signalwegs reguliert werden.

Hiefür wurden humane MSC aus dem Beckenkamm von acht Patienten isoliert, gepoolt und auf einer trans-well permeablen Membran mit Tumorzellen der etablierten PEK-Zelllinie PCI-13 ko-kultiviert und mit Monolayer-Kulturen verglichen. Monolayerund Ko-Kulturen wurden mit TGF- $\beta_{1}$ induziert und mit nicht-induzierten Kulturen verglichen. Im Vorfeld der Versuche erfolgte zunächst eine Charakterisierung der MSC mittels FACS und eine osteogene, adipogene und chondrogene Differenzierung. Im Zuge der Experimente wurde die Expression von Vimentin und E-Cadherin durch IF-Analysen ausgewertet. Darüber hinaus wurden qualitative reverse Transkriptase Polymerase-KettenReaktion (qRT-PCR) Analysen der Tumortransitions-Marker Vimentin, E-Cadherin, Wnt-3, 
$\beta$-Catenin, Snail1, Twist und MMP-14 durchgeführt. Veränderungen im AKT-, Erk- und mTOR-Signalweg wurden durch Proteinanalysen mittels Bicinchoninic Acid Assay (BCA) und PathScan ${ }^{\circledR}$ untersucht.

MSC scheinen in Ko-Kultur mit PCI-13 einen suppressiven Einfluss auf die Proliferation der Tumorzellen zu nehmen. Die Induktion mit dem Zytokin TGF- $\beta_{1}$ hob diesen suppressiven Einfluss der Ko-Kultur auf die Proliferation der PCI-13 jedoch wieder auf. Die Induktion mit TGF- $\beta_{1}$ führte zu einer eher EMT-progressiven Wirkung, in dem die Zytokingabe einen direkten Einfluss auf die Expression wichtiger EMT-Marker wie Vimentin, E-Cadherin, Snail1 und Twist nahm.

Auch die Analyse der AKT-, Erk- und mTOR-Signalwege zeigte eine progressive Aktivierung dieser Signalwege durch TGF- $\beta_{1}$. So wurde der AKT-Signalweg durch TGF- $\beta_{1}$-Induktion und Ko-Kultivierung in PCI-13 und MSC aktiviert und es kam zu einem Beginn des Erk- und mTOR-Signalwegs. Damit wird insgesamt deutlich, dass der Einfluss von TGF- $\beta_{1}$ in der Ko-Kultur zwischen MSC und PCI-13 eine Tumorzellentwicklung fördern kann. 


\section{$6 \quad$ Literaturverzeichnis}

Adachi M, Imai K (2002): The proapoptotic BH3-only protein BAD transduces cell death signals independently of its interaction with Bcl-2. Cell death and differentiation $\underline{9}, 1240$ 1247

Anastas JN, Moon RT (2013): WNT signalling pathways as therapeutic targets in cancer. Nature reviews. Cancer $\underline{13}, 11-26$

Assani G, Zhou Y (2019): Effect of modulation of epithelial-mesenchymal transition regulators Snail1 and Snail2 on cancer cell radiosensitivity by targeting of the cell cycle, cell apoptosis and cell migration/invasion. Oncology letters $\underline{17}, 23-30$

Avdulov S, Li S, Michalek V, Burrichter D, Peterson M, Perlman DM, Manivel JC, Sonenberg N, Yee D, Bitterman PB et al. (2004): Activation of translation complex eIF4F is essential for the genesis and maintenance of the malignant phenotype in human mammary epithelial cells. Cancer cell $\underline{5}, 553-563$

Batlle E, Sancho E, Franci C, Dominguez D, Monfar M, Baulida J, Garcia De Herreros A (2000): The transcription factor snail is a repressor of E-cadherin gene expression in epithelial tumour cells. Nature cell biology $2,84-89$

Batlle R, Alba-Castellon L, Loubat-Casanovas J, Armenteros E, Franci C, Stanisavljevic J, Banderas R, Martin-Caballero J, Bonilla F, Baulida J et al. (2013): Snail1 controls TGF-beta responsiveness and differentiation of mesenchymal stem cells. Oncogene $\underline{32}$, 3381-3389

Berx G, van Roy F (2009): Involvement of members of the cadherin superfamily in cancer. Cold Spring Harbor perspectives in biology 1 , a003129

Bhome R, Bullock MD, Al Saihati HA, Goh RW, Primrose JN, Sayan AE, Mirnezami AH (2015): A top-down view of the tumor microenvironment: structure, cells and signaling. Frontiers in cell and developmental biology $\underline{3}, 33$

Birchmeier W, Behrens J (1994): Cadherin expression in carcinomas: role in the formation of cell junctions and the prevention of invasiveness. Biochimica et biophysica acta $1198,11-$ 26

Birkedal-Hansen B, Pavelic ZP, Gluckman JL, Stambrook P, Li YQ, Stetler-Stevenson WG (2000): MMP and TIMP gene expression in head and neck squamous cell carcinomas and adjacent tissues. Oral diseases $\underline{6}, 376-382$

Bjorklund M, Koivunen E (2005): Gelatinase-mediated migration and invasion of cancer cells. Biochimica et biophysica acta 1755, 37-69

Böhrnsen F, Fricke M, Sander C, Leha A, Schliephake H, Kramer FJ (2015): Interactions of human MSC with head and neck squamous cell carcinoma cell line PCI-13 reduce markers of epithelia-mesenchymal transition. Clin Oral Investig $\underline{19}, 1121-1128$

Boyera N, Cavey D, Delamadeleine F, Bouclier M, Hensby C, Shroot B (1993): A novel in vitro model for the study of human keratinocyte/leucocyte interactions under autologous conditions. Br J Dermatol 129, 521-529 
Brazil DP, Hemmings BA (2001): Ten years of protein kinase B signalling: a hard Akt to follow. Trends in biochemical sciences $\underline{26}, 657-664$

Bruzzese F, Leone A, Rocco M, Carbone C, Piro G, Caraglia M, Di Gennaro E, Budillon A (2011): HDAC inhibitor vorinostat enhances the antitumor effect of gefitinib in squamous cell carcinoma of head and neck by modulating ErbB receptor expression and reverting EMT. Journal of cellular physiology $\underline{226}, 2378-2390$

Cai J, Guan H, Fang L, Yang Y, Zhu X, Yuan J, Wu J, Li M (2013): MicroRNA-374a activates $\mathrm{Wnt} /$ beta-catenin signaling to promote breast cancer metastasis. The Journal of clinical investigation $\underline{123}, 566-579$

Caraci F, Gili E, Calafiore M, Failla M, La Rosa C, Crimi N, Sortino MA, Nicoletti F, Copani A, Vancheri C (2008): TGF-beta1 targets the GSK-3beta/beta-catenin pathway via ERK activation in the transition of human lung fibroblasts into myofibroblasts. Pharmacological research $\underline{57}, 274-282$

Cargnello M, Roux PP (2011): Activation and function of the MAPKs and their substrates, the MAPK-activated protein kinases. Microbiology and molecular biology reviews : MMBR $\underline{75}, 50-83$

Casarsa C, Bassani N, Ambrogi F, Zabucchi G, Boracchi P, Biganzoli E, Coradini D (2011): Epithelial-to-mesenchymal transition, cell polarity and stemness-associated features in malignant pleural mesothelioma. Cancer letters $\underline{302}$, 136-143

Ch'ng S, Sullivan M, Yuan L, Davis P, Tan ST (2006): Mast cells dysregulate apoptotic and cell cycle genes in mucosal squamous cell carcinoma. Cancer cell international $\underline{6}, 28$

Chan TS, Shaked Y, Tsai KK (2019): Targeting the interplay between cancer fibroblasts, mesenchymal stem cells, and cancer stem cells in desmoplastic cancers. Frontiers in oncology $\underline{9}, 688$

Chao KC, Yang HT, Chen MW (2012): Human umbilical cord mesenchymal stem cells suppress breast cancer tumourigenesis through direct cell-cell contact and internalization. Journal of cellular and molecular medicine $\underline{16}, 1803-1815$

Chen YW, Chen KH, Huang PI, Chen YC, Chiou GY, Lo WL, Tseng LM, Hsu HS, Chang KW, Chiou SH (2010): Cucurbitacin I suppressed stem-like property and enhanced radiation-induced apoptosis in head and neck squamous carcinoma--derived CD44(+)ALDH1(+) cells. Molecular cancer therapeutics $\underline{9}, 2879-2892$

Christiansen JJ, Rajasekaran AK (2006): Reassessing epithelial to mesenchymal transition as a prerequisite for carcinoma invasion and metastasis. Cancer research $\underline{66}, 8319-8326$

Collins JJ, Thebaud B (2014): Lung mesenchymal stromal cells in development and disease: to serve and protect? Antioxidants \& redox signaling 21, 1849-1862

Coons AH (1954): Labelled antigens and antibodies. Annual review of microbiology $\underline{8}, 333-$ 352 
Literaturverzeichnis

Cross DA, Alessi DR, Cohen P, Andjelkovich M, Hemmings BA (1995): Inhibition of glycogen synthase kinase-3 by insulin mediated by protein kinase B. Nature $\underline{378}$, 785-789

Cully M, You H, Levine AJ, Mak TW (2006): Beyond PTEN mutations: the PI3K pathway as an integrator of multiple inputs during tumorigenesis. Nature reviews. Cancer $\underline{6}, 184-192$

Curry JM, Sprandio J, Cognetti D, Luginbuhl A, Bar-ad V, Pribitkin E, Tuluc M (2014): Tumor microenvironment in head and neck squamous cell carcinoma. Seminars in oncology $\underline{41}, 217-234$

da Silva SD, Alaoui-Jamali MA, Soares FA, Carraro DM, Brentani HP, Hier M, Rogatto SR, Kowalski LP (2014): TWIST1 is a molecular marker for a poor prognosis in oral cancer and represents a potential therapeutic target. Cancer $\underline{120}$, 352-362

Datta SR, Brunet A, Greenberg ME (1999): Cellular survival: a play in three Akts. Genes \& development $\underline{13}, 2905-2927$

Deryugina EI, Quigley JP (2015): Tumor angiogenesis: MMP-mediated induction of intravasation- and metastasis-sustaining neovasculature. Matrix biology : journal of the International Society for Matrix Biology 44-46, 94-112

Dominici M, Le Blanc K, Mueller I, Slaper-Cortenbach I, Marini F, Krause D, Deans R, Keating A, Prockop D, Horwitz E (2006): Minimal criteria for defining multipotent mesenchymal stromal cells. The International Society for Cellular Therapy position statement. Cytotherapy $\underline{8}, 315-317$

Eastham AM, Spencer H, Soncin F, Ritson S, Merry CL, Stern PL, Ward CM (2007): Epithelial-mesenchymal transition events during human embryonic stem cell differentiation. Cancer research $\underline{67}, 11254-11262$

Easwaran V, Pishvaian M, Salimuddin, Byers S (1999): Cross-regulation of beta-cateninLEF/TCF and retinoid signaling pathways. Current biology : CB $\underline{9}, 1415-1418$

Egeblad M, Werb Z (2002): New functions for the matrix metalloproteinases in cancer progression. Nature reviews. Cancer $\underline{2}, 161-174$

Eggenhofer E, Luk F, Dahlke MH, Hoogduijn MJ (2014): The life and fate of mesenchymal stem cells. Frontiers in immunology $\underline{5}, 148$

Engelman JA, Luo J, Cantley LC (2006): The evolution of phosphatidylinositol 3-kinases as regulators of growth and metabolism. Nature reviews. Genetics $\underline{7}, 606-619$

Eriksson JE, Dechat T, Grin B, Helfand B, Mendez M, Pallari HM, Goldman RD (2009): Introducing intermediate filaments: from discovery to disease. The Journal of clinical investigation $\underline{119}, 1763-1771$

Ferris RL, Blumenschein G, Jr., Fayette J, Guigay J, Colevas AD, Licitra L, Harrington K, Kasper S, Vokes EE, Even C et al. (2016): Nivolumab for recurrent squamous-cell carcinoma of the head and neck. The New England journal of medicine 375, 1856-1867 
Literaturverzeichnis

Fidler IJ (2003): The pathogenesis of cancer metastasis: the 'seed and soil' hypothesis revisited. Nature reviews. Cancer $\underline{3}, 453-458$

Fierro FA, Sierralta WD, Epunan MJ, Minguell JJ (2004): Marrow-derived mesenchymal stem cells: role in epithelial tumor cell determination. Clinical \& experimental metastasis $\underline{21}, 313-319$

Fingar DC, Salama S, Tsou C, Harlow E, Blenis J (2002): Mammalian cell size is controlled by mTOR and its downstream targets S6K1 and 4EBP1/eIF4E. Genes \& development $\underline{16}$, $1472-1487$

Fingar DC, Richardson CJ, Tee AR, Cheatham L, Tsou C, Blenis J (2004): mTOR controls cell cycle progression through its cell growth effectors S6K1 and 4E-BP1/eukaryotic translation initiation factor 4E. Molecular and cellular biology 24, 200-216

Gache C, Berthois Y, Martin PM, Saez S (1998): Positive regulation of normal and tumoral mammary epithelial cell proliferation by fibroblasts in coculture. In vitro cellular \& developmental biology. Animal 34, 347-351

Goers L, Freemont P, Polizzi KM (2014): Co-culture systems and technologies: taking synthetic biology to the next level. J R Soc Interface $\underline{11}$

Guo X, Ramirez A, Waddell DS, Li Z, Liu X, Wang XF (2008): Axin and GSK3- control Smad3 protein stability and modulate TGF- signaling. Genes \& development $\underline{22}, 106-120$

Guo Y, Yin J, Zha L, Wang Z (2013): Clinicopathological significance of platelet-derived growth factor B, platelet-derived growth factor receptor-beta, and E-cadherin expression in gastric carcinoma. Contemporary oncology (Poznan, Poland) 17, 150-155

Gupta GP, Massague J (2006): Cancer metastasis: building a framework. Cell $\underline{127}, 679-695$

Hanahan D, Weinberg RA (2000): The hallmarks of cancer. Cell $\underline{100}, 57-70$

Hanahan D, Weinberg RA (2011): Hallmarks of cancer: the next generation. Cell $\underline{144}, 646-$ 674

Hanahan D, Coussens LM (2012): Accessories to the crime: functions of cells recruited to the tumor microenvironment. Cancer cell 21, 309-322

Hashibe M, Brennan P, Chuang SC, Boccia S, Castellsague X, Chen C, Curado MP, Dal Maso L, Daudt AW, Fabianova E et al. (2009): Interaction between tobacco and alcohol use and the risk of head and neck cancer: pooled analysis in the International Head and Neck Cancer Epidemiology Consortium. Cancer epidemiology, biomarkers \& prevention : a publication of the American Association for Cancer Research, cosponsored by the American Society of Preventive Oncology $\underline{18}, 541-550$

Hass R, Kasper C, Bohm S, Jacobs R (2011): Different populations and sources of human mesenchymal stem cells (MSC): A comparison of adult and neonatal tissue-derived MSC. Cell communication and signaling : CCS $\underline{9}, 12$ 
Literaturverzeichnis

Hayry V, Makinen LK, Atula T, Sariola H, Makitie A, Leivo I, Keski-Santti H, Lundin J, Haglund C, Hagstrom J (2010): Bmi-1 expression predicts prognosis in squamous cell carcinoma of the tongue. British journal of cancer $\underline{102}, 892-897$

Hazan RB, Phillips GR, Qiao RF, Norton L, Aaronson SA (2000): Exogenous expression of $\mathrm{N}$-cadherin in breast cancer cells induces cell migration, invasion, and metastasis. The Journal of cell biology $\underline{148}, 779-790$

Heneweer M, Muusse M, Dingemans M, de Jong PC, van den Berg M, Sanderson JT (2005): Co-culture of primary human mammary fibroblasts and MCF-7 cells as an in vitro breast cancer model. Toxicol Sci $\underline{83}, 257-263$

Heo DS, Snyderman C, Gollin SM, Pan S, Walker E, Deka R, Barnes EL, Johnson JT, Herberman RB, Whiteside TL (1989): Biology, cytogenetics, and sensitivity to immunological effector cells of new head and neck squamous cell carcinoma lines. Cancer research $\underline{49}, 5167-5175$

Horwitz EM, Le Blanc K, Dominici M, Mueller I, Slaper-Cortenbach I, Marini FC, Deans RJ, Krause DS, Keating A (2005): Clarification of the nomenclature for MSC: The International Society for Cellular Therapy position statement. Cytotherapy $\underline{7}$, 393-395

Hulsken J, Birchmeier W, Behrens J (1994): E-cadherin and APC compete for the interaction with beta-catenin and the cytoskeleton. The Journal of cell biology 127, 2061-2069

Hung KF, Chang CS, Liu CJ, Lui MT, Cheng CY, Kao SY (2006): Differential expression of E-cadherin in metastatic lesions comparing to primary oral squamous cell carcinoma. Journal of oral pathology \& medicine : official publication of the International Association of Oral Pathologists and the American Academy of Oral Pathology $\underline{35}, 589-594$

Ichikawa K, Kubota Y, Nakamura T, Weng JS, Tomida T, Saito H, Takekawa M (2015): MCRIP1, an ERK substrate, mediates ERK-induced gene silencing during epithelialmesenchymal transition by regulating the co-repressor CtBP. Molecular cell $\underline{58}, 35-46$

Ivaska J, Pallari HM, Nevo J, Eriksson JE (2007): Novel functions of vimentin in cell adhesion, migration, and signaling. Experimental cell research $\underline{313}$, 2050-2062

Jacob A, Prekeris R (2015): The regulation of MMP targeting to invadopodia during cancer metastasis. Frontiers in cell and developmental biology $\underline{3}, 4$

Jamieson C, Sharma M, Henderson BR (2012): Wnt signaling from membrane to nucleus: beta-catenin caught in a loop. The international journal of biochemistry \& cell biology 44 , $847-850$

Jemal A, Bray F, Center MM, Ferlay J, Ward E, Forman D (2011): Global cancer statistics. CA: a cancer journal for clinicians $\underline{61}, 69-90$

Johnson GL, Lapadat R (2002): Mitogen-activated protein kinase pathways mediated by ERK, JNK, and p38 protein kinases. Science (New York, N.Y.) 298, 1911-1912 
Literaturverzeichnis

Johnstone B, Hering TM, Caplan AI, Goldberg VM, Yoo JU (1998): In vitro chondrogenesis of bone marrow-derived mesenchymal progenitor cells. Experimental cell research $\underline{238}, 265-$ 272

Kalluri R, Neilson EG (2003): Epithelial-mesenchymal transition and its implications for fibrosis. The Journal of clinical investigation 112, 1776-1784

Kalluri R, Weinberg RA (2009): The basics of epithelial-mesenchymal transition. The Journal of clinical investigation $\underline{119}, 1420-1428$

Kim IA, Bae SS, Fernandes A, Wu J, Muschel RJ, McKenna WG, Birnbaum MJ, Bernhard EJ (2005): Selective inhibition of Ras, phosphoinositide 3 kinase, and Akt isoforms increases the radiosensitivity of human carcinoma cell lines. Cancer research $\underline{65}, 7902-7910$

Klein T, Bischoff R (2011): Active metalloproteases of the A Disintegrin and Metalloprotease (ADAM) family: biological function and structure. Journal of proteome research $\underline{10}, 17-33$

Korbling M, Estrov Z (2003): Adult stem cells for tissue repair - a new therapeutic concept? The New England journal of medicine 349, 570-582

Korita PV, Wakai T, Ajioka Y, Inoue M, Takamura M, Shirai Y, Hatakeyama K (2010): Aberrant expression of vimentin correlates with dedifferentiation and poor prognosis in patients with intrahepatic cholangiocarcinoma. Anticancer research $\underline{30}$, 2279-2285

Kovacina KS, Park GY, Bae SS, Guzzetta AW, Schaefer E, Birnbaum MJ, Roth RA (2003): Identification of a proline-rich Akt substrate as a 14-3-3 binding partner. The Journal of biological chemistry $\underline{278}, 10189-10194$

Kucerova L, Skolekova S, Matuskova M, Bohac M, Kozovska Z (2013): Altered features and increased chemosensitivity of human breast cancer cells mediated by adipose tissuederived mesenchymal stromal cells. BMC cancer $\underline{13}, 535$

Kulasinghe A, Perry C, Jovanovic L, Nelson C, Punyadeera C (2015): Circulating tumour cells in metastatic head and neck cancers. International journal of cancer $\underline{136}, 2515-2523$

Kurahara S, Shinohara M, Ikebe T, Nakamura S, Beppu M, Hiraki A, Takeuchi H, Shirasuna K (1999): Expression of MMPS, MT-MMP, and TIMPs in squamous cell carcinoma of the oral cavity: correlations with tumor invasion and metastasis. Head \& neck $\underline{21}$, 627-638

Kyriakis JM, App H, Zhang XF, Banerjee P, Brautigan DL, Rapp UR, Avruch J (1992): Raf1 activates MAP kinase-kinase. Nature $\underline{358}, 417-421$

Lamouille S, Xu J, Derynck R (2014): Molecular mechanisms of epithelial-mesenchymal transition. Nature reviews. Molecular cell biology 15, 178-196

Laplante M, Sabatini DM (2012): mTOR signaling in growth control and disease. Cell $\underline{149}$, 274-293

Leef G, Thomas SM (2013): Molecular communication between tumor-associated fibroblasts and head and neck squamous cell carcinoma. Oral oncology $\underline{49}, 381-386$ 
Lin CJ, Grandis JR, Carey TE, Gollin SM, Whiteside TL, Koch WM, Ferris RL, Lai SY (2007): Head and neck squamous cell carcinoma cell lines: established models and rationale for selection. Head \& neck 29 , 163-188

Liotta LA, Kohn EC (2001): The microenvironment of the tumour-host interface. Nature $\underline{411}, 375-379$

Livak KJ, Schmittgen TD (2001): Analysis of relative gene expression data using real-time quantitative PCR and the 2(-Delta Delta C(T)) Method. Methods (San Diego, Calif.) 25, 402-408

Luo J, Ok Lee S, Liang L, Huang CK, Li L, Wen S, Chang C (2014): Infiltrating bone marrow mesenchymal stem cells increase prostate cancer stem cell population and metastatic ability via secreting cytokines to suppress androgen receptor signaling. Oncogene $\underline{33}, 2768-$ 2778

Lv FJ, Tuan RS, Cheung KM, Leung VY (2014): Concise review: the surface markers and identity of human mesenchymal stem cells. Stem cells (Dayton, Ohio) $\underline{32}, 1408-1419$

Lynch M, Fitzgerald C, Johnston KA, Wang S, Schmidt EV (2004): Activated eIF4Ebinding protein slows $\mathrm{G} 1$ progression and blocks transformation by c-myc without inhibiting cell growth. The Journal of biological chemistry $\underline{279}, 3327-3339$

Lyons JG, Patel V, Roue NC, Fok SY, Soon LL, Halliday GM, Gutkind JS (2008): Snail upregulates proinflammatory mediators and inhibits differentiation in oral keratinocytes. Cancer research $\underline{68}, 4525-4530$

Madhunapantula SV, Sharma A, Robertson GP (2007): PRAS40 deregulates apoptosis in malignant melanoma. Cancer research $\underline{67}, 3626-3636$

Mannello F, Luchetti F, Falcieri E, Papa S (2005): Multiple roles of matrix metalloproteinases during apoptosis. Apoptosis : an international journal on programmed cell death $\underline{10}, 19-24$

Manning BD, Cantley LC (2007): AKT/PKB signaling: navigating downstream. Cell $\underline{129}$, 1261-1274

Massague J (2012): TGFbeta signalling in context. Nature reviews. Molecular cell biology $\underline{13}, 616-630$

Masszi A, Di Ciano C, Sirokmany G, Arthur WT, Rotstein OD, Wang J, McCulloch CA, Rosivall L, Mucsi I, Kapus A (2003): Central role for Rho in TGF-beta1-induced alphasmooth muscle actin expression during epithelial-mesenchymal transition. American journal of physiology. Renal physiology 284, F911-924

Meirelles Lda S, Nardi NB (2003): Murine marrow-derived mesenchymal stem cell: isolation, in vitro expansion, and characterization. British journal of haematology $\underline{123}, 702-$ 711 
Literaturverzeichnis

Mendelsohn AH, Lai CK, Shintaku IP, Fishbein MC, Brugman K, Elashoff DA, Abemayor E, Dubinett SM, St John MA (2012): Snail as a novel marker for regional metastasis in head and neck squamous cell carcinoma. American journal of otolaryngology $\underline{33}$, 6-13

Metelmann H, Kaduk W: Tumoren in Kopf-Hals-Bereich. In: Horch H (Hrsg): MundKiefer-Gesichtschirurgie. Elsevier, München/Jena 2007

Molinolo AA, Amornphimoltham P, Squarize CH, Castilho RM, Patel V, Gutkind JS (2009): Dysregulated molecular networks in head and neck carcinogenesis. Oral oncology $\underline{45}, 324-$ 334

Monteverde T, Muthalagu N, Port J, Murphy DJ (2015): Evidence of cancer-promoting roles for AMPK and related kinases. The FEBS journal 282, 4658-4671

Mook OR, Frederiks WM, Van Noorden CJ (2004): The role of gelatinases in colorectal cancer progression and metastasis. Biochimica et biophysica acta 1705, 69-89

Mukai F, Ishiguro K, Sano Y, Fujita SC (2002): Alternative splicing isoform of tau protein kinase I/glycogen synthase kinase 3beta. Journal of neurochemistry $\underline{81}$, 1073-1083

Nagaraj NS, Datta PK (2010): Targeting the transforming growth factor-beta signaling pathway in human cancer. Expert opinion on investigational drugs $\underline{19}$, 77-91

Nieman MT, Prudoff RS, Johnson KR, Wheelock MJ (1999): N-cadherin promotes motility in human breast cancer cells regardless of their E-cadherin expression. The Journal of cell biology $\underline{147}, 631-644$

Nieto MA (2011): The ins and outs of the epithelial to mesenchymal transition in health and disease. Annual review of cell and developmental biology 27, 347-376

Nijkamp MM, Span PN, Hoogsteen IJ, van der Kogel AJ, Kaanders JH, Bussink J (2011): Expression of E-cadherin and vimentin correlates with metastasis formation in head and neck squamous cell carcinoma patients. Radiotherapy and oncology : journal of the European Society for Therapeutic Radiology and Oncology 99, 344-348

Nishida E, Gotoh Y (1993): The MAP kinase cascade is essential for diverse signal transduction pathways. Trends in biochemical sciences $\underline{18}, 128-131$

Okada A, Bellocq JP, Rouyer N, Chenard MP, Rio MC, Chambon P, Basset P (1995): Membrane-type matrix metalloproteinase (MT-MMP) gene is expressed in stromal cells of human colon, breast, and head and neck carcinomas. Proceedings of the National Academy of Sciences of the United States of America 92, 2730-2734

Oshimori N, Fuchs E (2012): The harmonies played by TGF-beta in stem cell biology. Cell stem cell $\underline{11}, 751-764$

Ou DL, Chien HF, Chen CL, Lin TC, Lin LI (2008): Role of Twist in head and neck carcinoma with lymph node metastasis. Anticancer research $\underline{28}, 1355-1359$

Ozguven BY, Karacetin D, Kabukcuoglu F, Taskin T, Yener S (2011): Immunohistochemical study of E-cadherin and beta-catenin expression in colorectal 
carcinomas. Polish journal of pathology : official journal of the Polish Society of Pathologists $\underline{62}, 19-24$

Pages G, Lenormand P, L'Allemain G, Chambard JC, Meloche S, Pouyssegur J (1993): Mitogen-activated protein kinases p42mapk and $\mathrm{p} 44 \mathrm{mapk}$ are required for fibroblast proliferation. Proceedings of the National Academy of Sciences of the United States of America 90, 8319-8323

Paget S (1989): The distribution of secondary growths in cancer of the breast. 1889. Cancer metastasis reviews $\underline{8}, 98-101$

Peitzsch C, Nathansen J, Schniewind SI, Schwarz F, Dubrovska A (2019): Cancer Stem Cells in Head and Neck Squamous Cell Carcinoma: Identification, Characterization and Clinical Implications. Cancers $\underline{11}$ (616), 1-24

Pittenger MF, Mackay AM, Beck SC, Jaiswal RK, Douglas R, Mosca JD, Moorman MA, Simonetti DW, Craig S, Marshak DR (1999): Multilineage potential of adult human mesenchymal stem cells. Science (New York, N.Y.) 284, 143-147

Poggi A, Musso A, Dapino I, Zocchi MR (2014): Mechanisms of tumor escape from immune system: role of mesenchymal stromal cells. Immunology letters $\underline{159}, 55-72$

Porta C, Paglino C, Mosca A (2014): Targeting PI3K/Akt/mTOR Signaling in Cancer. Frontiers in oncology $\underline{4}, 64$

Putzke AP, Ventura AP, Bailey AM, Akture C, Opoku-Ansah J, Celiktas M, Hwang MS, Darling DS, Coleman IM, Nelson PS et al. (2011): Metastatic progression of prostate cancer and e-cadherin regulation by zeb1 and SRC family kinases. The American journal of pathology $\underline{179}, 400-410$

Qin Q, Xu Y, He T, Qin C, Xu J (2012): Normal and disease-related biological functions of Twist1 and underlying molecular mechanisms. Cell research 22, 90-106

Radisky ES, Radisky DC (2010): Matrix metalloproteinase-induced epithelial-mesenchymal transition in breast cancer. Journal of mammary gland biology and neoplasia $\underline{15}, 201-212$

Rallapalli S, Bishi DK, Verma RS, Cherian KM, Guhathakurta S (2009): A multiplex PCR technique to characterize human bone marrow derived mesenchymal stem cells. Biotechnology letters $\underline{31}, 1843-1850$

Ramakrishnan AB, Cadigan KM (2017): Wnt target genes and where to find them. F1000Research $\underline{6}, 746$

Ribeiro AS, Sousa B, Carreto L, Mendes N, Nobre AR, Ricardo S, Albergaria A, CameselleTeijeiro JF, Gerhard R, Soderberg O et al. (2013): P-cadherin functional role is dependent on E-cadherin cellular context: a proof of concept using the breast cancer model. The Journal of pathology $\underline{229}, 705-718$

Rommel C, Clarke BA, Zimmermann S, Nunez L, Rossman R, Reid K, Moelling K, Yancopoulos GD, Glass DJ (1999): Differentiation stage-specific inhibition of the RafMEK-ERK pathway by Akt. Science (New York, N.Y.) 286, 1738-1741 
Roorda BD, Elst A, Boer TG, Kamps WA, de Bont ES (2010): Mesenchymal stem cells contribute to tumor cell proliferation by direct cell-cell contact interactions. Cancer investigation $\underline{28}, 526-534$

Rotter N, Oder J, Schlenke P, Lindner U, Bohrnsen F, Kramer J, Rohwedel J, Huss R, Brandau S, Wollenberg B et al. (2008): Isolation and characterization of adult stem cells from human salivary glands. Stem cells and development $\underline{17}, 509-518$

Routray S, Sunkavali A, Bari KA (2014): Carcinoma-associated fibroblasts, its implication in head and neck squamous cell carcinoma: a mini review. Oral diseases $\underline{20}, 246-253$

Roux PP, Blenis J (2004): ERK and p38 MAPK-activated protein kinases: a family of protein kinases with diverse biological functions. Microbiology and molecular biology reviews : MMBR $\underline{68}, 320-344$

Saito A, Narasimhan P, Hayashi T, Okuno S, Ferrand-Drake M, Chan PH (2004): Neuroprotective role of a proline-rich Akt substrate in apoptotic neuronal cell death after stroke: relationships with nerve growth factor. The Journal of neuroscience : the official journal of the Society for Neuroscience $\underline{24}, 1584-1593$

Sanchez-Tillo E, Liu Y, de Barrios O, Siles L, Fanlo L, Cuatrecasas M, Darling DS, Dean DC, Castells A, Postigo A (2012): EMT-activating transcription factors in cancer: beyond EMT and tumor invasiveness. Cellular and molecular life sciences : CMLS $\underline{69}, 3429-3456$

Satelli A, Li S (2011): Vimentin in cancer and its potential as a molecular target for cancer therapy. Cellular and molecular life sciences : CMLS $\underline{68}$, 3033-3046

Sharma M, Jamieson C, Johnson M, Molloy MP, Henderson BR (2012): Specific armadillo repeat sequences facilitate beta-catenin nuclear transport in live cells via direct binding to nucleoporins Nup62, Nup153, and RanBP2/Nup358. The Journal of biological chemistry $\underline{287}, 819-831$

Shin S, Dimitri CA, Yoon SO, Dowdle W, Blenis J (2010): ERK2 but not ERK1 induces epithelial-to-mesenchymal transformation via DEF motif-dependent signaling events. Molecular cell $\underline{38}, 114-127$

Shukla S, Sinha S, Khan S, Kumar S, Singh K, Mitra K, Maurya R, Meeran SM (2016): Cucurbitacin B inhibits the stemness and metastatic abilities of NSCLC via downregulation of canonical Wnt/beta-catenin signaling axis. Scientific reports $\underline{6}, 21860$

Smith A, Teknos TN, Pan Q (2013): Epithelial to mesenchymal transition in head and neck squamous cell carcinoma. Oral oncology $\underline{49}, 287-292$

Sotiropoulou PA, Perez SA, Gritzapis AD, Baxevanis CN, Papamichail M (2006): Interactions between human mesenchymal stem cells and natural killer cells. Stem cells (Dayton, Ohio) 24, 74-85

Stegeman H, Kaanders JH, Wheeler DL, van der Kogel AJ, Verheijen MM, Waaijer SJ, Iida M, Grenman R, Span PN, Bussink J (2012): Activation of AKT by hypoxia: a potential target for hypoxic tumors of the head and neck. BMC cancer $\underline{12}, 463$ 
Steinberg A, Asher A, Bailey C, Fu JB (2015): The role of physical rehabilitation in stem cell transplantation patients. Support Care Cancer 23, 2447-2460

Sternlicht MD, Werb Z (2001): How matrix metalloproteinases regulate cell behavior. Annual review of cell and developmental biology 17, 463-516

Sun H, Charles CH, Lau LF, Tonks NK (1993): MKP-1 (3CH134), an immediate early gene product, is a dual specificity phosphatase that dephosphorylates MAP kinase in vivo. Cell $\underline{75}, 487-493$

Sun L, Diamond ME, Ottaviano AJ, Joseph MJ, Ananthanarayan V, Munshi HG (2008): Transforming growth factor-beta 1 promotes matrix metalloproteinase-9-mediated oral cancer invasion through snail expression. Molecular cancer research : MCR $\underline{6}, 10-20$

Syn NL, Teng MWL, Mok TSK, Soo RA (2017): De-novo and acquired resistance to immune checkpoint targeting. The Lancet. Oncology $\underline{18}$, e731-e741

Talmadge JE, Fidler IJ (2010): AACR centennial series: the biology of cancer metastasis: historical perspective. Cancer research $\underline{70}, 5649-5669$

ten Berge D, Koole W, Fuerer C, Fish M, Eroglu E, Nusse R (2008): Wnt signaling mediates self-organization and axis formation in embryoid bodies. Cell stem cell $\underline{3}, 508-518$

Theocharis S, Kotta-Loizou I, Klijanienko J, Giaginis C, Alexandrou P, Dana E, Rodriguez J, Patsouris E, Sastre-Garau X (2014): Extracellular signal-regulated kinase (ERK) expression and activation in mobile tongue squamous cell carcinoma: associations with clinicopathological parameters and patients survival. Tumour biology : the journal of the International Society for Oncodevelopmental Biology and Medicine 35, 6455-6465

Tiwari N, Gheldof A, Tatari M, Christofori G (2012): EMT as the ultimate survival mechanism of cancer cells. Seminars in cancer biology 22, 194-207

Tropel P, Noel D, Platet N, Legrand P, Benabid AL, Berger F (2004): Isolation and characterisation of mesenchymal stem cells from adult mouse bone marrow. Experimental cell research $\underline{295}, 395-406$

Turley SJ, Cremasco V, Astarita JL (2015): Immunological hallmarks of stromal cells in the tumour microenvironment. Nature reviews. Immunology $\underline{15}$, 669-682

van Roy F (2014): Beyond E-cadherin: roles of other cadherin superfamily members in cancer. Nature reviews. Cancer $\underline{14}, 121-134$

Vander Haar E, Lee SI, Bandhakavi S, Griffin TJ, Kim DH (2007): Insulin signalling to mTOR mediated by the Akt/PKB substrate PRAS40. Nature cell biology $\underline{9}, 316-323$

Wang YZ, Wu KP, Wu AB, Yang ZC, Li JM, Mo YL, Xu M, Wu B, Yang ZX (2014): MMP-14 overexpression correlates with poor prognosis in non-small cell lung cancer. Tumour biology : the journal of the International Society for Oncodevelopmental Biology and Medicine 35, 9815-9821 
Weinberg RA (2008): Twisted epithelial-mesenchymal transition blocks senescence. Nature cell biology $\underline{10}, 1021-1023$

Wheeler SE, Shi H, Lin F, Dasari S, Bednash J, Thorne S, Watkins S, Joshi R, Thomas SM (2014): Enhancement of head and neck squamous cell carcinoma proliferation, invasion, and metastasis by tumor-associated fibroblasts in preclinical models. Head \& neck $\underline{36}, 385-392$

Wiza C, Nascimento EB, Ouwens DM (2012): Role of PRAS40 in Akt and mTOR signaling in health and disease. American journal of physiology. Endocrinology and metabolism $\underline{302}$, E1453-1460

Wullschleger S, Loewith R, Hall MN (2006): TOR signaling in growth and metabolism. Cell $\underline{124}, 471-484$

Xing X, Tang YB, Yuan G, Wang Y, Wang J, Yang Y, Chen M (2013): The prognostic value of E-cadherin in gastric cancer: a meta-analysis. International journal of cancer $\underline{132}$, 2589-2596

Xu Z, Jiang Y, Steed H, Davidge S, Fu Y (2010): TGFbeta and EGF synergistically induce a more invasive phenotype of epithelial ovarian cancer cells. Biochemical and biophysical research communications $\underline{401}, 376-381$

Xue G, Hemmings BA (2012): Phosphorylation of basic helix-loop-helix transcription factor Twist in development and disease. Biochemical Society transactions $\underline{40}, 90-93$

Yang F, Zeng Q, Yu G, Li S, Wang CY (2006): Wnt/beta-catenin signaling inhibits death receptor-mediated apoptosis and promotes invasive growth of HNSCC. Cellular signalling $\underline{18}, 679-687$

Yang MH, Chen CL, Chau GY, Chiou SH, Su CW, Chou TY, Peng WL, Wu JC (2009): Comprehensive analysis of the independent effect of twist and snail in promoting metastasis of hepatocellular carcinoma. Hepatology (Baltimore, Md.) 50, 1464-1474

Yingling JM, Blanchard KL, Sawyer JS (2004): Development of TGF-beta signalling inhibitors for cancer therapy. Nature reviews. Drug discovery $\underline{3}, 1011-1022$

Zeisberg M, Neilson EG (2009): Biomarkers for epithelial-mesenchymal transitions. The Journal of clinical investigation $\underline{119}, 1429-1437$

Zhang J, Tian XJ, Xing J (2016): Signal Transduction Pathways of EMT Induced by TGFbeta, SHH, and WNT and Their Crosstalks. Journal of clinical medicine 5 (4), 41

Zhao L, Chen S, Yang P, Cao H, Li L (2019): The role of mesenchymal stem cells in hematopoietic stem cell transplantation: prevention and treatment of graft-versus-host disease. Stem cell research \& therapy $\underline{10}, 182$

Zhou BP, Hung MC (2005): Wnt, hedgehog and snail: sister pathways that control by GSK3 beta and beta-Trcp in the regulation of metastasis. Cell cycle (Georgetown, Tex.) 4 , 772776 


\section{Danksagung}

Mein besonderer Dank gilt meinem Doktorvater Herrn Priv.-Doz. Dr. med. Dr. med. dent. F. Böhrnsen für die Vergabe des Themas, die herausragende Betreuung und die Möglichkeit, erste Schritte in die Welt der wissenschaftlichen Forschung zu gehen.

Den Mitarbeiterinnen und Mitarbeitern des Labors der Abteilung Mund-, Kiefer- und Gesichtschirurgie der Universitätsmedizin Göttingen danke ich für die unkomplizierte Aufnahme in ihr Team und die stets freundliche Unterstützung bei all meinen Anliegen. Dabei gilt mein besonderer Dank Herrn Dr. rer. nat. Dipl. Biol. H. J. Rolf, Frau Dr. rer. nat. Dipl. Biol. N. Aeckerle sowie M. Hoch für ihre unermüdliche und über das normale Maß hinausgehende Hilfsbereitschaft.

Mein Dank gilt ebenfalls dem Labor der Abteilung Hämatologie und Onkologie für die freundliche Unterstützung bei der Durchführung der Durchflusszytometrie. 